\title{
Stereocontrolled Synthesis of Arylomycin-Based Gram-Negative Antibiotic GDC-5338
}

Nicholas Wong, * Filip Petronijević,* Allen Y. Hong,* Xin Linghu, Sean M. Kelly, Haiyun Hou, Theresa Cravillion, Ngiap-Kie Lim, Sarah J. Robinson, Chong Han, Carmela Molinaro, C. Gregory Sowell, Francis Gosselin

Department of Small Molecule Process Chemistry, Genentech, Inc., I DNA Way, South San Francisco, California 94080, United States

\author{
wong.nicholas@gene.com \\ petronijevic.filip@gene.com \\ hong.allen@gene.com
}

\section{Supporting Information}

Table of Contents

Page

1. General Information S2

2. Procedures for the Preparation of Macrocyclic Core $2 \quad$ S3

3. Suzuki-Miyaura Macrocyclization Optimization _ S12

4. Observation of Cyclic and Linear Oligomers Derived from Linear Tripeptide 6_....................... S14

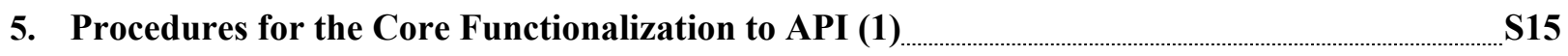

6. X-ray Crystallographic Analysis of Macrocycle 2

7. NMR Spectra $\quad$ S42 


\section{General Information}

General Considerations. Unless otherwise noted, all reactions were run under a nitrogen atmosphere. All reagents and solvents were purchased from commercial suppliers and used without further purification. Anhydrous solvents were utilized if available, but no effort was undertaken to further increase the purity of commercially available solvents.

Analytical Information. ${ }^{1} \mathrm{H}$ and ${ }^{13} \mathrm{C}$ Nuclear Magnetic Resonance spectra were recorded on a Bruker Avance $300 \mathrm{MHz}$, Bruker Avance III $500 \mathrm{MHz}$, or Bruker Avance III $600 \mathrm{MHz}$ NMR spectrometer at ambient temperature. Data for ${ }^{1} \mathrm{H}$ NMR were reported in ppm relative to residual $\operatorname{DMSO}(\delta 2.50 \mathrm{ppm})$ as follows: chemical shift, multiplicity $(\mathrm{br}=$ broad signal, $\mathrm{s}=$ singlet, $\mathrm{d}=$ doublet, $\mathrm{t}=$ triplet, $\mathrm{q}=$ quartet, $\mathrm{p}=$ pentet, sept $=$ septet, $\mathrm{m}=$ multiplet), coupling constants, and integration. All ${ }^{13} \mathrm{C}$ NMR spectra are reported in ppm relative to residual DMSO ( $\left.\delta 39.52 \mathrm{ppm}\right)$, and were obtained with complete ${ }^{1} \mathrm{H}$ decoupling unless otherwise stated. High-resolution mass spectrometry (HRMS) data was acquired on a Thermo Scientific Orbitrap Fusion mass spectrometer. HPLC analyses were performed on an Agilent 1260 Infinity HPLC system with a UV detector at 220, 254, and $280 \mathrm{~nm}$ using an ACE 3 C8, Waters SL XSelect C18, or Ascentis Express C18 column. Melting points were measured by differential scanning calorimetry (DSC, Mettler Toledo HP DSC I) and were reported as onset temperature. 


\section{Procedures for the Preparation of Macrocyclic Core 2}

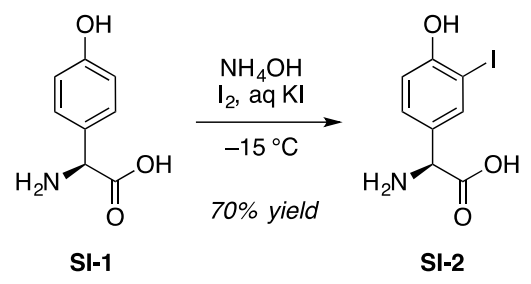

\section{Iodo-Hpg SI-2}

L-4-Hydroxyphenylglycine (SI-1) (8.2 g, $49.1 \mathrm{mmol}, 100 \mathrm{~mol} \%$ ) was dissolved in $25 \mathrm{wt} \%$ aq $\mathrm{NH}_{4} \mathrm{OH}(40 \mathrm{~mL})$ and cooled to $-20^{\circ} \mathrm{C}$. In a separate vessel, $\mathrm{I}_{2}(11.9 \mathrm{~g}, 46.8 \mathrm{mmol}, 0.95 \mathrm{~mol} \%)$ was added to a mixture of KI (9.4 g, $56.6 \mathrm{mmol}, 115 \mathrm{~mol} \%)$ in $\mathrm{H}_{2} \mathrm{O}(20 \mathrm{~mL})$ and stirred for $3 \mathrm{~h}$ at $25{ }^{\circ} \mathrm{C}$. The $\mathrm{I}_{2} / \mathrm{KI}$ solution was then added to the solution of SI-1 maintaining the internal temperature $\leq-15{ }^{\circ} \mathrm{C}$. The reaction was stirred for $6 \mathrm{~h}$ and quenched with 15 wt $\%$ aq $\mathrm{Na}_{2} \mathrm{SO}_{3}$ (4.0 g, $31.7 \mathrm{mmol}, 65 \mathrm{~mol} \%$ ) and stirred for $1 \mathrm{~h}$. The solution was diluted with $\mathrm{H}_{2} \mathrm{O}(50 \mathrm{~mL})$ and then $\mathrm{NH}_{3}$ was removed under reduced pressure until $\mathrm{pH}$ 9.0. The temperature was adjusted to 25 ${ }^{\circ} \mathrm{C}, \mathrm{H}_{2} \mathrm{O}(80 \mathrm{~mL})$ was added and $\mathrm{pH}$ was adjusted to 6.5 with $6 \mathrm{M} \mathrm{HCl}(8 \mathrm{~mL})$. The resulting slurry was stirred at $25^{\circ} \mathrm{C}$ for $6 \mathrm{~h}$ and then the solids were filtered, washed with $\mathrm{H}_{2} \mathrm{O}(80 \mathrm{~mL})$, acetone $(20 \mathrm{~mL})$, and then dried under reduced pressure at $50{ }^{\circ} \mathrm{C}$ for $24 \mathrm{~h}$ to afford $\mathbf{S I - 2}$ as a white solid (10.1 g, 34.5 mmol, 70\% yield). HPLC: 96.1 A\%. mp: $180{ }^{\circ} \mathrm{C} .{ }^{1} \mathrm{H} \mathrm{NMR}(300 \mathrm{MHz}$, DMSO- $d_{6}$ with 100 mol \% TFA added for dissolution): 8.68 (br s, $\left.3 \mathrm{H}\right), 7.88$ (d, $J=2.2 \mathrm{~Hz}, 1 \mathrm{H}$ ), $7.35(\mathrm{dd}, J=8.4,2.2 \mathrm{~Hz}, 1 \mathrm{H}), 6.99(\mathrm{~d}, J=8.4 \mathrm{~Hz}, 1 \mathrm{H}), 5.03$ (q, $J=5.4 \mathrm{~Hz}, 1 \mathrm{H}) .{ }^{13} \mathrm{C}$ NMR $(75$ MHz, DMSO- $d_{6}$ with 100 mol \% TFA added for dissolution): 171.6, 159.3, 140.2, 131.2, 127.0, 116.6, 86.0, 56.0. HRMS $(m / z)$ calcd for $\mathrm{C}_{8} \mathrm{H}_{8} \mathrm{INO}_{3}[\mathrm{M}+\mathrm{H}]^{+}$293.9622, found 293.9625. 


\section{Supporting Information}

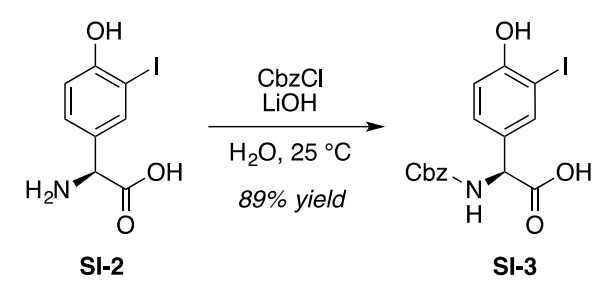

\section{N-Cbz Iodo-Hpg SI-3}

To a solution of iodo-Hpg SI-2 (10 g, $34.0 \mathrm{mmol}, 100 \mathrm{~mol} \%)$ in $\mathrm{H}_{2} \mathrm{O}(45 \mathrm{~mL})$ at $25^{\circ} \mathrm{C}$ was added $7 \mathrm{wt} \%$ aq $\mathrm{LiOH}(41 \mathrm{~mL}, 119 \mathrm{mmol}, 350 \mathrm{~mol} \%)$, maintaining the internal temperature $\leq 30{ }^{\circ} \mathrm{C}$. The solution was cooled to $10^{\circ} \mathrm{C}$ and a solution of benzyl chloroformate $(7.0 \mathrm{~g}, 41.0$ mmol, $120 \mathrm{~mol} \%$ ) in 1,4-dioxane (23 mL) was slowly added maintaining the internal temperature $\leq 10{ }^{\circ} \mathrm{C}$. The mixture was concentrated to $\sim 100 \mathrm{~mL}$ under reduced pressure maintaining the internal temperature $\leq 50{ }^{\circ} \mathrm{C}$. The reactor was cooled to $20{ }^{\circ} \mathrm{C}$ and 2 wt $\%$ aq LiOH (82 mL, $68 \mathrm{mmol}, 200 \mathrm{~mol} \%$ ) was added to the reaction while maintaining the temperature $\leq 25{ }^{\circ} \mathrm{C}$. The mixture was stirred for $3 \mathrm{~h}$ then washed with $\mathrm{CH}_{2} \mathrm{Cl}_{2}(60 \mathrm{~mL})$. The aqueous layer was acidified with $6 \mathrm{M}$ aq $\mathrm{HCl}(20 \mathrm{~mL})$ to $\mathrm{pH} 1$ then extracted with $\mathrm{CH}_{2} \mathrm{Cl}_{2}(2 \times$ $60 \mathrm{~mL}$ ). The combined organic layers were concentrated to $\sim 30 \mathrm{~mL}$ under reduced pressure while maintaining the internal temperature $\leq 40{ }^{\circ} \mathrm{C}$. The reaction was solvent-switched to EtOAc and concentrated to $\sim 30 \mathrm{~mL}$. The mixture was cooled to $25^{\circ} \mathrm{C}$, seeded with SI-3 $(9.2 \mathrm{mg}, 0.09$ wt $\%)$, and $n$-heptane $(110 \mathrm{~mL})$ was added over $1 \mathrm{~h}$. The resulting solids were filtered, washed with $n$-heptane $(4 \times 5 \mathrm{~mL})$, and dried under reduced pressure at $50{ }^{\circ} \mathrm{C}$ for $24 \mathrm{~h}$ to afford $\mathbf{S I - 3}$ as a white solid (12.9 g, 30.2 mmol, 89\% yield). HPLC: 92.3 A\%, 99\% ee. mp: $198{ }^{\circ} \mathrm{C}$. ${ }^{1} \mathrm{H}$ NMR (300 MHz, DMSO-d $): 8.14$ (br s, 2H), $7.63(\mathrm{~s}, 1 \mathrm{H}), 7.50-7.25(\mathrm{~m}, 4 \mathrm{H}), 7.16$ (dd, J = 8.4, 2.2 $\mathrm{Hz}, 1 \mathrm{H}), 7.07$ (d, $J=6.6 \mathrm{~Hz}, 1 \mathrm{H}), 6.83$ (d, $J=8.3 \mathrm{~Hz}, 1 \mathrm{H}), 5.03$ (d, $J=2.2 \mathrm{~Hz}, 2 \mathrm{H}), 4.62(\mathrm{~d}, J=$ $6.8 \mathrm{~Hz}, 1 \mathrm{H}) .{ }^{13} \mathrm{C}$ NMR (75 MHz, DMSO- $\left.d_{6}\right): 172.5,156.4,155.8,138.2,137.7,134.9,129.3$, 129.1, 128.6, 128.5, 115.3, 85.0, 66.1, 59.5. HRMS $(m / z)$ calcd for $\mathrm{C}_{16} \mathrm{H}_{14}\left[\mathrm{NO}_{5}[\mathrm{M}+\mathrm{H}]^{+}\right.$ 427.9989 , found 427.9990 . 


\section{Supporting Information}

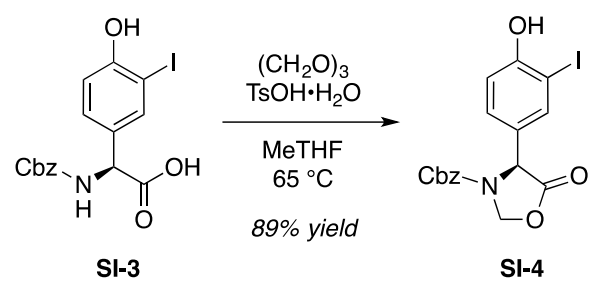

\section{Oxazolidinone SI-4}

To a solution of $N$-Cbz-iodo-Hpg SI-3 (10.2 g, 24.2 mmol, $100 \mathrm{~mol} \%$ ) in MeTHF (96 mL) was added $\mathrm{MgSO}_{4}(24.1 \mathrm{~g}, 200 \mathrm{mmol}, 825 \mathrm{~mol} \%)$ and $\mathrm{TsOH} \cdot \mathrm{H}_{2} \mathrm{O}(19.2 \mathrm{~g}, 101.2 \mathrm{mmol}, 420 \mathrm{~mol} \%)$ and the mixture was heated to $65^{\circ} \mathrm{C}$. 1,3,5-Trioxane (10.1 g, $\left.112 \mathrm{mmol}, 460 \mathrm{~mol} \%\right)$ in MeTHF $(60 \mathrm{~mL})$ was added while maintaining the internal temperature $\leq 70{ }^{\circ} \mathrm{C}$. The mixture was heated at $65{ }^{\circ} \mathrm{C}$ and stirred for $24 \mathrm{~h}$. Upon reaction completion, the solvent was concentrated to $\sim 180$ $\mathrm{mL}$ while maintaining the temperature $\leq 40{ }^{\circ} \mathrm{C}$. The temperature was adjusted to $5{ }^{\circ} \mathrm{C}$ and $7 \mathrm{wt} \%$ aq $\mathrm{NaHCO}_{3}(120 \mathrm{~mL})$ was added while maintaining temperature $\leq 25^{\circ} \mathrm{C}$. The solids were filtered and washed with MeTHF $(4 \times 6 \mathrm{~mL})$. The layers were split and the aqueous layer was extracted with EtOAc $(60 \mathrm{~mL})$. The combined organic layers were washed twice with $25 \mathrm{wt} \%$ aq $\mathrm{NaCl}$ $(60 \mathrm{~mL})$, concentrated to $\sim 36 \mathrm{~mL}$ under reduced pressure, and $n$-heptane $(120 \mathrm{~mL})$ was added. The mixture was stirred for $5 \mathrm{~h}$ then the solids were filtered, washed with $n$-heptane $(2 \times 6 \mathrm{~mL})$, and dried under reduced pressure at $40{ }^{\circ} \mathrm{C}$ for $42 \mathrm{~h}$ to afford SI-4 as a white solid (9.3 g, 21.2 mmol, 89\% yield). HPLC: 83.6 A\%, 99\% ee. mp: $203{ }^{\circ} \mathrm{C} .{ }^{1} \mathrm{H}$ NMR (500 MHz, DMSO- $\left.d_{6}\right)$ : $11.32(\mathrm{~s}, 1 \mathrm{H}), 8.52(\mathrm{~s}, 1 \mathrm{H}), 8.25-8.00(\mathrm{~m}, 5 \mathrm{H}), 7.84$ (br s, 1H), $7.70(\mathrm{~d}, J=8.4 \mathrm{~Hz}, 1 \mathrm{H}), 6.44$ (s, 1H), $6.34(\mathrm{~s}, 1 \mathrm{H}), 6.08$ (br s, 1H), $5.94-5.75$ (m, 2H). ${ }^{13} \mathrm{C}$ NMR (126 MHz, DMSO- $\left.d_{6}\right): 172.1$, $157.9,153.3,138.2,137.0,129.3,129.2,128.8,127.9,116.0,79.2,67.6,67.5,58.1,26.1$. HRMS $(m / z)$ calcd for $\mathrm{C}_{17} \mathrm{H}_{14} \mathrm{INO}_{5}[\mathrm{M}+\mathrm{H}]$ 439.9989, found 439.9990 . 


\section{Supporting Information}

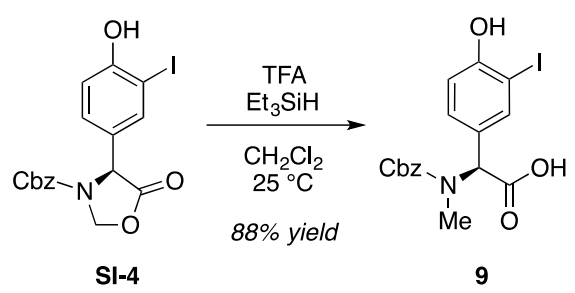

\section{$\mathrm{N}$-Me $\mathrm{N}$-Cbz Iodo-Hpg 9}

To a solution of oxazolidinone SI-4 (9 g, $20.5 \mathrm{mmol}, 100 \mathrm{~mol} \%$ ) in $\mathrm{CH}_{2} \mathrm{Cl}_{2}(45 \mathrm{~mL})$ and TFA (26 g, $228.9 \mathrm{mmol}, 1100 \mathrm{~mol} \%$ ) was added $\mathrm{Et}_{3} \mathrm{SiH}(8.6 \mathrm{~g}, 74 \mathrm{mmol}, 360 \mathrm{~mol} \%$ ) while maintaining the internal temperature $\leq 30{ }^{\circ} \mathrm{C}$. The reaction mixture was stirred for $20 \mathrm{~h}, \mathrm{CH}_{2} \mathrm{Cl}_{2}$ (27 mL) was added and the solvent concentrated to $\sim 27 \mathrm{~mL} . \mathrm{CH}_{2} \mathrm{Cl}_{2}(45 \mathrm{~mL})$ was added followed by $15 \mathrm{wt} \%$ aq $\mathrm{Na}_{2} \mathrm{CO}_{3}(35 \mathrm{~mL})$ until $\mathrm{pH} 10$. The layers were separated. The aqueous layer was washed with $\mathrm{CH}_{2} \mathrm{Cl}_{2}(45 \mathrm{~mL})$, then adjusted to $\mathrm{pH} 1$ with $6 \mathrm{M}$ aq $\mathrm{HCl}(10 \mathrm{~mL})$ and stirred for $3 \mathrm{~h}$. The resulting slurry was filtered. The filter cake was washed with $\mathrm{CH}_{2} \mathrm{Cl}_{2}(4 \mathrm{~mL})$. The solids were reslurried in $\mathrm{H}_{2} \mathrm{O}(45 \mathrm{~mL})$, filtered, and the filter cake was washed with $\mathrm{H}_{2} \mathrm{O}(2$ $\times 5 \mathrm{~mL})$ and dried under reduced pressure at $50{ }^{\circ} \mathrm{C}$ for $24 \mathrm{~h}$ to afford 9 as a white solid $(8 \mathrm{~g}, 18.1$ mmol, 88\% yield). HPLC: 98.7 A\%, 99\% ee. ${ }^{1} \mathrm{H}$ NMR (500 MHz, DMSO- $\left.d_{6}\right): 13.13$ (s, 1H), 10.55 (s, 1H), $7.60(\mathrm{~d}, J=2.2 \mathrm{~Hz}, 1 \mathrm{H}), 7.45-7.33(\mathrm{~m}, 5 \mathrm{H}), 7.16(\mathrm{dd}, J=8.4,2.2 \mathrm{~Hz}, 1 \mathrm{H}), 6.93$ $(\mathrm{d}, J=8.3 \mathrm{~Hz}, 1 \mathrm{H}), 5.68(\mathrm{~s}, 1 \mathrm{H}), 5.17(\mathrm{~s}, 2 \mathrm{H}), 2.69(\mathrm{~s}, 3 \mathrm{H}) .{ }^{13} \mathrm{C}$ NMR $\left(126 \mathrm{MHz}, \mathrm{DMSO}-d_{6}\right)$ : $172.3,157.6,140.2$, 137.6, 131.3, 129.3, 128.8, 128.4, 128.1, 115.8, 85.3, 67.5, 62.2, 32.0. HRMS $(m / z)$ calcd for $\mathrm{C}_{17} \mathrm{H}_{17} \mathrm{INO}_{3}[\mathrm{M}+\mathrm{H}]^{+} 442.0146$, found 442.0154 . 


\section{Supporting Information}

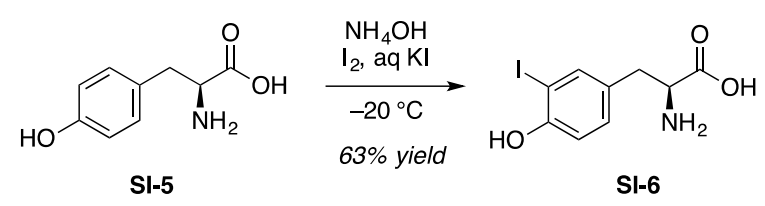

\section{Iodo-Tyr SI-6}

L-tyrosine (SI-5) (100 g, 552 mmol, 100 mol \%) was dissolved in 25 wt \% aq $\mathrm{NH}_{4} \mathrm{OH}(1500$ $\mathrm{mL}$ ) and cooled to $-5{ }^{\circ} \mathrm{C}$. In a separate vessel $\mathrm{I}_{2}(147 \mathrm{~g}, 580 \mathrm{mmol}, 105 \mathrm{~mol} \%)$ was added to a mixture of KI (108 g, $653 \mathrm{mmol}, 120 \mathrm{~mol} \%)$ in $\mathrm{H}_{2} \mathrm{O}(270 \mathrm{~mL})$ and stirred for $3 \mathrm{~h}$ at $25^{\circ} \mathrm{C}$. The $\mathrm{I}_{2} / \mathrm{KI}$ solution was then added to the solution of 11 while maintaining the internal temperature $\leq-$ $20{ }^{\circ} \mathrm{C}$. The reaction was stirred for $14 \mathrm{~h}$, quenched with $15 \mathrm{wt} \%$ aq $\mathrm{Na}_{2} \mathrm{SO}_{3}(50 \mathrm{~mL})$ and stirred for $1 \mathrm{~h}$. The solution was heated to $45{ }^{\circ} \mathrm{C}$ and $\mathrm{H}_{2} \mathrm{O} / \mathrm{NH}_{3}$ were distilled until $\sim 1400 \mathrm{~mL}$. The temperature was adjusted to $25{ }^{\circ} \mathrm{C}$, the reaction was diluted with $\mathrm{H}_{2} \mathrm{O}(700 \mathrm{~mL})$ and seeded with S3 (130 mg, $0.13 \mathrm{wt} \%)$. The reaction was adjusted to $\mathrm{pH} 7.8$ with $6 \mathrm{M} \mathrm{HCl} \mathrm{(25} \mathrm{mL)} \mathrm{and} \mathrm{stirred}$ for $6 \mathrm{~h}$. The resulting slurry was filtered and the solids reslurried in $\mathrm{H}_{2} \mathrm{O}(920 \mathrm{~mL})$, filtered, washed with acetone $(50 \mathrm{~mL})$, and dried under reduced pressure at $55^{\circ} \mathrm{C}$ for $24 \mathrm{~h}$ to afford SI-6 as a white solid (106 g, $344 \mathrm{mmol}, 63 \%$ yield). HPLC: $97.8 \mathrm{~A} \%,>99: 1 \mathrm{dr} .{ }^{1} \mathrm{H}$ NMR (500 MHz, DMSO-d $\left.)_{6}\right) 12.68(\mathrm{~s}, 1 \mathrm{H}), 8.26(\mathrm{~s}, 3 \mathrm{H}), 7.60(\mathrm{~s}, 1 \mathrm{H}), 7.10(\mathrm{dd}, J=8.1,2.1 \mathrm{~Hz}, 1 \mathrm{H}), 6.87(\mathrm{~d}, J=$ $8.2 \mathrm{~Hz}, 1 \mathrm{H}), 4.15(\mathrm{q}, J=5.8 \mathrm{~Hz}, 1 \mathrm{H}), 3.07-2.95(\mathrm{~m}, 2 \mathrm{H}) .{ }^{13} \mathrm{C}$ NMR (126 MHz, DMSO- $d_{6}$ with $100 \mathrm{~mol} \%$ TFA added for dissolution): 171.7, 157.1, 140.7, 131.8, 128.2, 116.1, 85.9, 35.4. HRMS $(m / z)$ calcd for $\mathrm{C}_{9} \mathrm{H}_{11} \mathrm{INO}_{3}[\mathrm{M}+\mathrm{H}] 307.9778$, found 307.9778. 


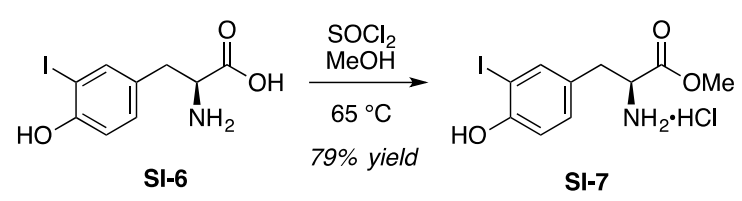

\section{Iodo-Ty Methyl Ester Hydrochloride SI-7}

To a solution of L-iodo-tyrosine SI-6 (100 g, $326 \mathrm{mmol}, 100 \mathrm{~mol} \%)$ in MeOH (500 mL) cooled to $0{ }^{\circ} \mathrm{C}$ was added $\mathrm{SOCl}_{2}(77 \mathrm{~g}, 653 \mathrm{mmol}, 200 \mathrm{~mol} \%)$ while maintaining the internal temperature $\leq 10{ }^{\circ} \mathrm{C}$. The reaction was heated to $65{ }^{\circ} \mathrm{C}$ and stirred for $2 \mathrm{~h}$. Upon reaction completion, the solution was cooled to $25{ }^{\circ} \mathrm{C}$ and the solvent was distilled under reduced pressure to $\sim 250 \mathrm{~mL}$ while maintaining the internal temperature $\leq 50{ }^{\circ} \mathrm{C}$. The solvent was switched to EtOAc, concentrated to $\sim 250 \mathrm{~mL}$, cooled to $5{ }^{\circ} \mathrm{C}$ and stirred for $2 \mathrm{~h}$. The resulting slurry was filtered, and the filter cake was washed with EtOAc $(30 \mathrm{~mL})$ and dried under reduced pressure at $40{ }^{\circ} \mathrm{C}$ for $48 \mathrm{~h}$ to afford SI-7 as a white solid (92.1 g, $258 \mathrm{mmol}, 79 \%$ yield). HPLC: 99 A\%. mp: $201{ }^{\circ} \mathrm{C} .{ }^{1} \mathrm{H}$ NMR (500 MHz, DMSO-d $)$ ) 10.54 (s, 1H), 8.73 (s, 3H), 7.57 (d, $J=2.1$ $\mathrm{Hz}, 1 \mathrm{H}), 7.07(\mathrm{dd}, J=8.2,2.1 \mathrm{~Hz}, 1 \mathrm{H}), 6.96(\mathrm{~d}, J=8.3 \mathrm{~Hz}, 1 \mathrm{H}), 4.21$ (t, $J=6.4 \mathrm{~Hz}, 1 \mathrm{H}), 3.71(\mathrm{~s}$, 3H), 3.15 - $2.99(\mathrm{~m}, 2 \mathrm{H}) .{ }^{13} \mathrm{C}$ NMR (126 MHz, DMSO-d 6 ): 170.3, 157.0, 140.4, 131.4, 127.8, 116.0, 85.7, 54.2, 53.5, 35.2. HRMS $(m / z)$ calcd for $\mathrm{C}_{10} \mathrm{H}_{13} \mathrm{INO}_{3}[\mathrm{M}+\mathrm{H}]^{+} 321.9935$, found 321.9929. 


\section{Supporting Information}

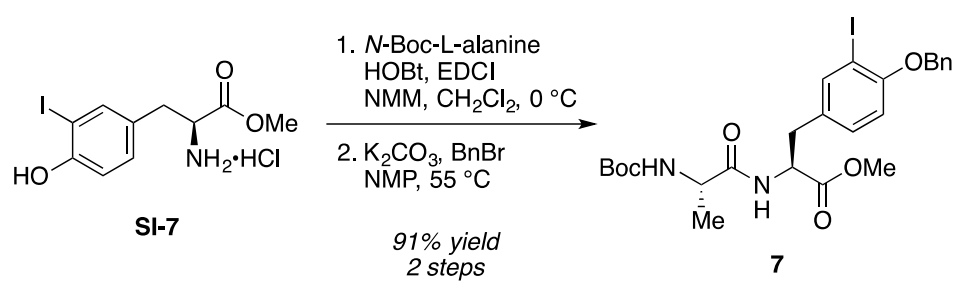

\section{Ala-Tyr Dipeptide 7}

To a solution of $N$-Boc-L-alanine ( $30 \mathrm{~g}, 159 \mathrm{mmol}, 100 \mathrm{~mol} \%$ ) in $\mathrm{CH}_{2} \mathrm{Cl}_{2}(350 \mathrm{~mL})$ was added $\mathrm{HOBt} \cdot \mathrm{H}_{2} \mathrm{O}(26 \mathrm{~g}, 173 \mathrm{mmol}, 109 \mathrm{~mol} \%)$. The internal temperature was adjusted to $-5{ }^{\circ} \mathrm{C}$ and $\mathrm{EDCI} \cdot \mathrm{HCl}(36 \mathrm{~g}, 188 \mathrm{mmol}, 118 \mathrm{~mol} \%)$ was added while maintaining the internal temperature $\leq 0{ }^{\circ} \mathrm{C}$ and stirred for $1 \mathrm{~h}$. Iodo-tyrosine SI-7 (52 g, $\left.144 \mathrm{mmol}, 91 \mathrm{~mol} \%\right)$ in $\mathrm{CH}_{2} \mathrm{Cl}_{2}(350 \mathrm{~mL})$ was added to the reaction mixture followed by NMM (43 g, $361 \mathrm{mmol}, 227 \mathrm{~mol} \%)$. The reaction was stirred for $2 \mathrm{~h}, \mathrm{H}_{2} \mathrm{O}(630 \mathrm{~mL})$ was added and the layers were split. The aqueous layer was extracted with $\mathrm{CH}_{2} \mathrm{Cl}_{2}(340 \mathrm{~mL})$ and the combined organic layers were washed with $10 \mathrm{wt} \%$ aq citric acid $(510 \mathrm{~mL}), 5 \mathrm{wt} \%$ aq $\mathrm{NaHCO}_{3}(260 \mathrm{~mL})$ and $\mathrm{H}_{2} \mathrm{O}(260 \mathrm{~mL})$. The organic layer was solvent switched to MTBE under reduced pressure and concentrated to $\sim 180 \mathrm{~mL}$ while maintaining the internal temperature $\leq 40{ }^{\circ} \mathrm{C}$. NMP $(160 \mathrm{~mL})$ and $\mathrm{K}_{2} \mathrm{CO}_{3}(40 \mathrm{~g}, 289 \mathrm{mmol}, 182$ mol \%) were added then the mixture was heated to $35^{\circ} \mathrm{C}$. Benzyl bromide $(29.6 \mathrm{~g}, 173 \mathrm{mmol}$, $109 \mathrm{~mol} \mathrm{\%}$ ) was added, then the mixture was heated to $55^{\circ} \mathrm{C}$ and stirred for $2 \mathrm{~h}$. The reaction temperature was adjusted to $25^{\circ} \mathrm{C}, \mathrm{H}_{2} \mathrm{O}(320 \mathrm{~mL})$ was added and the resulting slurry was stirred for $1 \mathrm{~h}$. The reaction was cooled to $0{ }^{\circ} \mathrm{C}$, stirred for $1 \mathrm{~h}$, filtered, washed with $\mathrm{H}_{2} \mathrm{O}(30 \mathrm{~mL})$, and MTBE $(20 \mathrm{~mL})$. The solids were dissolved in EtOAc $(710 \mathrm{~mL})$ and extracted with $\mathrm{H}_{2} \mathrm{O}(260$ $\mathrm{mL}$ ). The organic layer was concentrated to $\sim 320 \mathrm{~mL}$ under reduced pressure at $55^{\circ} \mathrm{C}, n$-heptane $(180 \mathrm{~mL})$ was added and then the temperature was adjusted to $0{ }^{\circ} \mathrm{C}$. The resulting slurry was filtered, the filter cake was washed with $n$-heptane $(30 \mathrm{~mL})$ and dried under reduced pressure at $40{ }^{\circ} \mathrm{C}$ for $26 \mathrm{~h}$ to afford dipeptide 7 as a white solid ( $77 \mathrm{~g}, 132 \mathrm{mmol}, 91 \%$ yield, 2 steps). HPLC: 99 A\%, >99:1 dr. mp: $261{ }^{\circ} \mathrm{C} .{ }^{1} \mathrm{H}$ NMR $\left(500 \mathrm{MHz}\right.$, DMSO- $\left.d_{6}\right): 8.11(\mathrm{~d}, J=7.7 \mathrm{~Hz}, 1 \mathrm{H})$, 7.63 (s, 1H), 7.49 (d, $J=7.5 \mathrm{~Hz}, 2 \mathrm{H}), 7.40$ (t, $J=7.5 \mathrm{~Hz}, 2 \mathrm{H}), 7.32$ (t, $J=7.3 \mathrm{~Hz}, 1 \mathrm{H}), 7.19$ (dd, $J=8.4,2.2 \mathrm{~Hz}, 1 \mathrm{H}), 6.98(\mathrm{~d}, J=8.5 \mathrm{~Hz}, 1 \mathrm{H}), 6.82(\mathrm{~d}, J=7.8 \mathrm{~Hz}, 1 \mathrm{H}), 5.15(\mathrm{~s}, 2 \mathrm{H}), 4.42(\mathrm{q}, J=$ $7.2 \mathrm{~Hz}, 1 \mathrm{H}), 3.96$ (p, $J=7.3 \mathrm{~Hz}, 1 \mathrm{H}), 3.58$ (s, 3H), 3.02-2.79 (m, 2H), 1.37 (s, 9H), 1.13 (d, $J=$ $7.2 \mathrm{~Hz}, 3 \mathrm{H}) .{ }^{13} \mathrm{C}$ NMR (126 MHz, DMSO- $\left.d_{6}\right): 173.3,172.2,156.0,155.3,140.0,137.3,132.0$, 
$130.8,128.9,128.2,127.6,113.2,87.0,78.5,70.5,53.9,52.3,50.1,35.6,28.7,18.7$. HRMS $(\mathrm{m} / \mathrm{z})$ calcd for $\mathrm{C}_{20} \mathrm{H}_{24} \mathrm{IN}_{2} \mathrm{O}_{4}[\mathrm{M}+\mathrm{H}-\mathrm{Boc}]^{+} 483.0775$ found 483.0783 .
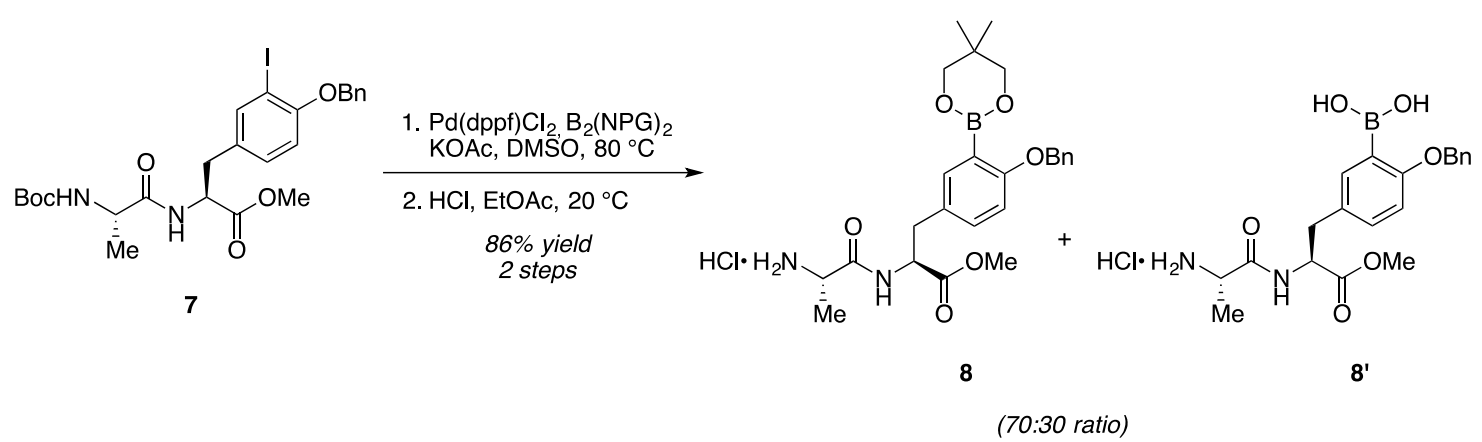

Ala-Tyr Dipeptide Boronic Ester 8 and Boronic Acid 8': To a solution of $N$-Boc-dipeptide 12 $^{1}$ (20.0 g, $34.3 \mathrm{mmol}, \quad 100 \mathrm{~mol} \%)$ in DMSO $(140 \mathrm{~mL})$ at $25{ }^{\circ} \mathrm{C}$ was added bis(neopentylglycolato)diboron (11.1 g, $49.1 \mathrm{mmol}, 143 \mathrm{~mol} \%$ ) and KOAc (13.7 g, $138.5 \mathrm{mmol}$, $404 \mathrm{~mol} \%)$. The resulting mixture was sparged with $\mathrm{N}_{2}$ for $6 \mathrm{~h}$ at $25{ }^{\circ} \mathrm{C} . \operatorname{Pd}(\mathrm{dppf}) \mathrm{Cl}_{2}(0.26 \mathrm{~g}$, $0.35 \mathrm{mmol}, 1.0 \mathrm{~mol} \%$ ) was added and the reaction was sparged with $\mathrm{N}_{2}$ for $2 \mathrm{~h}$ then heated to 80 ${ }^{\circ} \mathrm{C}$ for $5 \mathrm{~h}$. The reaction temperature was adjusted to $25{ }^{\circ} \mathrm{C}$ and MTBE $(200 \mathrm{~mL})$ and $\mathrm{H}_{2} \mathrm{O}(200$ $\mathrm{mL}$ ) were added. The reaction mixture was filtered and the layers were separated. The aqueous layer was extracted with MTBE $(150 \mathrm{~mL})$. The combined organics layers were washed with 25 wt $\%$ aq $\mathrm{NaCl}(100 \mathrm{~mL})$ then concentrated to $\sim 150 \mathrm{~mL}$. The crude MTBE solution was cooled to $20{ }^{\circ} \mathrm{C}$ and $4 \mathrm{M} \mathrm{HCl}$ in EtOAc $(43.5 \mathrm{~mL}, 172 \mathrm{mmol}, 500 \mathrm{~mol} \%)$ was added, maintaining the internal temperature below $25{ }^{\circ} \mathrm{C}$. The mixture was stirred for $8 \mathrm{~h}$ then MTBE $(100 \mathrm{~mL})$ was added and stirred for an additional $10 \mathrm{~h}$. The slurry was filtered, and the filter cake was washed with MTBE $(20 \mathrm{~mL})$ and dried under reduced pressure at $35^{\circ} \mathrm{C}$ for $24 \mathrm{~h}$ to afford a mixture of boronic ester $\mathbf{8}$ and boronic acid $\mathbf{8}^{\prime}$ (70:30) as a brown solid (15 g, 29.7 mmol, 86\% yield, 2 steps). Note: The mixture of boronic ester $\mathbf{8}$ and boronic acid $\mathbf{8}^{\prime}$ was fully converted to boronic acid $\mathbf{8}^{\prime}$ for characterization purposes. HPLC: $94 \mathrm{~A} \% .{ }^{1} \mathrm{H}$ NMR (500 MHz, DMSO- $\left.d_{6}\right): 8.82(\mathrm{~d}, J$ $=7.5 \mathrm{~Hz}, 1 \mathrm{H}), 7.64(\mathrm{~s}, 5 \mathrm{H}), 7.52(\mathrm{~d}, J=7.1 \mathrm{~Hz}, 2 \mathrm{H}), 7.48(\mathrm{~d}, J=2.4 \mathrm{~Hz}, 1 \mathrm{H}), 7.44$ (dd, $J=8.3$, $6.7 \mathrm{~Hz}, 2 \mathrm{H}), 7.41-7.34(\mathrm{~m}, 1 \mathrm{H}), 7.29$ (dd, $J=8.5,2.4 \mathrm{~Hz}, 1 \mathrm{H}), 7.03$ (d, $J=8.5 \mathrm{~Hz}, 1 \mathrm{H}), 5.19$ (s,

(1) Epifano, F.; Sosa, S.; Tubaro, A.; Marcotullio, M. C.; Curini, M.; Genovese, S. Topical antiinflammatory activity of boropinic acid and its natural and semi-synthetic derivatives. Bioorg. Med. Chem. Lett. 2011, 21, 769-772. 
2H), $4.51-4.43(\mathrm{~m}, 1 \mathrm{H}), 3.77(\mathrm{q}, J=7.0 \mathrm{~Hz}, 1 \mathrm{H}), 3.65(\mathrm{~s}, 3 \mathrm{H}), 3.08-2.88(\mathrm{~m}, 2 \mathrm{H}), 1.35(\mathrm{~d}, J=$ $6.9 \mathrm{~Hz}, 3 \mathrm{H}) .{ }^{13} \mathrm{C}$ NMR (126 MHz, DMSO- $\left.d_{6}\right): 172.5,171.7,162.3,138.0,137.1,133.0,129.7$, 129.4, 128.8, 128.5, 128.4 112.6, 70.4, 55.1, 52.9, 49.1, 36.6, 18.7. HRMS $(\mathrm{m} / z)$ calcd for $\mathrm{C}_{20} \mathrm{H}_{25} \mathrm{BN}_{2} \mathrm{O}_{6}[\mathrm{M}+\mathrm{H}]^{+}$: 401.1878, found 401.1887 .
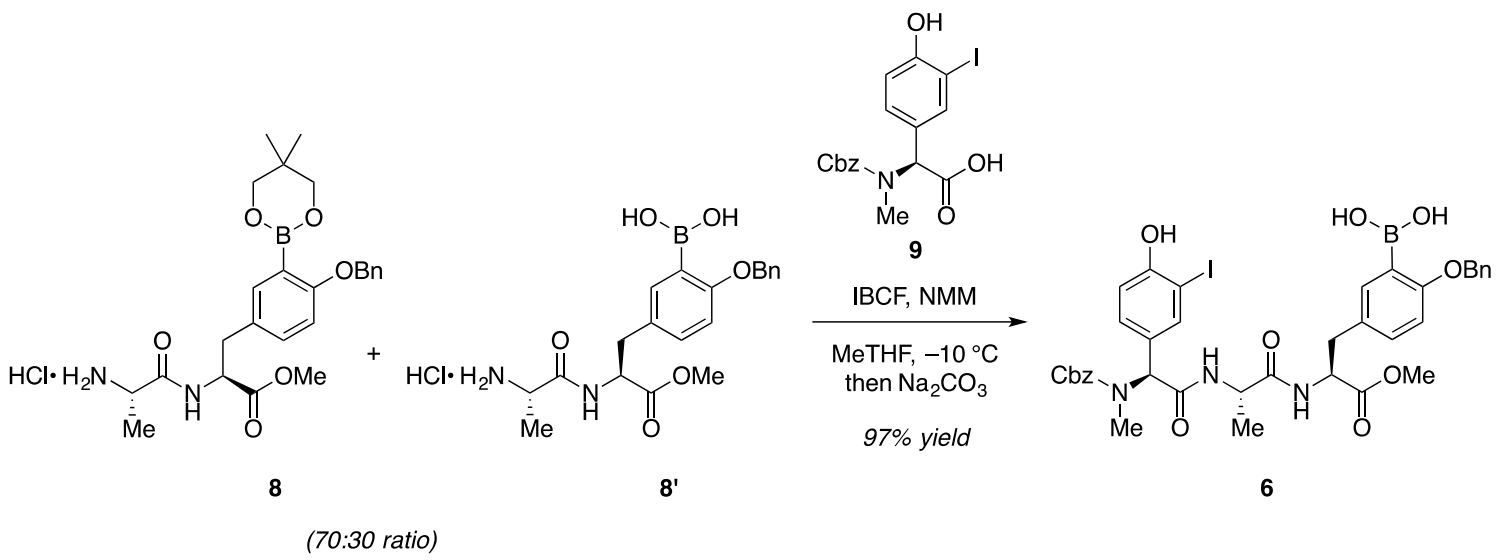

Hpg-Ala-Tyr Tripeptide Boronic Acid 6: To a solution of a mixture of dipeptides 8 and $\mathbf{8}^{\prime}$ (70:30 ratio) (4.7 g, $9.29 \mathrm{mmol}, 100 \mathrm{~mol} \%$ ) and functionalized Hpg $9^{2}$ (4.1 g, $9.29 \mathrm{mmol}, 100$ mol \%) in MeTHF $(20 \mathrm{~mL})$ cooled to $-10{ }^{\circ} \mathrm{C}$ was added NMM (2.1 g, $\left.10.3 \mathrm{mmol}, 111 \mathrm{~mol} \%\right)$ followed by a solution of isobutyl chloroformate (1.4 g, $10.4 \mathrm{mmol}, 112 \mathrm{~mol} \%)$ in MeTHF (50 $\mathrm{mL})$ over $12 \mathrm{~h}$. Upon reaction completion, $\mathrm{H}_{2} \mathrm{O}(100 \mathrm{~mL})$ was added, followed by $\mathrm{Na}_{2} \mathrm{CO}_{3}(0.22$ g, $2.10 \mathrm{mmol}, 0.23 \mathrm{~mol} \%$ ), and the reaction was stirred for $2 \mathrm{~h}$. The layers were split and the organic layer was washed with $20 \mathrm{wt} \%$ aq $\mathrm{NH}_{4} \mathrm{Cl}(60 \mathrm{~mL})$. The reaction was solvent switched from MeTHF to EtOH, concentrated to $\sim 30 \mathrm{~mL}$, and treated with seeded crystals of tripeptide 6 (4.5 mg, $0.1 \mathrm{wt} \%)$. $n$-Heptane $(50 \mathrm{~mL})$ was added over $5 \mathrm{~h}$ and the mixture was stirred for $12 \mathrm{~h}$ at $20{ }^{\circ} \mathrm{C}$. The resulting slurry was filtered, the filter cake was washed with $n$-heptane $(5 \mathrm{~mL})$ and dried under reduced pressure at $40^{\circ} \mathrm{C}$ for $42 \mathrm{~h}$ to afford tripeptide 6 as an off-white solid $(6.4 \mathrm{~g}$, 7.8 mmol, 97\% yield). HPLC: 95 A\%, >99:1 dr. ${ }^{1} \mathrm{H}$ NMR (500 MHz, DMSO- $\left.d_{6}\right): 10.43$ (s, 1H), $8.36-8.25(\mathrm{~m}, 2 \mathrm{H}), 7.70(\mathrm{~s}, 2 \mathrm{H}), 7.52(\mathrm{~d}, J=2.2 \mathrm{~Hz}, 1 \mathrm{H}), 7.46(\mathrm{~d}, J=7.1 \mathrm{~Hz}, 2 \mathrm{H}), 7.44-7.28$ (m, 9H), $7.24(\mathrm{dd}, J=8.4,2.4 \mathrm{~Hz}, 1 \mathrm{H}), 7.06(\mathrm{dd}, J=8.4,2.2 \mathrm{~Hz}, 1 \mathrm{H}), 6.95(\mathrm{~d}, J=8.5 \mathrm{~Hz}, 1 \mathrm{H})$, $6.84(\mathrm{~d}, J=8.3 \mathrm{~Hz}, 1 \mathrm{H}), 5.75(\mathrm{~s}, 1 \mathrm{H}), 5.19-5.06(\mathrm{~m}, 4 \mathrm{H}), 4.43-4.29(\mathrm{~m}, 2 \mathrm{H}), 3.56(\mathrm{~s}, 3 \mathrm{H})$, $2.99-2.84(\mathrm{~m}, 2 \mathrm{H}), 2.63(\mathrm{~s}, 3 \mathrm{H}), 1.17(\mathrm{~d}, J=6.2 \mathrm{~Hz}, 3 \mathrm{H}) .{ }^{13} \mathrm{C}$ NMR $\left(126 \mathrm{MHz}, \mathrm{DMSO}-d_{6}\right)$ :

(2) Lim, N.-K.; Linghu, X.; Wong, N.; Zhang, H.; Sowell, C. G.; Gosselin, F. Macrolactamization approaches to arylomycin antibiotics core. Org. Lett. 2019, 21, 147-151. 
$172.7,172.4,169.5,161.8,156.8,139.7,137.5,137.3,136.6,132.5,130.6,129.3,129.0,128.9$, 128.4, 128.3, 128.1, 122.5, 115.1, 112.1, 84.9, 70.0, 60.9, 54.7, 52.2, 48.5, 36.5, 22.1, 21.6, 18.4 . HRMS $(m / z)$ calcd for $\mathrm{C}_{37} \mathrm{H}_{40} \mathrm{BIN}_{3} \mathrm{O}_{10}[\mathrm{M}+\mathrm{H}]^{+}$824.1846, found 824.1864.

\section{Suzuki-Miyaura Macrocyclization Optimization}

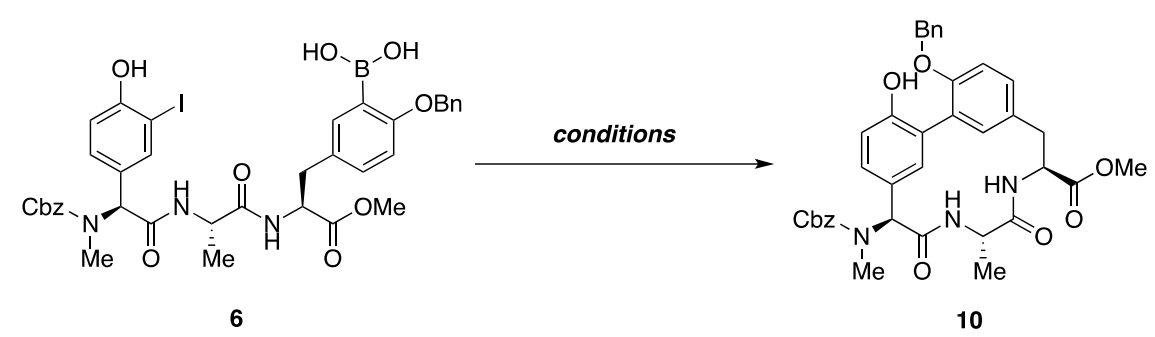

Procedure: To a 96-well plate in a glove box was added pre-catalyst or catalyst and ligand as a solution in THF $(1 \mu \mathrm{mol})$, followed by a slurry of base in THF $(5 \mu \mathrm{mol})$. Solvent was removed in a vacuum centrifuge. To each well was added boronic acid 6 ( $5 \mu \mathrm{mol})$ as a solution in THF (200 $\mu \mathrm{L})$, and $\mathrm{H}_{2} \mathrm{O}(13.5 \mu \mathrm{L})$. The sealed plate was placed on a shaker at $500 \mathrm{rpm}$ and heated to $60{ }^{\circ} \mathrm{C}$ for $15 \mathrm{~h}$. The resulting wells were diluted with a mixture of $\mathrm{THF} / \mathrm{CH}_{3} \mathrm{CN}(30: 70,500 \mu \mathrm{L})$ and analyzed by HPLC. See Table S-1 for HTE results. 


\section{Supporting Information}

Table S-1. High-Throughput Experimentation (HTE) Results

\begin{tabular}{|c|c|c|c|c|c|c|c|c|c|c|c|c|c|}
\hline & 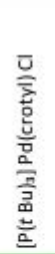 & 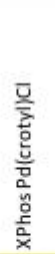 & 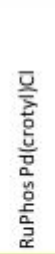 & 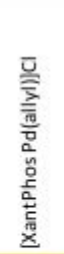 & 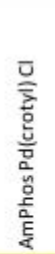 & 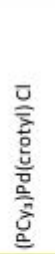 & 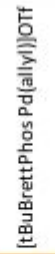 & 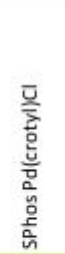 & $\begin{array}{l}\frac{2}{\frac{a}{1}} \\
\frac{1}{n} \\
\frac{a}{a} \\
a\end{array}$ & $\begin{array}{l}\text { m } \\
\text { 苔 } \\
\text { 믐 }\end{array}$ & 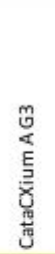 & 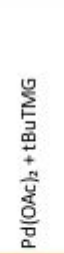 & \\
\hline CsF & $76 \%$ & $45 \%$ & $53 \%$ & $35 \%$ & $41 \%$ & $52 \%$ & $25 \%$ & $57 \%$ & $35 \%$ & $48 \%$ & $48 \%$ & $18 \%$ & \multirow{4}{*}{ 1:1 THF: $\mathrm{H}_{2} \mathrm{O}$} \\
\hline $\mathrm{KHCO}_{3}$ & $71 \%$ & $9 \%$ & $14 \%$ & $45 \%$ & $28 \%$ & $40 \%$ & $12 \%$ & $11 \%$ & $29 \%$ & $40 \%$ & $36 \%$ & $21 \%$ & \\
\hline $\mathrm{K}_{3} \mathrm{PO}_{4}$ & $80 \%$ & $30 \%$ & $31 \%$ & $37 \%$ & $36 \%$ & $39 \%$ & $14 \%$ & $30 \%$ & $27 \%$ & $46 \%$ & $42 \%$ & $21 \%$ & \\
\hline $\mathrm{K}_{2} \mathrm{CO}_{3}$ & $85 \%$ & $16 \%$ & $19 \%$ & $39 \%$ & $26 \%$ & $32 \%$ & $12 \%$ & $17 \%$ & $32 \%$ & $43 \%$ & $22 \%$ & $3 \%$ & \\
\hline CSF & $59 \%$ & $52 \%$ & $54 \%$ & $33 \%$ & $46 \%$ & $49 \%$ & $4 \%$ & $42 \%$ & $50 \%$ & $48 \%$ & $47 \%$ & $25 \%$ & \multirow{4}{*}{ 1:1 MeTHF: $\mathrm{H}_{2} \mathrm{O}$} \\
\hline $\mathrm{KHCO}_{3}$ & $61 \%$ & $33 \%$ & $43 \%$ & $17 \%$ & $50 \%$ & $52 \%$ & $4 \%$ & $39 \%$ & $34 \%$ & $50 \%$ & $39 \%$ & $19 \%$ & \\
\hline $\mathrm{K}_{3} \mathrm{PO}_{4}$ & $73 \%$ & $43 \%$ & $42 \%$ & $14 \%$ & $50 \%$ & $49 \%$ & $20 \%$ & $40 \%$ & $26 \%$ & $57 \%$ & $47 \%$ & $19 \%$ & \\
\hline $\mathrm{K}_{2} \mathrm{CO}_{3}$ & $62 \%$ & $25 \%$ & $33 \%$ & $12 \%$ & $40 \%$ & $39 \%$ & $12 \%$ & $36 \%$ & $41 \%$ & $49 \%$ & $37 \%$ & $20 \%$ & \\
\hline CsF & $65 \%$ & $1 \%$ & $27 \%$ & $29 \%$ & $63 \%$ & $8 \%$ & $5 \%$ & $43 \%$ & $32 \%$ & $24 \%$ & $45 \%$ & $7 \%$ & \multirow{4}{*}{$1: 1 \mathrm{CH}_{3} \mathrm{CN}: \mathrm{H}_{2} \mathrm{O}$} \\
\hline $\mathrm{KHCO}_{3}$ & $85 \%$ & $8 \%$ & $25 \%$ & $20 \%$ & $71 \%$ & $8 \%$ & $3 \%$ & $30 \%$ & $36 \%$ & $19 \%$ & $65 \%$ & $7 \%$ & \\
\hline $\mathrm{K}_{3} \mathrm{PO}_{4}$ & $78 \%$ & $18 \%$ & $38 \%$ & $26 \%$ & $74 \%$ & $7 \%$ & $6 \%$ & $41 \%$ & $39 \%$ & $20 \%$ & $73 \%$ & $8 \%$ & \\
\hline $\mathrm{K}_{2} \mathrm{CO}_{3}$ & $73 \%$ & $8 \%$ & $22 \%$ & $16 \%$ & $65 \%$ & $7 \%$ & $3 \%$ & $27 \%$ & $39 \%$ & $14 \%$ & $73 \%$ & $7 \%$ & \\
\hline $\mathrm{CsF}$ & $48 \%$ & $26 \%$ & $30 \%$ & $25 \%$ & $60 \%$ & $54 \%$ & $5 \%$ & $43 \%$ & $55 \%$ & $48 \%$ & $49 \%$ & $25 \%$ & \multirow{4}{*}{ 1:1 EtOH: $\mathrm{H}_{2} \mathrm{O}$} \\
\hline $\mathrm{KHCO}_{3}$ & $28 \%$ & $5 \%$ & $4 \%$ & $7 \%$ & $30 \%$ & $10 \%$ & $4 \%$ & $4 \%$ & $68 \%$ & $16 \%$ & $44 \%$ & $15 \%$ & \\
\hline $\mathrm{K}_{3} \mathrm{PO}_{4}$ & $34 \%$ & $9 \%$ & $15 \%$ & $5 \%$ & $15 \%$ & $7 \%$ & $3 \%$ & $12 \%$ & $36 \%$ & $14 \%$ & $19 \%$ & $4 \%$ & \\
\hline $\mathrm{K}_{2} \mathrm{CO}_{3}$ & $1 \%$ & $1 \%$ & $2 \%$ & $1 \%$ & $1 \%$ & $1 \%$ & $3 \%$ & $5 \%$ & $16 \%$ & $4 \%$ & 38 & $1 \%$ & \\
\hline $\mathrm{CsF}_{5}$ & $41 \%$ & $22 \%$ & $33 \%$ & $12 \%$ & $39 \%$ & $46 \%$ & $1 \%$ & $39 \%$ & $34 \%$ & $45 \%$ & $39 \%$ & $14 \%$ & \multirow{4}{*}{ 1:1 Anisole: $\mathrm{H}_{2} \mathrm{O}$} \\
\hline $\mathrm{KHCO}_{3}$ & $47 \%$ & $29 \%$ & $41 \%$ & $1 \%$ & $41 \%$ & $50 \%$ & $1 \%$ & $42 \%$ & $36 \%$ & $43 \%$ & $41 \%$ & $16 \%$ & \\
\hline $\mathrm{K}_{3} \mathrm{PO}_{4}$ & $46 \%$ & $32 \%$ & $38 \%$ & $1 \%$ & $42 \%$ & $42 \%$ & $1 \%$ & $38 \%$ & $25 \%$ & $41 \%$ & $47 \%$ & $14 \%$ & \\
\hline $\mathrm{K}_{2} \mathrm{CO}_{3}$ & $40 \%$ & $24 \%$ & $39 \%$ & $1 \%$ & $39 \%$ & $44 \%$ & $1 \%$ & $30 \%$ & $31 \%$ & $48 \%$ & $48 \%$ & $16 \%$ & \\
\hline CsF & $20 \%$ & $18 \%$ & $23 \%$ & $1 \%$ & $22 \%$ & $29 \%$ & $1 \%$ & $22 \%$ & $18 \%$ & $16 \%$ & $20 \%$ & $1 \%$ & \multirow{4}{*}{ 1:1 Toluene: $\mathrm{H}_{2} \mathrm{O}$} \\
\hline $\mathrm{KHCO}_{3}$ & $23 \%$ & $19 \%$ & $28 \%$ & $1 \%$ & $23 \%$ & $20 \%$ & $1 \%$ & $24 \%$ & $17 \%$ & $26 \%$ & $26 \%$ & $1 \%$ & \\
\hline $\mathrm{K}_{3} \mathrm{PO}_{4}$ & $39 \%$ & $26 \%$ & $28 \%$ & $1 \%$ & $28 \%$ & $26 \%$ & $1 \%$ & $28 \%$ & $15 \%$ & $28 \%$ & $26 \%$ & $1 \%$ & \\
\hline $\mathrm{K}_{2} \mathrm{CO}_{3}$ & $31 \%$ & $23 \%$ & $23 \%$ & $1 \%$ & $27 \%$ & $25 \%$ & $1 \%$ & $27 \%$ & $17 \%$ & $28 \%$ & $24 \%$ & $1 \%$ & \\
\hline CsF & $72 \%$ & $29 \%$ & $36 \%$ & $29 \%$ & $47 \%$ & $63 \%$ & $20 \%$ & $43 \%$ & $46 \%$ & $56 \%$ & $44 \%$ & $15 \%$ & \multirow{4}{*}{ 1:1 1,4-Dioxane: $\mathrm{H}_{2} \mathrm{O}$} \\
\hline $\mathrm{KHCO}_{3}$ & $74 \%$ & $39 \%$ & $49 \%$ & $38 \%$ & $49 \%$ & $59 \%$ & $17 \%$ & $41 \%$ & $40 \%$ & $51 \%$ & $39 \%$ & $18 \%$ & \\
\hline $\mathrm{K}_{3} \mathrm{PO}_{4}$ & $82 \%$ & $46 \%$ & $44 \%$ & $36 \%$ & $60 \%$ & $69 \%$ & $26 \%$ & $45 \%$ & $48 \%$ & $63 \%$ & $49 \%$ & $17 \%$ & \\
\hline $\mathrm{K}_{2} \mathrm{CO}_{3}$ & $56 \%$ & $26 \%$ & $28 \%$ & $28 \%$ & $39 \%$ & $40 \%$ & $20 \%$ & $28 \%$ & $46 \%$ & $49 \%$ & $41 \%$ & $16 \%$ & \\
\hline CsF & $68 \%$ & $33 \%$ & $35 \%$ & $14 \%$ & $55 \%$ & $63 \%$ & $1 \%$ & $41 \%$ & $47 \%$ & $48 \%$ & $41 \%$ & $1 \%$ & \multirow{4}{*}{$1: 1 \mathrm{t}$-amylOH: $\mathrm{H}_{2} \mathrm{O}$} \\
\hline $\mathrm{KHCO}_{3}$ & $49 \%$ & $16 \%$ & $16 \%$ & $1 \%$ & $35 \%$ & $42 \%$ & $1 \%$ & $18 \%$ & $49 \%$ & $40 \%$ & $54 \%$ & $20 \%$ & \\
\hline $\mathrm{K}_{3} \mathrm{PO}_{4}$ & $59 \%$ & $28 \%$ & $37 \%$ & $1 \%$ & $34 \%$ & $38 \%$ & $1 \%$ & $42 \%$ & $46 \%$ & $64 \%$ & $58 \%$ & $17 \%$ & \\
\hline $\mathrm{K}_{2} \mathrm{CO}_{3}$ & $41 \%$ & $17 \%$ & $19 \%$ & $1 \%$ & $24 \%$ & $33 \%$ & $1 \%$ & $26 \%$ & $45 \%$ & $48 \%$ & $32 \%$ & $1 \%$ & \\
\hline
\end{tabular}

Note: The amount of cyclization product $\mathbf{1 0}$ is reported in HPLC A\%. 


\section{Observation of Cyclic and Linear Oligomers Derived from Linear Tripeptide 6}

Figure S-1. HPLC Evidence for Cyclic and Linear Oligomer Formation

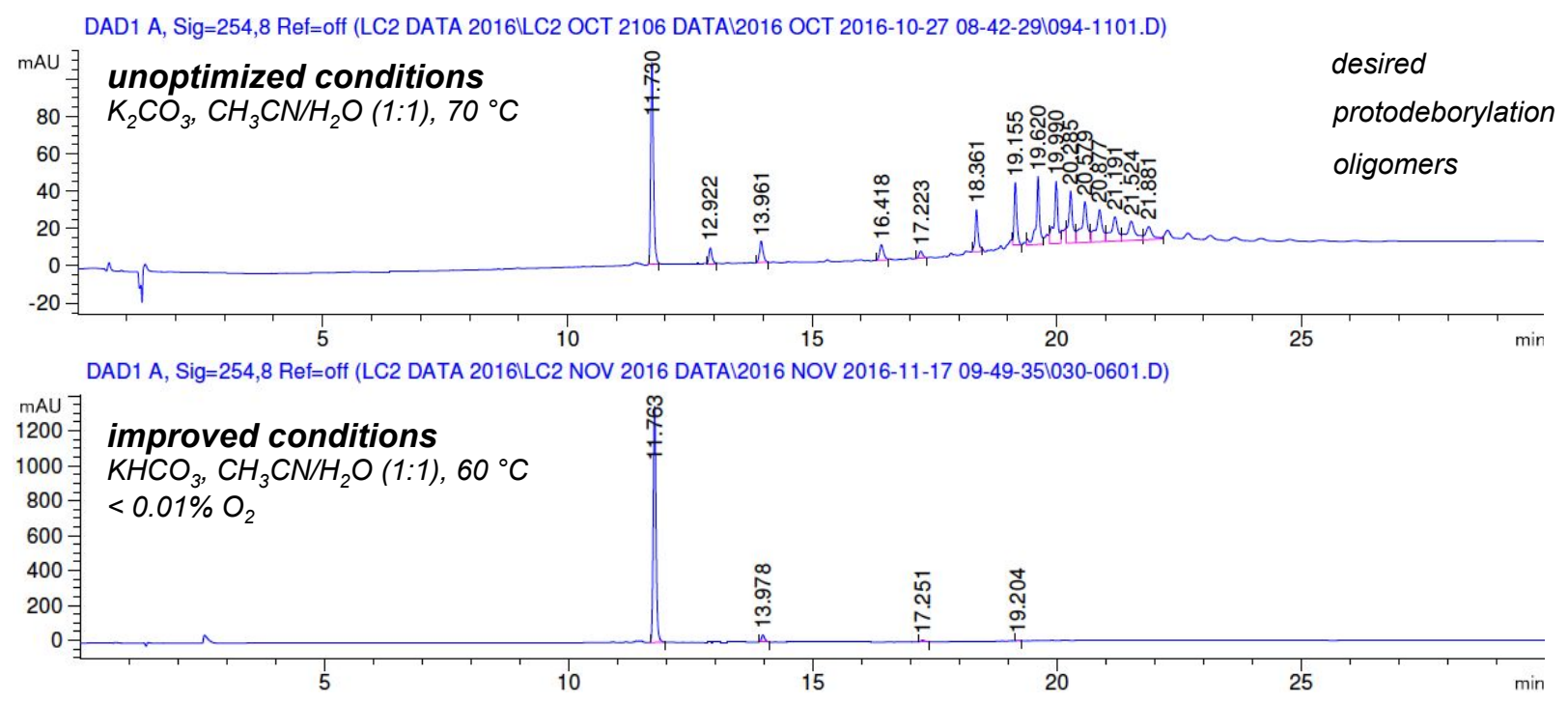

Figure S-2. Protodeborylation Product 11 and Proposed Structures of Linear and Cyclic Oligomers Derived from Linear Tripeptide 6

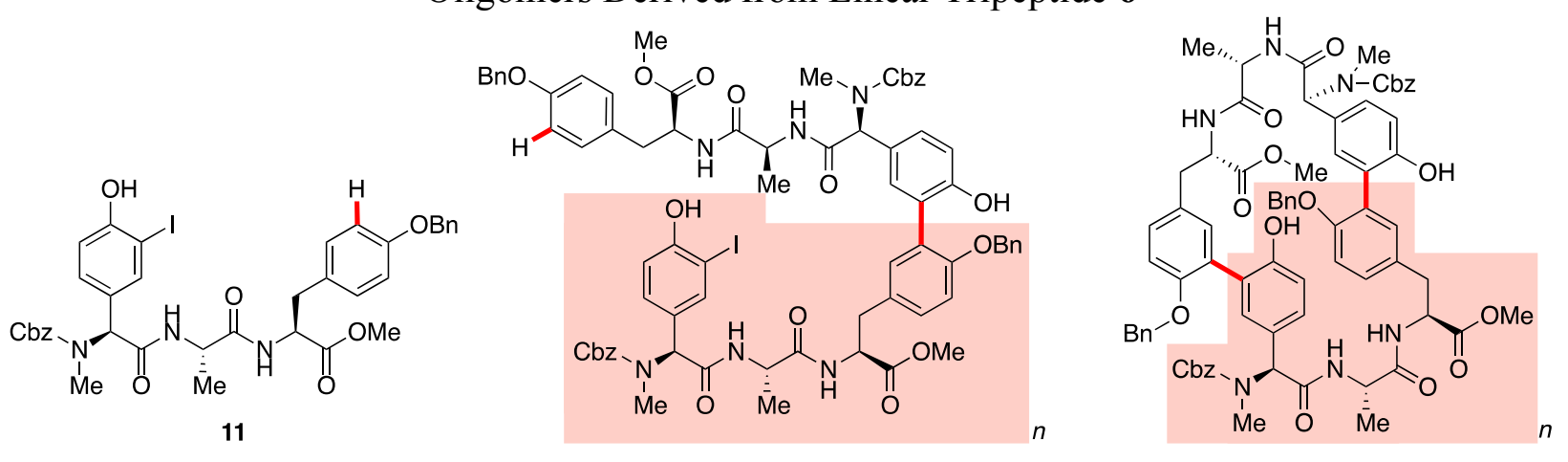




\section{Procedures for the Core Functionalization to API (1)}

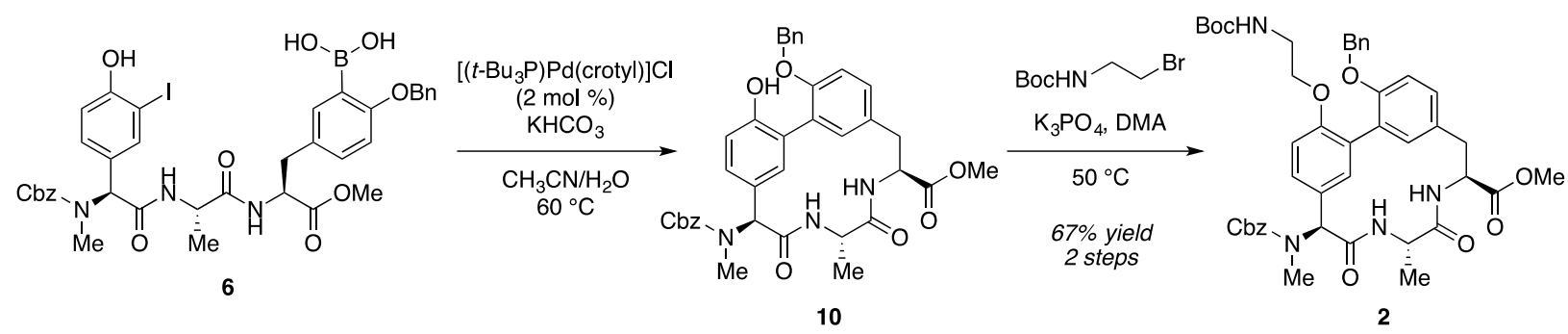

Macrocyclic Core 2: Boronic acid 6 (120 g, $146 \mathrm{mmol}, 100 \mathrm{~mol} \%$ ) was dissolved in $\mathrm{CH}_{3} \mathrm{CN}$ $(480 \mathrm{~mL})$ and sparged with $\mathrm{N}_{2}$ for $5 \mathrm{~h} .{ }^{31}$ In a second vessel was dissolved [( $\left.\left.t-\mathrm{Bu}_{3} \mathrm{P}\right) \mathrm{Pd}(\mathrm{crotyl})\right] \mathrm{Cl}$ (1.2 g, $2.9 \mathrm{mmol}, 2.0 \mathrm{~mol} \%$ ) in $\mathrm{CH}_{3} \mathrm{CN}(8 \mathrm{~mL})$, which was sparged for $0.5 \mathrm{~h}$. In a third vessel was dissolved $\mathrm{KHCO}_{3}(15.3 \mathrm{~g}, 153 \mathrm{mmol}, 105 \mathrm{~mol} \%)$ in a mixture of $\mathrm{CH}_{3} \mathrm{CN} / \mathrm{H}_{2} \mathrm{O}(1: 1,900$ $\mathrm{mL}$ ), which was sparged with $\mathrm{N}_{2}$ for $5 \mathrm{~h}$. The $\mathrm{KHCO}_{3}$ solution was heated to $60{ }^{\circ} \mathrm{C}$ then the solution of $\left[\left(t-\mathrm{Bu}_{3} \mathrm{P}\right) \mathrm{Pd}(\right.$ crotyl $\left.)\right] \mathrm{Cl}$ in $\mathrm{CH}_{3} \mathrm{CN}$ was added. The solution of boronic acid 6 in $\mathrm{CH}_{3} \mathrm{CN}$ was added to the $\mathrm{KHCO}_{3} /[(t-\mathrm{Bu} 3 \mathrm{P}) \mathrm{Pd}($ crotyl $)] \mathrm{Cl}$ solution over $2 \mathrm{~h}$ and stirred for $5 \mathrm{~h}$. The mixture was cooled to $25^{\circ} \mathrm{C} . \mathrm{CH}_{2} \mathrm{Cl}_{2}(150 \mathrm{~mL})$ was added and the layers were separated. The organic layer was concentrated to $\sim 150 \mathrm{~mL}$ under reduced pressure while maintaining the internal temperature below $40{ }^{\circ} \mathrm{C}$ to afford a solution of macrocycle $\mathbf{1 0}(83.7 \mathrm{~g}, 128.5 \mathrm{mmol}$, $88 \%$ assay yield). DMA $(600 \mathrm{~mL})$ was added and the mixture was concentrated to remove residual $\mathrm{CH}_{2} \mathrm{Cl}_{2}$ and $\mathrm{CH}_{3} \mathrm{CN}$. The resulting DMA solution was heated to $50{ }^{\circ} \mathrm{C} . \mathrm{K}_{3} \mathrm{PO}_{4}(155 \mathrm{~g}$, $730 \mathrm{mmol}, 500 \mathrm{~mol} \%$ ) and tert-butyl (2-bromoethyl)carbamate (165.8 g, $730 \mathrm{mmol}, 500 \mathrm{~mol} \%)$ were added and the reaction was stirred for $1.5 \mathrm{~h}$. Upon reaction completion, EtOAc $(2000 \mathrm{~mL})$ and $\mathrm{H}_{2} \mathrm{O}(2000 \mathrm{~mL})$ were added then layers were split. The organic layer was washed with $10 \%$ aq $\mathrm{NaCl}(3 \times 1000 \mathrm{~mL})$, then concentrated to $\sim 420 \mathrm{~mL}$ and $\mathrm{MeOH}(550 \mathrm{~mL})$ was added. MTBE $(450 \mathrm{~mL})$ was added and the resulting suspension was stirred for $5 \mathrm{~h}$ at $15{ }^{\circ} \mathrm{C}$. Solids were filtered, washed with a mixture of EtOAc/MTBE $(1: 1,250 \mathrm{~mL})$, and dried at $40{ }^{\circ} \mathrm{C}$ under reduced pressure to afford macrocyclic core 2 as an off-white solid $(77.8 \mathrm{~g}, 97.9 \mathrm{mmol}, 67 \%$ yield, 2 steps). HPLC: 98.0 A\%. mp: $236{ }^{\circ} \mathrm{C}$. ${ }^{1} \mathrm{H}$ NMR (500 MHz, DMSO- $\left.d_{6}\right): 9.05$ (t, $J=8.3$ $\mathrm{Hz}, 1 \mathrm{H}), 8.46(\mathrm{dd}, J=28.2,9.0 \mathrm{~Hz}, 1 \mathrm{H}), 7.42-7.31(\mathrm{~m}, 5 \mathrm{H}), 7.29-7.07(\mathrm{~m}, 8 \mathrm{H}), 7.03(\mathrm{~d}, J=$ $8.5 \mathrm{~Hz}, 1 \mathrm{H}), 6.71-6.64(\mathrm{~m}, 3 \mathrm{H}), 6.00(\mathrm{~d}, J=5.2 \mathrm{~Hz}, 1 \mathrm{H}), 5.26-5.09(\mathrm{~m}, 4 \mathrm{H}), 4.91-4.82(\mathrm{~m}$,

(3) $\mathrm{O}_{2}$ levels were $<0.01 \%$ in the headspace after 30 minutes of sparging for a $20 \mathrm{~g}$ scale reaction. Increased sparging times were used as a precaution for larger scales. 
1H), $4.75-4.67(\mathrm{~m}, 1 \mathrm{H}), 4.07-3.99(\mathrm{~m}, 1 \mathrm{H}), 3.95(\mathrm{~d}, J=8.4 \mathrm{~Hz}, 1 \mathrm{H}), 3.69(\mathrm{~s}, 3 \mathrm{H}), 3.29(\mathrm{~d}, J=$ $16.7 \mathrm{~Hz}, 1 \mathrm{H}), 3.24-3.15(\mathrm{~m}, 2 \mathrm{H}), 3.05-2.95$ (m, 1H), 2.61 (d, J=17.7 Hz, 3H), 1.34 (s, 9H), 1.20 - $1.13(\mathrm{~m}, 3 \mathrm{H}) .{ }^{13} \mathrm{C}$ NMR $\left(126 \mathrm{MHz}, \mathrm{DMSO}-d_{6}\right): 171.6,171.5,169.6,155.6,155.1,154.9$, $154.6,153.2$, 137.0, 136.5, 136.3, 134.0, 133.9, 130.1, 129.4, 129.2, 128.3, 127.7, 127.6, 127.3, 127.0, 126.9, 126.8, 126.1, 126.0, 113.0, 112.2, 77.2, 69.0, 66.2, 65.8, 65.4, 60.4, 51.7, 49.1, 46.9, $31.9,31.5,30.9,27.5,18.7,18.6$. HRMS $(m / z)$ calcd for $\mathrm{C}_{44} \mathrm{H}_{51} \mathrm{~N}_{4} \mathrm{O}_{10}[\mathrm{M}+\mathrm{H}]^{+} 795.3600$, found 795.3599 .
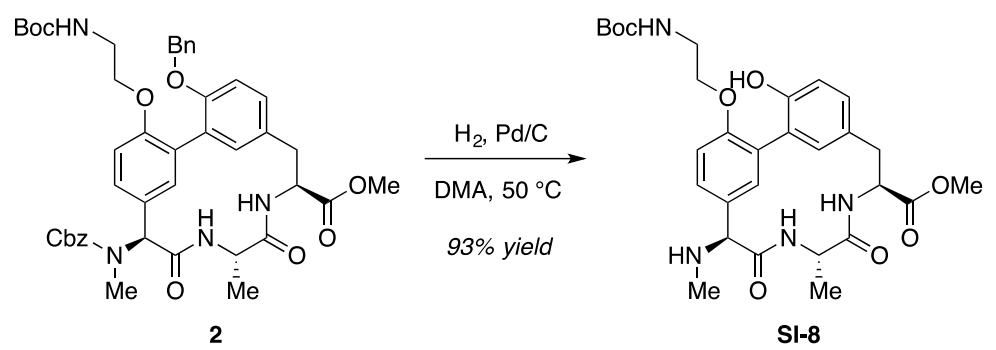

Phenol SI-8: Macrocycle 2 (6.0 g, $7.5 \mathrm{mmol}, 100 \mathrm{~mol} \%)$ and 10\% $\mathrm{Pd} / \mathrm{C}(1.2 \mathrm{~g}, 0.2 \mathrm{wt} \%)$ in DMA $(60 \mathrm{~mL})$ was evacuated and backfilled with $\mathrm{H}_{2}(1 \mathrm{~atm})$ three times. The resulting mixture was heated to $50{ }^{\circ} \mathrm{C}$ and stirred for $16 \mathrm{~h}$. Upon reaction completion, the mixture was diluted with EtOAc $(180 \mathrm{~mL})$, filtered through a celite pad $(6 \mathrm{~g}, 100 \mathrm{wt} \%)$ and washed with EtOAc $(120 \mathrm{~mL})$. Combined organics were washed with $10 \%$ aq $\mathrm{NaCl}(4 \times 100 \mathrm{~mL})$ then dried over $\mathrm{Na}_{2} \mathrm{SO}_{4}(6 \mathrm{~g})$ filtered, and slurried with activated carbon $(1 \mathrm{~g})$ for $30 \mathrm{~min}$. The slurry was filtered and solvents were removed under reduced pressure until a solid was obtained. Solids were slurried in a mixture of EtOAc and petroleum ether $(1: 5,60 \mathrm{~mL})$ for $16 \mathrm{~h}$, filtered, and dried under reduced pressure at $40{ }^{\circ} \mathrm{C}$ for $16 \mathrm{~h}$ to afford phenol SI-8 as a white solid (4.0 g, $7.0 \mathrm{mmol}, 93 \%$ yield). HPLC: 97 A\%, 99.2:0.8 dr. ${ }^{1} \mathrm{H}$ NMR (500 MHz, DMSO-d $) \delta 8.99$ (d, J=8.8 Hz, 1H), 8.68 (s, $1 \mathrm{H}), 8.51(\mathrm{~d}, J=8.8 \mathrm{~Hz}, 1 \mathrm{H}), 7.38-7.28(\mathrm{~m}, 1 \mathrm{H}), 7.02(\mathrm{dd}, J=8.3,2.4 \mathrm{~Hz}, 1 \mathrm{H}), 6.95(\mathrm{~d}, J=8.6$ $\mathrm{Hz}, 1 \mathrm{H}), 6.88(\mathrm{~d}, J=2.4 \mathrm{~Hz}, 1 \mathrm{H}), 6.74(\mathrm{~d}, J=8.3 \mathrm{~Hz}, 2 \mathrm{H}), 4.77-4.64(\mathrm{~m}, 1 \mathrm{H}), 4.49$ (t, $J=10.3$ $\mathrm{Hz}, 1 \mathrm{H}), 4.36(\mathrm{~s}, 1 \mathrm{H}), 3.99(\mathrm{td}, J=6.3,2.1 \mathrm{~Hz}, 2 \mathrm{H}), 3.70(\mathrm{~s}, 3 \mathrm{H}), 3.22(\mathrm{q}, J=6.1 \mathrm{~Hz}, 2 \mathrm{H}), 2.98$ $(\mathrm{d}, J=14.6 \mathrm{~Hz}, 1 \mathrm{H}), 2.83(\mathrm{dd}, J=14.8,11.8 \mathrm{~Hz}, 1 \mathrm{H}), 2.29(\mathrm{~s}, 3 \mathrm{H}), 1.36(\mathrm{~s}, 9 \mathrm{H}), 1.21(\mathrm{~d}, J=6.8$ $\mathrm{Hz}, 3 \mathrm{H}) .{ }^{13} \mathrm{C}$ NMR $\left(126 \mathrm{MHz}, \mathrm{DMSO}-d_{6}\right) \delta 173.4,172.4,172.4,156.1,154.8,153.7,133.3$, $132.9,132.5,129.3,129.0,128.4,126.9,126.3,116.1,112.4,78.3,67.3,64.8,53.5,52.8,48.7$, 35.0, 34.9, 28.7, 20.1. HRMS $(m / z)$ calcd for $\mathrm{C}_{29} \mathrm{~N}_{4} \mathrm{O}_{8} \mathrm{H}_{39}[\mathrm{M}+\mathrm{H}]^{+}$571.2762, found 571.2758. 


\section{Supporting Information}
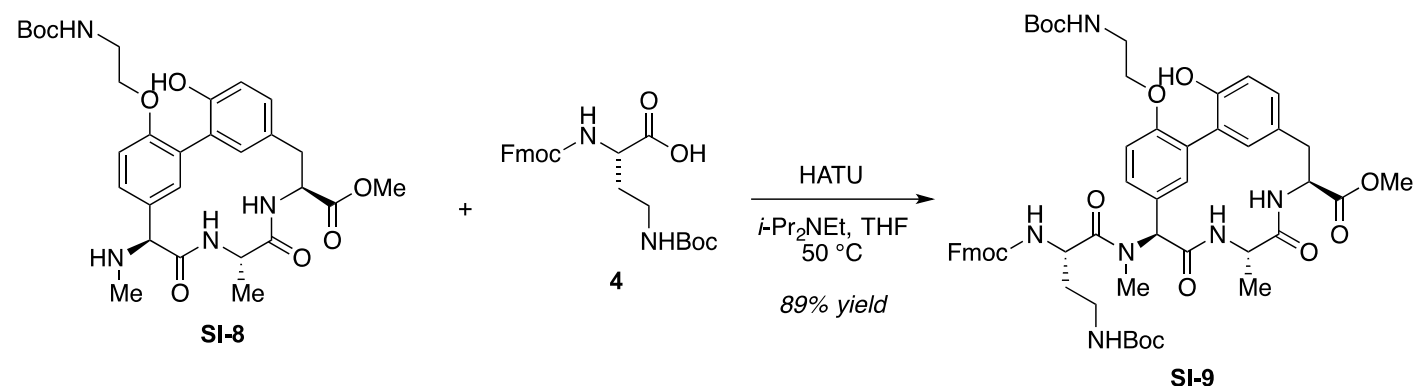

Amide SI-9: To a solution of the amine SI-8 (70.0 g, $121 \mathrm{mmol}, 100 \mathrm{~mol} \%)$ and acid 4 (58.9 g, $134 \mathrm{mmol}, 110 \mathrm{~mol} \%)$ in THF $(700 \mathrm{~mL})$ at room temperature was added $i$-Pr 2 NEt $(42.4 \mathrm{~mL}, 243$ mmol, $200 \mathrm{~mol} \%$ ) and HATU (49.5 g, $128 \mathrm{mmol}, 105 \mathrm{~mol} \%)$. The mixture was heated at $50{ }^{\circ} \mathrm{C}$ for $12 \mathrm{~h}$, then cooled to room temperature and diluted with $i$-PrOAc $(280 \mathrm{~mL})$ and $4.5 \mathrm{wt} \% \mathrm{aq}$ $\mathrm{NaHCO}_{3}(560 \mathrm{~mL})$. The layers were separated, and the organic phase was washed with $\mathrm{H}_{2} \mathrm{O}(210$ $\mathrm{mL}$ ). The organic layer was concentrated to $\sim 700 \mathrm{~mL}$ and then distilled at constant volume while THF (2500 mL) was added portionwise to achieve $\mathrm{H}_{2} \mathrm{O}$ content of 0.24 wt $\%$ (by KF analysis). The obtained solution was then heated to $70{ }^{\circ} \mathrm{C}$, diluted with $\mathrm{CH}_{3} \mathrm{CN}(230 \mathrm{~mL})$, treated with seed crystals of amide SI-2 (0.70 g, $1.0 \mathrm{wt} \%)$ in THF/CH$/ \mathrm{CN}_{3}(50: 50,16 \mathrm{~mL})$, and stirred for $4 \mathrm{~h}$. To this mixture was added another portion of $\mathrm{CH}_{3} \mathrm{CN}(460 \mathrm{~mL})$ over $2 \mathrm{~h}$. The suspension was stirred for another $5 \mathrm{~h}$ at $70{ }^{\circ} \mathrm{C}$, and then cooled to $30{ }^{\circ} \mathrm{C}$ over another $5 \mathrm{~h}$. The obtained mixture was filtered, the cake washed with $\mathrm{CH}_{3} \mathrm{CN}(420 \mathrm{~mL})$, and then dried at $50{ }^{\circ} \mathrm{C}$ under vacuum to obtain desired amide SI-9 (106.5 g, $107 \mathrm{mmol}, 89 \%$ yield) as a white solid. HPLC: 99.0 A\%, 99.5:0.5 dr. mp: $172{ }^{\circ} \mathrm{C} .{ }^{1} \mathrm{H}$ NMR (600 MHz, DMSO-d $): \delta 9.03(\mathrm{~d}, J=8.0 \mathrm{~Hz}, 1 \mathrm{H}), 8.69(\mathrm{~s}, 1 \mathrm{H}), 8.47(\mathrm{~d}$, $J=9.0 \mathrm{~Hz}, 1 \mathrm{H}), 7.90(\mathrm{dd}, J=7.7,4.4 \mathrm{~Hz}, 2 \mathrm{H}), 7.76(\mathrm{dd}, J=7.7,4.4 \mathrm{~Hz}, 2 \mathrm{H}), 7.72(\mathrm{~d}, J=7.9 \mathrm{~Hz}$, 1H), $7.43(\mathrm{td}, J=7.5,4.0 \mathrm{~Hz}, 2 \mathrm{H}), 7.35$ (q, $J=7.5 \mathrm{~Hz}, 2 \mathrm{H}), 7.05(\mathrm{~m}, 3 \mathrm{H}), 6.89(\mathrm{~m}, 1 \mathrm{H}), 6.82$ (d, $J=8.2 \mathrm{~Hz}, 1 \mathrm{H}), 6.77(\mathrm{~m}, 1 \mathrm{H}), 6.75(\mathrm{~d}, J=2.0 \mathrm{~Hz}, 1 \mathrm{H}), 6.71(\mathrm{~d}, J=2.3 \mathrm{~Hz}, 1 \mathrm{H}), 6.34(\mathrm{~s}, 1 \mathrm{H})$, 4.81 (ddd, $J=11.7,8.0,2.8 \mathrm{~Hz}, 1 \mathrm{H}), 4.74(\mathrm{dd}, J=9.0,6.9 \mathrm{~Hz}, 1 \mathrm{H}), 4.44(\mathrm{ddd}, J=11.7,8.0,3.8$ Hz, 1H), 4.30 (d, J=7.2 Hz, 2H), 4.25 (d, $J=7.2 \mathrm{~Hz}, 1 \mathrm{H}), 4.03$ (m, 2H), 3.70 (s, 3H), 3.29 $3.18(\mathrm{~m}, 4 \mathrm{H}), 3.12-3.02(\mathrm{~m}, 1 \mathrm{H}), 3.01-2.92(\mathrm{~m}, 2 \mathrm{H}), 2.72(\mathrm{~s}, 3 \mathrm{H}), 1.92-1.80(\mathrm{~m}, 1 \mathrm{H}), 1.67$ $(\mathrm{dq}, J=15.0,7.9,6.7 \mathrm{~Hz}, 1 \mathrm{H}), 1.36(\mathrm{~d}, J=9.7 \mathrm{~Hz}, 18 \mathrm{H}), 1.19(\mathrm{~d}, J=6.9 \mathrm{~Hz}, 3 \mathrm{H}) .{ }^{13} \mathrm{C}$ NMR $\left(126 \mathrm{MHz}, \mathrm{DMSO}-d_{6}\right) \delta 172.3,172.1$ 172.0, 169.8, 156.1, 155.6, 155.5, 154.7, 152.7, 143.9, $143.7,140.7,140.7,134.3,130.6,129.1,128.8,128.7,128.1$, 127.6, 127.6, 127.4, 127.1, 127.1, $125.7,125.4,125.3,120.1,120.0,118.0,116.3,113.1,77.8,77.5,67.0,65.7,58.9,52.3,50.3$, 
49.1, 47.5, 46.7, 39.4, 36.9, 32.7, 32.1, 30.8, 28.2, 19.2. HRMS $(\mathrm{m} / \mathrm{z})$ calcd for $\mathrm{C}_{53} \mathrm{H}_{65} \mathrm{~N}_{6} \mathrm{O}_{13}$ $[\mathrm{M}+\mathrm{H}]^{+}$993.4604, found 993.4605 .

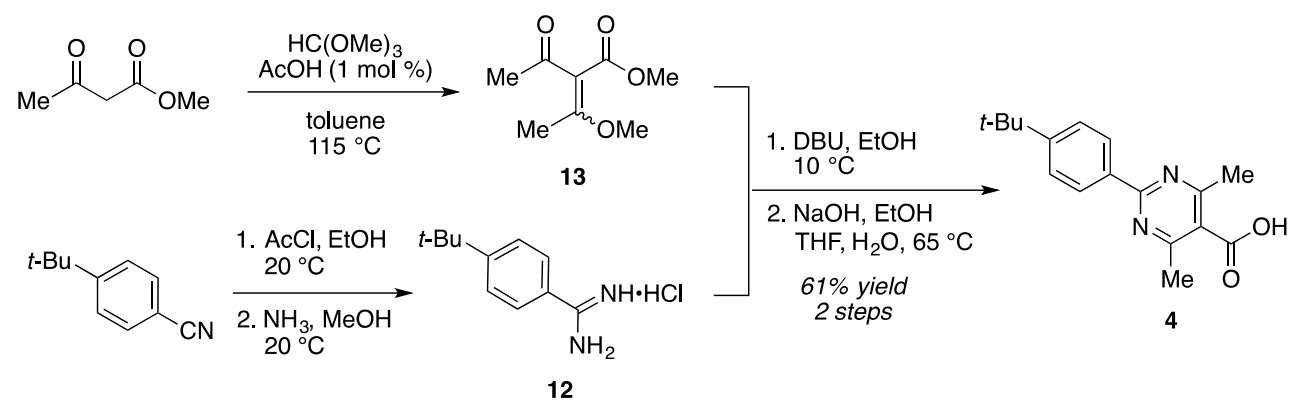

Ester 13: To a mixture of methyl acetoacetate (100.0 g, $0.861 \mathrm{~mol}, 100 \mathrm{~mol} \%)$, trimethyl orthoacetate (351.8 g, $2.93 \mathrm{~mol}, 340 \mathrm{~mol} \%)$ and AcOH (2.6 g, $0.044 \mathrm{~mol}, 0.051 \mathrm{~mol} \%)$ was added toluene $(500 \mathrm{~mL})$ and the mixture was stirred at $115^{\circ} \mathrm{C}$ for $45 \mathrm{~h}$. The mixture was then concentrated under reduced pressure, keeping temperature $<75^{\circ} \mathrm{C}$, to give crude ester $\mathbf{1 3}(124.9$ g) as a brown oil, which was used in the next step without additional purification. Spectroscopic data was consistent with previous reports. ${ }^{4}$

Amidine Hydrochloride 12: To a solution of 4-tert-butylbenzonitrile (10.0 g, $97.0 \mathrm{mmol}, 100$ mol \%) in EtOH (45.3 mL, $800 \mathrm{~mol} \%$ ) was added acetyl chloride (27.7 mL, $38.8 \mathrm{mmol}, 400 \mathrm{~mol}$ $\%$ ) and the mixture was stirred at $15-20{ }^{\circ} \mathrm{C}$ for $48 \mathrm{~h}$. The mixture was concentrated under reduced pressure to $\sim 20 \mathrm{~mL}$ and treated with $\mathrm{MTBE}(50 \mathrm{~mL})$ to obtain crude imidate ester as a hydrochloride salt (14.3 g), which was used in the next step directly without further purification. The imidate ester was then treated with $7 \mathrm{M} \mathrm{NH}_{3}$ in $\mathrm{MeOH}(71.5 \mathrm{~mL})$ for $15 \mathrm{~h}$, after which it was concentrated under reduced pressure and slurried with MTBE $(70 \mathrm{~mL})$. After filtration, the desired amidine hydrochloride 12 was obtained as a white solid (11.5 g), which was used in the

(4) The data for compound $\mathbf{1 3}$ (E/Z mixture) has been reported previously. See: (a) Roberge, G.; Brassard, P. Total syntheses of the methyl ether ester derivatives of the coccid anthraquinones laccaic acid D and kermesic acid. J. Chem. Soc., Perkin Trans. 1, 1978, 1041-1046; (b) Cameron, D. W.; Deutscher, D. J.; Feutrill, G. I.; Griffiths, P. G. Aust. J. Chem. 1981, 34, 24012421. 


\section{Supporting Information}

next step without additional purification. Spectroscopic data was consistent with previous reports. ${ }^{5}$

Carboxylic Acid 4: To a solution of amidine hydrochloride 12 (10.0 g, 4.70 mmol, $100 \mathrm{~mol} \%)$ and ester 13 (20.0 g, $11.6 \mathrm{mmol}, 250 \mathrm{~mol} \%)$ in $\mathrm{EtOH}(50 \mathrm{~mL})$ at $10{ }^{\circ} \mathrm{C}$ was added DBU $(14.9 \mathrm{~g}$, $9.79 \mathrm{mmol}, 210 \mathrm{~mol} \%$ ) and stirred for $2 \mathrm{~h}$. The mixture was then concentrated under reduced pressure and partitioned between $\operatorname{MTBE}(70 \mathrm{~mL})$ and $\mathrm{H}_{2} \mathrm{O}(70 \mathrm{~mL})$. The organic layer was washed with $\mathrm{H}_{2} \mathrm{O}(50 \mathrm{~mL})$ again, and then concentrated under reduced pressure to $\sim 20 \mathrm{~mL}$ to obtain crude methyl ester 13, which was then dissolved in THF $(50 \mathrm{~mL})$. To this mixture was then added a solution of $\mathrm{NaOH}(4.0 \mathrm{~g}, 10.1 \mathrm{mmol}, 215 \mathrm{~mol} \%)$ in $\mathrm{H}_{2} \mathrm{O}(20 \mathrm{~mL})$, and the reaction was stirred at $65{ }^{\circ} \mathrm{C}$ for $2 \mathrm{~h}$. The mixture was then concentrated under reduced pressure to $\sim 15$ $\mathrm{mL}$, dissolved in $\mathrm{H}_{2} \mathrm{O}(40 \mathrm{~mL})$, and then washed with MTBE $(50 \mathrm{~mL})$. The aqueous solution was cooled to $5^{\circ} \mathrm{C}$, and then treated with concentrated aq $\mathrm{HCl}$ to $\mathrm{pH} 2$. After stirring the mixture for $1 \mathrm{~h}$ at $20^{\circ} \mathrm{C}$, the solid was filtered and washed with additional portion of $\mathrm{H}_{2} \mathrm{O}(50 \mathrm{~mL})$. The obtained material was dried at $45^{\circ} \mathrm{C}$ for $24 \mathrm{~h}$ to obtain the carboxylic acid $4(8.1 \mathrm{~g}, 2.9 \mathrm{mmol}$, 61\% yield). HPLC: 98.9 A\%. mp: $233{ }^{\circ} \mathrm{C} .{ }^{1} \mathrm{H}$ NMR (500 MHz, DMSO- $\left.d_{6}\right) \delta 8.32(\mathrm{~d}, J=8.5 \mathrm{~Hz}$, 2H), $7.54(\mathrm{~d}, J=8.6 \mathrm{~Hz}, 2 \mathrm{H}), 2.56(\mathrm{~s}, 6 \mathrm{H}), 1.32(\mathrm{~s}, 9 \mathrm{H}) .{ }^{13} \mathrm{C}$ NMR $\left(126 \mathrm{MHz}, \mathrm{DMSO}-d_{6}\right) \delta$ $168.0,163.0,161.5,153.3,133.3,127.3,124.8,124.3,34.0,30.4,22.2$. HRMS $(\mathrm{m} / \mathrm{z})$ calcd for $\mathrm{C}_{17} \mathrm{H}_{21} \mathrm{~N}_{2} \mathrm{O}_{2}[\mathrm{M}+\mathrm{H}]^{+}$285.1598, found 285.1599.

(5) Amidine $\mathbf{1 2}$ is commercially available. Additionally, the data for $\mathbf{1 2}$ has been reported previously. See: (a) Petitjean, A.; Puntoriero, F. Campagna, S.; Juris, A.; Lehn, J.-M. Multicomponent Supramolecular Devices: Synthesis, Optical, and Electronic Properties of Bridged Bis-dirhodium and -diruthenium Complexes. Eur. J. Inorg. Chem. 2006, 3878-3892; (b) Talhout, R.; Villa, A.; Mark, A. E.; Engberts, J. B. F. N. J. Am. Chem. Soc. 2003, 125, 10570-10579. 


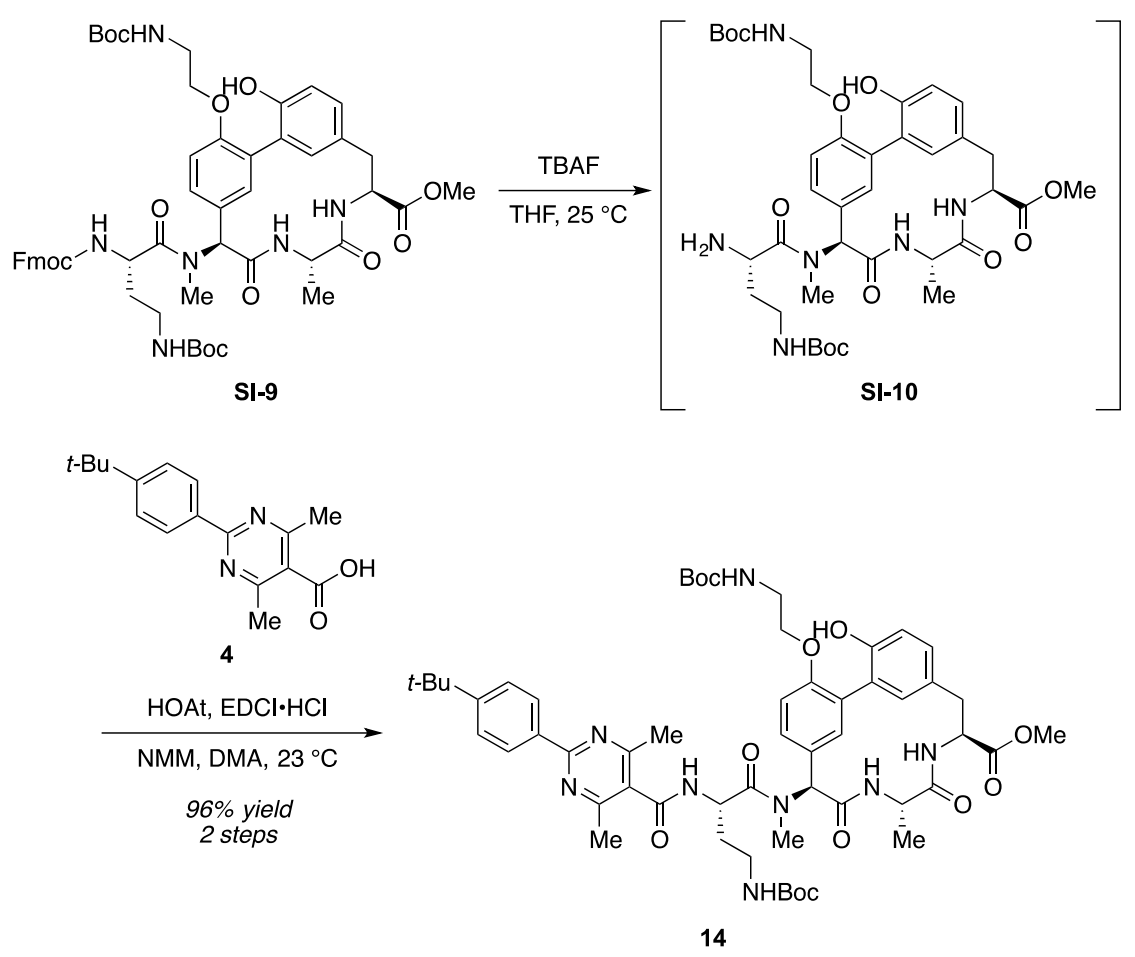

Amide 14: To a solution of Fmoc-amine SI-9 (40.0 g, $38.8 \mathrm{mmol}, 100 \mathrm{~mol} \%$ ) in THF (200 mL) at $25{ }^{\circ} \mathrm{C}$ was added a $1 \mathrm{M}$ solution of TBAF in THF $(100 \mathrm{~mL}, 97.0 \mathrm{mmol}, 250 \mathrm{~mol} \%)$ and stirred for $2 \mathrm{~h}$. To the reaction mixture was then added $i$-PrOAc $(120 \mathrm{~mL})$, followed by a solution of phosphate buffer ( $70 \mathrm{~g} \mathrm{~K}_{2} \mathrm{HPO}_{4}$ and $30 \mathrm{~g} \mathrm{~K}_{2} \mathrm{HPO}_{4}$ in $900 \mathrm{~mL} \mathrm{H} \mathrm{H}_{2} \mathrm{O}, 200 \mathrm{~mL}$ ). After phase separation, the organic layer was successively washed with the phosphate buffer ( $200 \mathrm{~mL}), 4.5$ wt $\%$ aq $\mathrm{NaHCO}_{3}(120 \mathrm{~mL})$, and additional phosphate buffer $(200 \mathrm{~mL})$. Upon concentration of the obtained solution to $\sim 150 \mathrm{~mL}$ under reduced pressure, $i$-PrOAc $(500 \mathrm{~mL})$ was added and concentrated again to the original volume $(150 \mathrm{~mL})$ to afford a crude solution of SI-10 (28.9 g, $34.8 \mathrm{mmol}, 100 \mathrm{~mol} \%)$. To the crude solution of amine SI-10 was added DMA (67 mL), carboxylic acid 4 (5.5 g, $34.8 \mathrm{mmol}, 100 \mathrm{~mol} \%$ ), and HOAt (5.5 g, $41.8 \mathrm{mmol}, 120 \mathrm{~mol} \%$ ). EDCI $\cdot \mathrm{HCl}(13.9 \mathrm{~g}, 69.7 \mathrm{mmol}, 200 \mathrm{~mol} \%)$ was added, followed by NMM (7.8 mL, $69.7 \mathrm{mmol}$, $200 \mathrm{~mol} \%$ ) and additional DMA (67 mL). After $19 \mathrm{~h}$ of stirring, the reaction was diluted with $i$ PrOAc $(134 \mathrm{~mL})$ and cooled to an internal temperature of $5{ }^{\circ} \mathrm{C}$. The reaction was quenched by the addition of $1.0 \mathrm{M} \mathrm{aq} \mathrm{HCl}(134 \mathrm{~mL})$ and warmed to $20^{\circ} \mathrm{C}$. The phases were separated and the organic phase was washed with $1.0 \mathrm{M}$ aq $\mathrm{HCl}(134 \mathrm{~mL}), 50 \%$ sat aq $\mathrm{NaHCO}_{3}(134 \mathrm{~mL})$, and $\mathrm{H}_{2} \mathrm{O}(134 \mathrm{~mL})$. The organic phase was concentrated under reduced pressure to $\sim 150 \mathrm{~mL}$. The crude solution was diluted with $i$-PrOAc $(100 \mathrm{~mL})$ and concentrated under reduced pressure to $\sim 150 \mathrm{~mL}$. The crude solution was diluted with $i$-PrOAc $(134 \mathrm{~mL})$. To a solution of $n$-heptane 


\section{Supporting Information}

$(460 \mathrm{~mL})$ heated to an internal temperature of $55^{\circ} \mathrm{C}$ was added the solution of crude amide SI10 dropwise over $30 \mathrm{~min}$, giving a white suspension. The mixture was gradually cooled to $20^{\circ} \mathrm{C}$ over $16 \mathrm{~h}$. The suspension was filtered through a filter funnel and the filter cake was washed twice with a solution of $i$-PrOAc/ $n$-heptane $(20: 80,63 \mathrm{~mL})$. The solids were dried by vacuum suction and $\mathrm{N}_{2}$ flow for $2.5 \mathrm{~h}$. The solids were further dried in a vacuum oven at $40{ }^{\circ} \mathrm{C}$ for $16 \mathrm{~h}$ to give amide 14 (34.6 g, $33.3 \mathrm{mmol}$, 96\% yield, 2 steps) was obtained as a white solid. HPLC: $99.5 \mathrm{~A} \%,>98: 2 \mathrm{dr} .{ }^{1} \mathrm{H}$ NMR $\left(600 \mathrm{MHz}, \mathrm{DMSO}-d_{6}\right) \delta 9.03(\mathrm{~d}, J=8.0 \mathrm{~Hz}, 1 \mathrm{H}), 9.00(\mathrm{~d}, J=7.1$ Hz, 1H), 8.69 (s, 1H), 8.47 (d, $J=8.9 \mathrm{~Hz}, 1 \mathrm{H}), 8.34$ (d, $J=8.5 \mathrm{~Hz}, 2 \mathrm{H}), 7.56(\mathrm{~d}, J=8.5 \mathrm{~Hz}, 2 \mathrm{H})$, $7.14(\mathrm{~d}, J=8.6 \mathrm{~Hz}, 1 \mathrm{H}), 7.11(\mathrm{dd}, J=8.7,2.3 \mathrm{~Hz}, 1 \mathrm{H}), 7.08-7.03(\mathrm{~m}, 2 \mathrm{H}), 6.83(\mathrm{~d}, J=8.5 \mathrm{~Hz}$, $1 \mathrm{H}), 6.80(\mathrm{~d}, J=2.3 \mathrm{~Hz}, 1 \mathrm{H}), 6.77(\mathrm{t}, J=5.5 \mathrm{~Hz}, 1 \mathrm{H}), 6.73(\mathrm{~m}, 1 \mathrm{H}), 6.44(\mathrm{~s}, 1 \mathrm{H}), 4.91-4.85(\mathrm{~m}$, 1H), 4.80 (ddd, $J=13.4,6.7,2.5 \mathrm{~Hz}, 1 \mathrm{H}), 4.75$ (dt, $J=9.0,6.8 \mathrm{~Hz}, 1 \mathrm{H}), 4.08$ (t, $J=6.3 \mathrm{~Hz}, 2 \mathrm{H}$ ), $3.71(\mathrm{~s}, 3 \mathrm{H}), 3.30-3.21$ (m, 3H), $3.10(\mathrm{dp}, J=28.5,7.1 \mathrm{~Hz}, 2 \mathrm{H}), 2.99$ (dd, $J=17.0,12.1 \mathrm{~Hz}$, 1H), $2.90(\mathrm{~s}, 3 \mathrm{H}), 2.53(\mathrm{~s}, 6 \mathrm{H}), 1.98-1.92(\mathrm{~m}, 1 \mathrm{H}), 1.77-1.68(\mathrm{~m}, 1 \mathrm{H}), 1.37$ (s, 18H), 1.35 (s, $9 \mathrm{H}), 1.20(\mathrm{~d}, J=6.7 \mathrm{~Hz}, 3 \mathrm{H}) .{ }^{13} \mathrm{C}$ NMR $\left(126 \mathrm{MHz}, \mathrm{DMSO}-d_{6}\right) \delta 172.1,172.1,172.0,169.7$, 166.7, 163.1, 161.8, 155.6, 155.6, 154.8, 153.5, 152.8, 134.4, 134.3, 130.7, 129.0, 128.8, 128.7, $128.1,127.9,127.7,127.4,125.7,125.4,116.4,113.2,77.8,77.5,67.0,58.8,52.3,50.4,47.5$, $47.5,39.8,36.8,34.6,32.8,32.3,31.0,30.4,28.2,28.2,22.0,19.2$. HRMS $(\mathrm{m} / \mathrm{z})$ calcd for $\mathrm{C}_{55} \mathrm{H}_{73} \mathrm{~N}_{8} \mathrm{O}_{12}[\mathrm{M}+\mathrm{H}]^{+} 1037.5342$ found 1037.5356. 


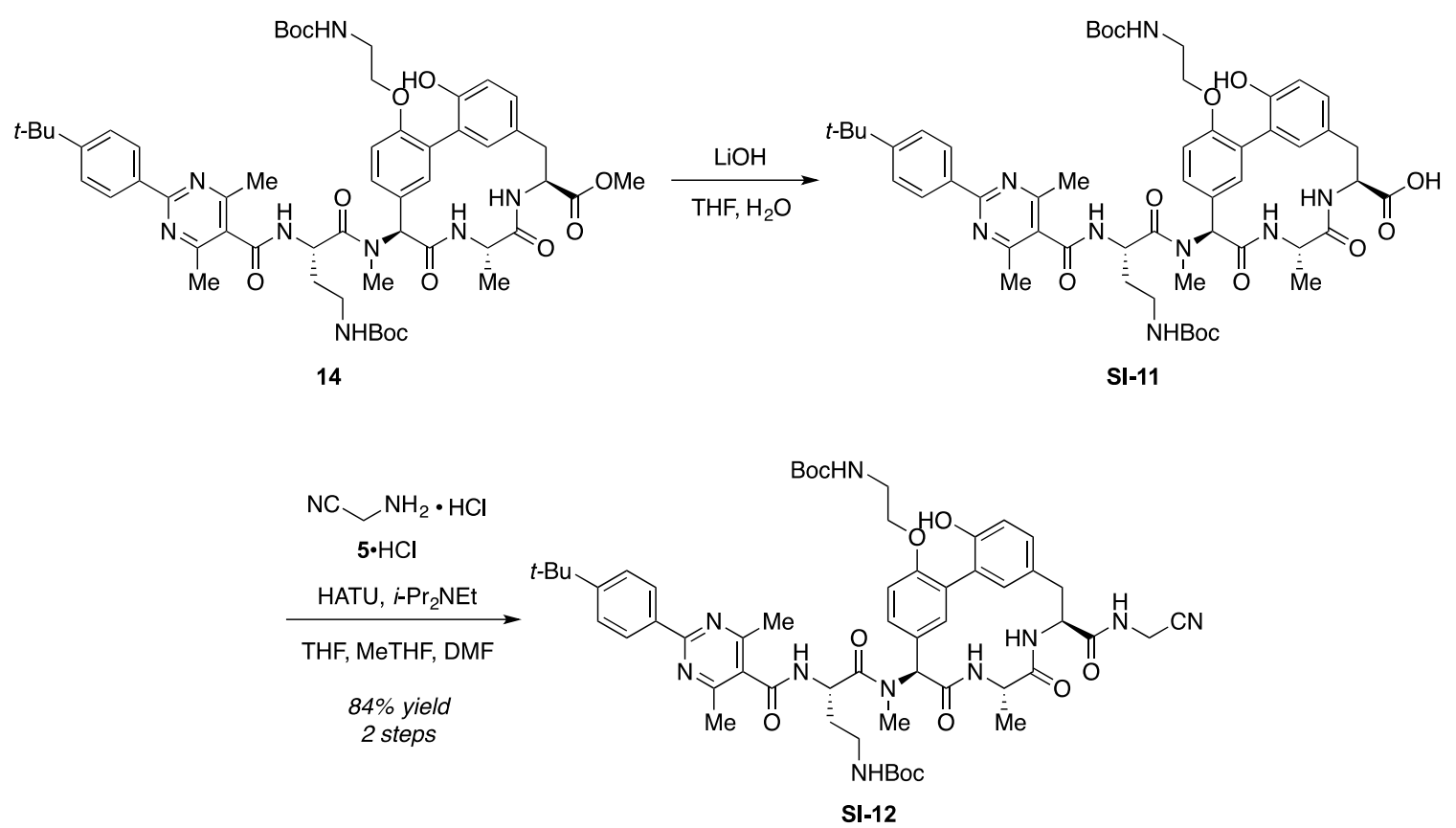

Amide SI-12: To a solution of amide 14 (100 g, $96.4 \mathrm{mmol}, 100 \mathrm{~mol} \%)$ in THF (500 mL) was added $\mathrm{H}_{2} \mathrm{O}(259 \mathrm{~mL})$. The reaction was cooled to $0{ }^{\circ} \mathrm{C}$. A solution of $1 \mathrm{M}$ aq $\mathrm{LiOH}(241 \mathrm{~mL}$, $241.0 \mathrm{mmol}, 250 \mathrm{~mol} \%$ ) at $0{ }^{\circ} \mathrm{C}$ was added dropwise over $30 \mathrm{~min}$, maintaining reaction internal temperature below $5{ }^{\circ} \mathrm{C}$. After $2.5 \mathrm{~h}$ of stirring, the reaction was quenched by the dropwise addition of $1 \mathrm{M}$ aq $\mathrm{HCl}(241 \mathrm{~mL}, 241.0 \mathrm{mmol}, 250 \mathrm{~mol} \%$ ) over $20 \mathrm{~min}$. MeTHF was added (500 $\mathrm{mL}$ ), giving a white biphasic mixture. The reaction was warmed to an internal temperature of 20 ${ }^{\circ} \mathrm{C}$. The phases were separated and the organic phase was washed with $\mathrm{H}_{2} \mathrm{O}(2 \times 300 \mathrm{~mL})$. The crude solution of acid SI-4 in THF/MeTHF was distilled to $\sim 300 \mathrm{~mL}$ and $\mathrm{H}_{2} \mathrm{O}$ levels were controlled below 1 wt \% (by KF analysis). In a separate reaction vessel, a mixture of aminoacetonitrile hydrochloride (9.94 g, $107.5 \mathrm{mmol}, 110 \mathrm{~mol} \%$ ) in DMF (50 mL) was treated with $i-\operatorname{Pr}_{2} \mathrm{NEt}(37.5 \mathrm{~mL}, 215.0 \mathrm{mmol}, 220 \mathrm{~mol} \%)$ and stirred for $30 \mathrm{~min}$. The crude solution of acid SI-11 in THF/MeTHF was treated with HATU (41.7 g, $107.5 \mathrm{mmol}, 110 \mathrm{~mol} \%)$ and stirred for $30 \mathrm{~min}$. The mixture of aminoacetonitrile hydrochloride, $i-\mathrm{Pr}_{2} \mathrm{NEt}$, and $\mathrm{DMF}$ was added dropwise through an addition funnel. The reaction was stirred for $2.5 \mathrm{~h}$. The reaction was quenched by the addition of $\mathrm{H}_{2} \mathrm{O}(500 \mathrm{~mL})$ and the phases were separated. The organic phase was washed further with $2.5 \mathrm{wt} \%$ aq $\mathrm{NaHCO}_{3}(500 \mathrm{~mL})$ and $\mathrm{H}_{2} \mathrm{O}(2 \times 500 \mathrm{~mL})$. The solution was distilled to $\sim 300 \mathrm{~mL}$. $\mathrm{CH}_{3} \mathrm{CN}(30 \mathrm{~mL}$ ) was added, followed by seed crystals of amide SI-12 (500 mg, 0.5 wt \%) in $\mathrm{CH}_{3} \mathrm{CN}(10 \mathrm{~mL})$. The mixture was aged at $70{ }^{\circ} \mathrm{C}$ for $1 \mathrm{~h}$ before the addition of a solution of $\mathrm{CH}_{3} \mathrm{CN} / \mathrm{H}_{2} \mathrm{O}(9: 1,600 \mathrm{~mL})$ over $1 \mathrm{~h}$. The resulting slurry was aged at 70 


\section{Supporting Information}

${ }^{\circ} \mathrm{C}$ for $6 \mathrm{~h}$, cooled to $5{ }^{\circ} \mathrm{C}$ over $6 \mathrm{~h}$, and held at $5{ }^{\circ} \mathrm{C}$ for $72 \mathrm{~h}$. The suspension was filtered then the filter cake was washed with $\mathrm{CH}_{3} \mathrm{CN}(2 \times 300 \mathrm{~mL})$. The solids were dried in a vacuum oven at $60{ }^{\circ} \mathrm{C}$ for $18 \mathrm{~h}$ to afford amide SI-12 (86.2 g, $81.2 \mathrm{mmol}, 84 \%$ yield, 2 steps). HPLC: $98.4 \mathrm{~A} \%$, > 98:2 dr. mp: $182{ }^{\circ} \mathrm{C} .{ }^{1} \mathrm{H}$ NMR $\left(500 \mathrm{MHz}\right.$, DMSO- $\left.d_{6}\right) \delta 9.00(\mathrm{~d}, J=7.1 \mathrm{~Hz}, 1 \mathrm{H}), 8.97(\mathrm{~d}, J=7.7$ $\mathrm{Hz}, 1 \mathrm{H}), 8.69$ (s, 1H), 8.66 (t, $J=5.7 \mathrm{~Hz}, 1 \mathrm{H}), 8.41$ (d, $J=9.0 \mathrm{~Hz}, 1 \mathrm{H}), 8.33(\mathrm{~d}, J=8.5 \mathrm{~Hz}, 2 \mathrm{H})$, $7.55(\mathrm{~d}, J=8.7 \mathrm{~Hz}, 2 \mathrm{H}), 7.13(\mathrm{~d}, J=8.6,1 \mathrm{H}), 7.10(\mathrm{dd}, J=8.8,2.2 \mathrm{~Hz}, 1 \mathrm{H}), 7.07$ (m, 1H), 7.05 (dd, $J=8.4,2.3 \mathrm{~Hz}, 1 \mathrm{H}), 6.84-6.77(\mathrm{~m}, 3 \mathrm{H}), 6.71$ (bs, 1H), $6.43(\mathrm{~s}, 1 \mathrm{H}), 4.87$ (m, 1H), 4.75 (dd, $J=8.9,6.7 \mathrm{~Hz}, 1 \mathrm{H}), 4.69$ (ddd, $J=11.1,7.7,2.6 \mathrm{~Hz}, 1 \mathrm{H}), 4.17(\mathrm{dd}, J=5.6,3.0 \mathrm{~Hz}, 2 \mathrm{H})$, 4.06 (t, $J=6.3 \mathrm{~Hz}, 2 \mathrm{H}), 3.26(\mathrm{~m}, 2 \mathrm{H}), 3.15-3.01$ (m, 3H), 2.96 (dd, $J=17.2,11.9 \mathrm{~Hz}, 1 \mathrm{H}), 2.89$ (s, 3H), $2.53(\mathrm{~s}, 6 \mathrm{H}), 1.94(\mathrm{~m}, 1 \mathrm{H}), 1.72(\mathrm{~m}, 1 \mathrm{H}), 1.37$ (s, 9H), $1.36(\mathrm{~s}, 9 \mathrm{H}), 1.34(\mathrm{~s}, 9 \mathrm{H}), 1.20$ (d, $J=6.7 \mathrm{~Hz}, 3 \mathrm{H}) .{ }^{13} \mathrm{C}$ NMR $\left(126 \mathrm{MHz}\right.$, DMSO- $\left.d_{6}\right) \delta 172.6,172.6,170.1,167.2,163.6,162.8$, $162.2,156.1,156.1,155.3,154.0,153.2,135.0,134.8,131.1,129.5,129.4,129.3,128.6,128.4$, 128.4, 128.1, 126.1, 125.9, 118.0, 116.8, 113.7, 78.3, 78.0, 67.6, 59.3, 51.9, 48.2, 48.0, 40.0, 37.3, 35.1, 34.2, 32.8, 31.5, 30.8, 28.7, 27.8, 22.6, 22.5, 19.8. HRMS $(\mathrm{m} / \mathrm{z})$ calcd for $\mathrm{C}_{56} \mathrm{H}_{73} \mathrm{~N}_{10} \mathrm{O}_{11}$ $[\mathrm{M}+\mathrm{H}]^{+}$1061.5455, found 1061.5446 . 


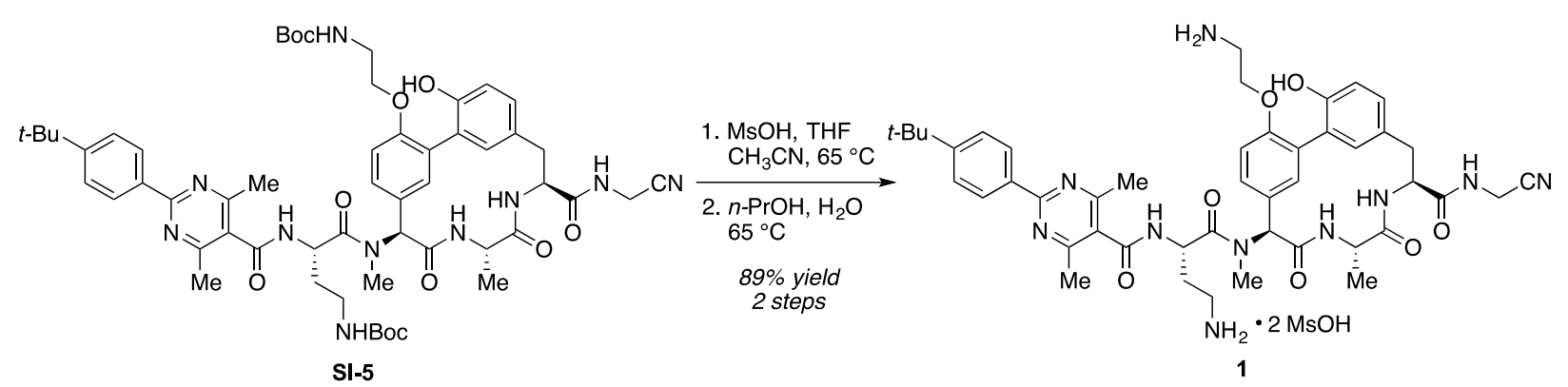

API (1): A suspension of amide SI-12 (59.8 g, $53.5 \mathrm{mmol}, 100 \mathrm{~mol} \%$ ) in THF (300 mL) was heated to $50-60{ }^{\circ} \mathrm{C}$ until a clear solution was formed. $\mathrm{CH}_{3} \mathrm{CN}(300 \mathrm{~mL})$ was added and the mixture was adjusted to an internal temperature of $65^{\circ} \mathrm{C}$. $\mathrm{MsOH}(8.42 \mathrm{~mL}, 128.0 \mathrm{mmol}, 240$ mol \%) was added and the reaction was stirred for $20 \mathrm{~h}$. The mixture was cooled to $\mathrm{rt}$ and solids filtered, then washed with $\mathrm{CH}_{3} \mathrm{CN}(300 \mathrm{~mL})$, and dried under reduced pressure at $40{ }^{\circ} \mathrm{C}$ for $16 \mathrm{~h}$. Crude API (1) (59.8 g) was obtained as a beige solid. Crude API (1) $(57.0 \mathrm{~g}, 54.1 \mathrm{mmol}, 100 \mathrm{~mol}$ \%) was dissolved in a mixture of $\mathrm{H}_{2} \mathrm{O} / n-\mathrm{PrOH}(20: 80,170 \mathrm{~mL})$ at $60{ }^{\circ} \mathrm{C} . n-\mathrm{PrOH}(980 \mathrm{~mL}, 16.0$ $\mathrm{mL} / \mathrm{g}$ ) was heated to $50^{\circ} \mathrm{C}$ and added to the mixture. The reaction was treated with seed crystals of API (1) (285 mg, $0.5 \mathrm{wt} \%$ ). The resulting mixture was heated to $65^{\circ} \mathrm{C}$ for $30 \mathrm{~min}$ then the resulting suspension was cooled to $0{ }^{\circ} \mathrm{C}$ over $14 \mathrm{~h}$. The solids were filtered through a medium frit funnel, affording API (1) as a crystalline white solid (50.8 g, $48.3 \mathrm{mmol}, 89 \%$ yield, 2 steps). HPLC: $99.1 \mathrm{~A} \%,>99: 1 \mathrm{dr} . \mathrm{mp}: 169^{\circ} \mathrm{C} .{ }^{1} \mathrm{H}$ NMR $\left(600 \mathrm{MHz}, \mathrm{DMSO}-d_{6}\right) \delta 9.16(\mathrm{~d}, J=7.4 \mathrm{~Hz}$, $1 \mathrm{H}), 8.97(\mathrm{~d}, J=7.9 \mathrm{~Hz}, 1 \mathrm{H}), 8.70(\mathrm{t}, J=5.7 \mathrm{~Hz}, 1 \mathrm{H}), 8.43(\mathrm{~d}, J=9.0 \mathrm{~Hz}, 1 \mathrm{H}), 8.33$ (d, $J=8.5$ $\mathrm{Hz}, 2 \mathrm{H}), 7.56(\mathrm{~d}, J=8.6 \mathrm{~Hz}, 2 \mathrm{H}), 7.17(\mathrm{~d}, J=8.6 \mathrm{~Hz}, 1 \mathrm{H}), 7.13$ (dd, $J=8.7,2.3 \mathrm{~Hz}, 1 \mathrm{H}), 7.07$ (dd, $J=8.5,2.4 \mathrm{~Hz}, 1 \mathrm{H}), 6.87$ (d, $J=8.3 \mathrm{~Hz}, 1 \mathrm{H}), 6.83$ (bs, 1H), 6.71 (bs, $1 \mathrm{H}), 6.43$ (s, 1H), 5.05 (ddd, $J=9.0,7.4,5.2 \mathrm{~Hz}, 1 \mathrm{H}$ ), $4.76(\mathrm{dd}, J=9.0,6.7 \mathrm{~Hz}, 1 \mathrm{H}$ ), 4.70 (ddd, $J=11.1,7.8,2.5 \mathrm{~Hz}$, $1 \mathrm{H}), 4.27$ (dt, $J=9.9,4.8 \mathrm{~Hz}, 1 \mathrm{H}), 4.21(\mathrm{td}, J=6.5,4.8 \mathrm{~Hz}, 1 \mathrm{H}), 4.18(\mathrm{dd}, J=5.6,2.8 \mathrm{~Hz}, 2 \mathrm{H})$, $3.19-3.13(\mathrm{~m}, 2 \mathrm{H}), 3.15-3.10(\mathrm{~m}, 1 \mathrm{H}), 3.01-2.94(\mathrm{~m}, 2 \mathrm{H}), 2.92(\mathrm{~s}, 3 \mathrm{H}), 2.51(\mathrm{~s}, 6 \mathrm{H}), 2.09(\mathrm{td}$, $J=14.4,5.7 \mathrm{~Hz}, 1 \mathrm{H}), 1.97(\mathrm{dtd}, J=14.4,9.2,5.6 \mathrm{~Hz}, 1 \mathrm{H}), 1.36$ (s, 9H), 1.21 (d, $J=6.7 \mathrm{~Hz}, 3 \mathrm{H})$. ${ }^{13} \mathrm{C}$ NMR (126 MHz, DMSO- $\left.d_{6}\right) \delta 172.1,171.9,171.0,169.5,166.7,162.9,161.9,154.4,153.6$, 152.3, 134.6, 134.1, 130.7, 129.1, 128.9, 128.9, 128.3, 128.1, 127.6, 127.6, 125.5, 125.4, 117.5, $116.4,113.3,65.6,59.1,51.3,47.7,47.5,39.3,36.0,34.5,33.6,32.6,30.9,27.3,22.0,19.3$. HRMS $(\mathrm{m} / \mathrm{z})$ calcd for $\mathrm{C}_{46} \mathrm{H}_{57} \mathrm{~N}_{10} \mathrm{O}_{7}[\mathrm{M}+\mathrm{H}]^{+}$861.4406, found 861.4404. 
6. X-ray Crystallographic Analysis of Macrocycle 2

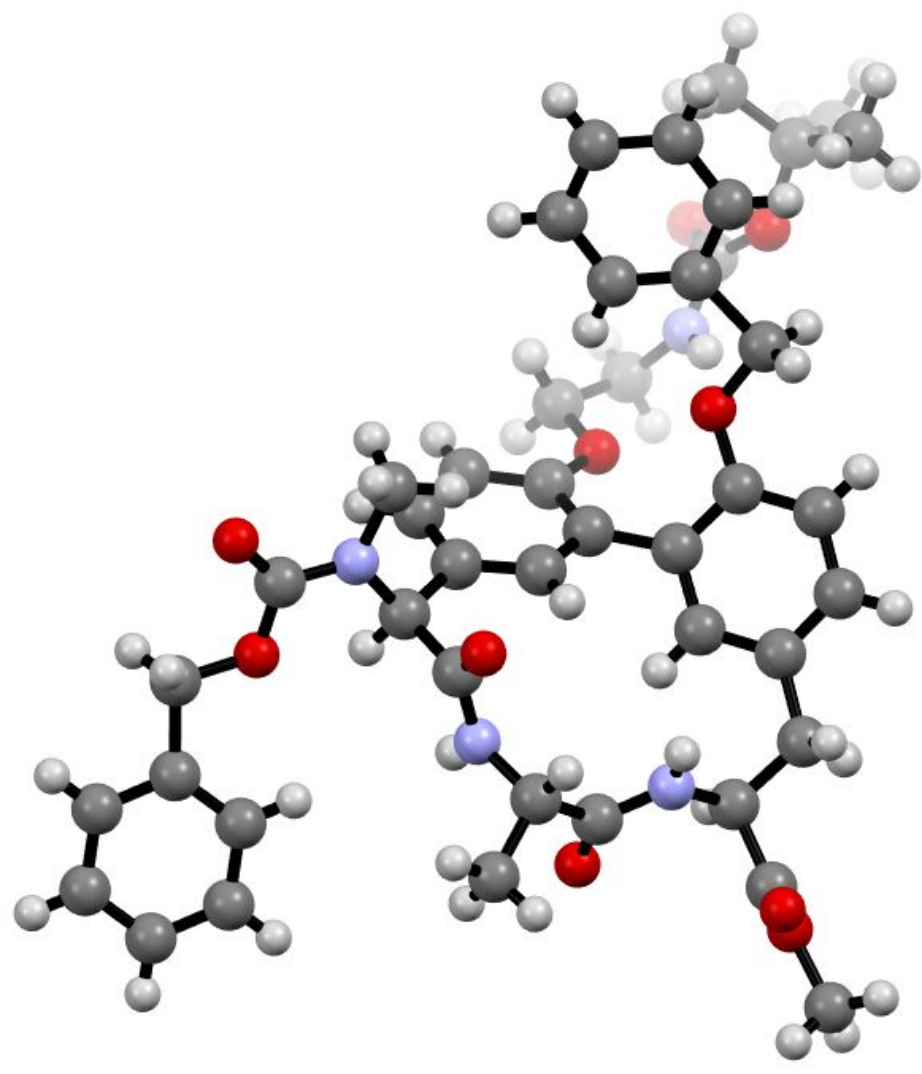

Figure S-3. X-ray Crystal Structure of Compound 2.<smiles>COC(=O)C(Cc1ccc(OCc2ccccc2)c(-c2cc([C@@H](C(=O)N[C@@H](C)C(=O)N[C@@H](C)C(=O)OCc3ccccc3)N(C)C)ccc2OCCNC(=O)OC(C)(C)C)c1)C(=O)OC</smiles>

Figure S-4. Chemical Structure of 2. 


\section{Supporting Information}

X-ray quality crystals were grown from a saturated 1,2-dichloroethane/ethanol/methanol solution followed by the slow vapor diffusion of diisopropyl ether to deposit the crystal diffracted. A colorless plate $0.060 \times 0.050$ × $0.030 \mathrm{~mm}$ in size was mounted on a Cryoloop with Paratone oil. Data were collected in a nitrogen gas stream at 100(2) K using and scans. Crystal-to-detector distance was $60 \mathrm{~mm}$ and exposure time was 5 seconds per frame using a scan width of $2.0^{\circ}$. Data collection was $100.0 \%$ complete to $67.000^{\circ}$ in $\theta$. A total of 168645 reflections were collected covering the indices, $-23<=h<=23,-36<=k<=33,-18<=l<=18.8169$ reflections were found to be symmetry independent, with an $\mathrm{R}_{\text {int }}$ of 0.0291 . Indexing and unit cell refinement indicated a $\mathrm{C}$ centered, orthorhombic lattice. The space group was found to be C 2221 (No. 20). The data were integrated using the Bruker SAINT software program and scaled using the SADABS software program. Solution by iterative methods (SHELXT-2014) produced a complete heavyatom phasing model consistent with the proposed structure. All non-hydrogen atoms were refined anisotropically by full-matrix least-squares (SHELXL-2016). All hydrogen atoms were placed using a riding model. Their positions were constrained relative to their parent atom using the appropriate HFIX command in SHELXL-2016. Absolute stereochemistry was unambiguously determined to be $S$ at all chiral centers. 


\section{Supporting Information}

Table 1. Crystal data and structure refinement for gene852.

X-ray ID

Sample/notebook ID

Empirical formula

Formula weight

Temperature

Wavelength

Crystal system

Space group

Unit cell dimensions

Volume

Z

Density (calculated)

Absorption coefficient

$\mathrm{F}(000)$

Crystal size

Theta range for data collection

Index ranges

Reflections collected

Independent reflections

Completeness to theta $=67.000^{\circ}$

Absorption correction

Max. and min. transmission

Refinement method

Data / restraints / parameters

Goodness-of-fit on $\mathrm{F}^{2}$

Final $\mathrm{R}$ indices [I $>2 \operatorname{sigma}(\mathrm{I})]$

$\mathrm{R}$ indices (all data)

Absolute structure parameter

Extinction coefficient

Largest diff. peak and hole gene 852

71451-130s

C44 H50 N4 O10

794.88

100(2) K

$1.54178 \AA$

Orthorhombic

C 2221

$\mathrm{a}=19.5580(5) \AA$

$\alpha=90^{\circ}$.

$\mathrm{b}=30.1004(9) \AA$

$\beta=90^{\circ}$.

$\mathrm{c}=15.0513(4) \AA$

$\gamma=90^{\circ}$.
8

$1.192 \mathrm{Mg} / \mathrm{m}^{3}$

$0.697 \mathrm{~mm}^{-1}$

3376

$0.060 \times 0.050 \times 0.030 \mathrm{~mm}^{3}$

2.694 to $68.486^{\circ}$.

$-23<=\mathrm{h}<=23,-36<=\mathrm{k}<=33,-18<=\mathrm{l}<=18$

168645

$8169[\mathrm{R}(\mathrm{int})=0.0291]$

$100.0 \%$

Semi-empirical from equivalents

0.929 and 0.858

Full-matrix least-squares on $\mathrm{F}^{2}$

8169 / 0 / 460

1.024

$\mathrm{R} 1=0.0537, \mathrm{wR} 2=0.1497$

$\mathrm{R} 1=0.0551, \mathrm{wR} 2=0.1519$

$0.006(16)$

n/a

0.339 and -0.368 e. $\AA^{-3}$ 


\section{Supporting Information}

Table 2. Atomic coordinates $\left(\times 10^{4}\right)$ and equivalent isotropic displacement parameters $\left(\AA^{2} \times 10^{3}\right)$ for gene852. $\mathrm{U}(\mathrm{eq})$ is defined as one third of the trace of the orthogonalized $\mathrm{U}^{\mathrm{ij}}$ tensor.

\begin{tabular}{|c|c|c|c|c|}
\hline & $\mathrm{x}$ & $\mathrm{y}$ & $\mathrm{z}$ & $\mathrm{U}(\mathrm{eq})$ \\
\hline$C(1)$ & $5096(2)$ & $7175(1)$ & $4968(2)$ & $34(1)$ \\
\hline$C(2)$ & $5490(2)$ & $7721(1)$ & $3910(2)$ & $32(1)$ \\
\hline$C(3)$ & $6094(2)$ & $7965(1)$ & $3490(2)$ & $33(1)$ \\
\hline$C(4)$ & $6794(2)$ & $7662(1)$ & $2285(2)$ & $28(1)$ \\
\hline$C(5)$ & $6759(2)$ & $7437(1)$ & $1372(2)$ & $28(1)$ \\
\hline$C(6)$ & 6553(2) & 6952(1) & $1467(2)$ & $29(1)$ \\
\hline$C(7)$ & $6429(2)$ & $6696(1)$ & $709(2)$ & $31(1)$ \\
\hline $\mathrm{C}(8)$ & $6179(2)$ & $6270(1)$ & 779(2) & $32(1)$ \\
\hline$C(9)$ & $6050(2)$ & 6086(1) & $1620(2)$ & $30(1)$ \\
\hline $\mathrm{C}(10)$ & 6201(2) & $6326(1)$ & $2388(2)$ & $29(1)$ \\
\hline$C(11)$ & $6455(2)$ & $6755(1)$ & $2292(2)$ & $28(1)$ \\
\hline $\mathrm{C}(12)$ & $6058(2)$ & $6169(1)$ & $3302(2)$ & $29(1)$ \\
\hline$C(13)$ & $6322(2)$ & $5777(1)$ & $3675(2)$ & $32(1)$ \\
\hline$C(14)$ & $6225(2)$ & $5692(1)$ & $4576(2)$ & $36(1)$ \\
\hline$C(15)$ & $5896(2)$ & $5998(1)$ & $5115(2)$ & $34(1)$ \\
\hline$C(16)$ & $5645(2)$ & $6393(1)$ & $4776(2)$ & $31(1)$ \\
\hline$C(17)$ & $5711(2)$ & $6463(1)$ & $3861(2)$ & $30(1)$ \\
\hline$C(18)$ & $5344(2)$ & $6742(1)$ & $5390(2)$ & $36(1)$ \\
\hline C(19) & $4821(2)$ & $7469(1)$ & $5719(3)$ & $41(1)$ \\
\hline$C(20)$ & $3870(2)$ & $7686(1)$ & $6555(3)$ & $51(1)$ \\
\hline $\mathrm{C}(21)$ & $5959(2)$ & $8467(1)$ & $3490(3)$ & $49(1)$ \\
\hline $\mathrm{C}(22)$ & $7977(2)$ & $7177(1)$ & 1089(3) & $42(1)$ \\
\hline$C(23)$ & $7527(2)$ & $7821(1)$ & $338(2)$ & $34(1)$ \\
\hline$C(24)$ & $7115(2)$ & $8484(2)$ & $-300(3)$ & $53(1)$ \\
\hline$C(25)$ & $6514(3)$ & $8816(2)$ & $-28(5)$ & $46(1)$ \\
\hline$C(26)$ & $6079(4)$ & $8784(2)$ & $699(5)$ & $60(2)$ \\
\hline$C(27)$ & $5563(4)$ & $9096(3)$ & $820(6)$ & $71(2)$ \\
\hline$C(28)$ & $5483(5)$ & $9441(3)$ & $213(8)$ & $103(3)$ \\
\hline$C(29)$ & $5918(5)$ & $9473(3)$ & $-514(7)$ & $117(4)$ \\
\hline$C(30)$ & $6433(4)$ & $9161(3)$ & $-635(6)$ & $81(2)$ \\
\hline$C(25 \mathrm{~A})$ & $6522(3)$ & $8752(2)$ & $-368(5)$ & $46(1)$ \\
\hline
\end{tabular}


Supporting Information

\begin{tabular}{|c|c|c|c|c|}
\hline$C(26 A)$ & 6081(3) & $8771(2)$ & $356(4)$ & $60(2)$ \\
\hline$C(27 \mathrm{~A})$ & $5516(3)$ & $9051(3)$ & $336(5)$ & $71(2)$ \\
\hline$C(28 \mathrm{~A})$ & $5392(4)$ & $9312(3)$ & $-408(7)$ & 103(3) \\
\hline$C(29 A)$ & $5832(5)$ & 9293(3) & $-1132(6)$ & $117(4)$ \\
\hline$C(30 A)$ & $6397(4)$ & $9013(3)$ & $-1112(5)$ & $81(2)$ \\
\hline $\mathrm{C}(31)$ & $5584(2)$ & $5430(1)$ & $966(2)$ & $33(1)$ \\
\hline$C(32)$ & $5281(2)$ & $5005(1)$ & $1320(2)$ & $34(1)$ \\
\hline$C(33)$ & $5933(2)$ & $4348(1)$ & $1766(2)$ & $31(1)$ \\
\hline$C(34)$ & $6739(2)$ & $3789(1)$ & $2290(2)$ & $38(1)$ \\
\hline$C(35)$ & $7175(2)$ & $3796(2)$ & 1453(3) & $51(1)$ \\
\hline$C(36)$ & $6232(3)$ & $3414(1)$ & 2297(3) & $53(1)$ \\
\hline$C(37)$ & $7191(2)$ & $3772(2)$ & $3108(3)$ & $48(1)$ \\
\hline $\mathrm{C}(38)$ & $7161(2)$ & $5198(2)$ & $3482(4)$ & $54(1)$ \\
\hline C(39) & $7690(4)$ & $5136(3)$ & $2637(6)$ & $51(1)$ \\
\hline $\mathrm{C}(40)$ & $7626(5)$ & $5339(4)$ & 1811(7) & $71(2)$ \\
\hline $\mathrm{C}(41)$ & $8099(6)$ & $5250(5)$ & $1145(6)$ & $100(3)$ \\
\hline $\mathrm{C}(42)$ & $8636(5)$ & 4959(4) & $1305(7)$ & $80(2)$ \\
\hline $\mathrm{C}(43)$ & 8701(4) & $4756(3)$ & 2131(9) & $65(2)$ \\
\hline $\mathrm{C}(44)$ & $8228(4)$ & $4845(3)$ & 2797(7) & $55(2)$ \\
\hline$C(39 A)$ & 7671(3) & $5052(2)$ & $2868(4)$ & $51(1)$ \\
\hline$C(40 A)$ & $7640(3)$ & $5208(3)$ & $2000(5)$ & $71(2)$ \\
\hline$C(41 \mathrm{~A})$ & $8137(4)$ & $5082(3)$ & 1389(4) & $100(3)$ \\
\hline$C(42 A)$ & $8664(3)$ & 4801(3) & $1646(5)$ & $80(2)$ \\
\hline$C(43 \mathrm{~A})$ & $8695(3)$ & $4645(2)$ & $2515(6)$ & $65(2)$ \\
\hline$C(44 A)$ & $8199(3)$ & $4771(2)$ & $3126(5)$ & $55(2)$ \\
\hline $\mathrm{N}(1)$ & $5636(1)$ & $7414(1)$ & $4519(2)$ & $31(1)$ \\
\hline $\mathrm{N}(2)$ & $6183(1)$ & 7799(1) & 2591(2) & $30(1)$ \\
\hline $\mathrm{N}(3)$ & $7409(1)$ & $7483(1)$ & $898(2)$ & $35(1)$ \\
\hline $\mathrm{N}(4)$ & $5774(2)$ & $4779(1)$ & $1877(2)$ & $36(1)$ \\
\hline $\mathrm{O}(1)$ & $5175(2)$ & $7705(1)$ & $6157(3)$ & $70(1)$ \\
\hline $\mathrm{O}(2)$ & $4157(1)$ & $7429(1)$ & $5819(2)$ & $42(1)$ \\
\hline $\mathrm{O}(3)$ & $4897(1)$ & 7813(1) & $3686(2)$ & $43(1)$ \\
\hline $\mathrm{O}(4)$ & $7327(1)$ & 7693(1) & 2703(2) & $36(1)$ \\
\hline $\mathrm{O}(5)$ & $8055(1)$ & $7875(1)$ & $-85(2)$ & $44(1)$ \\
\hline $\mathrm{O}(6)$ & 7001(1) & $8106(1)$ & $285(2)$ & $38(1)$ \\
\hline $\mathrm{O}(7)$ & $5755(1)$ & $5680(1)$ & $1739(2)$ & $34(1)$ \\
\hline
\end{tabular}


Supporting Information

\begin{tabular}{lllll}
$\mathrm{O}(8)$ & $5684(1)$ & $4113(1)$ & $1195(2)$ & $37(1)$ \\
$\mathrm{O}(9)$ & $6397(1)$ & $4223(1)$ & $2376(2)$ & $40(1)$ \\
$\mathrm{O}(10)$ & $6677(2)$ & $5501(1)$ & $3115(2)$ & $43(1)$ \\
\hline
\end{tabular}




\section{Supporting Information}

Table 3. Bond lengths $[\AA]$ and angles $\left[{ }^{\circ}\right]$ for gene 852 .

\begin{tabular}{|c|c|c|c|}
\hline $\mathrm{C}(1)-\mathrm{N}(1)$ & $1.446(5)$ & $\mathrm{C}(15)-\mathrm{H}(15)$ & 0.9500 \\
\hline $\mathrm{C}(1)-\mathrm{C}(18)$ & $1.531(5)$ & $\mathrm{C}(16)-\mathrm{C}(17)$ & $1.399(5)$ \\
\hline$C(1)-C(19)$ & $1.531(5)$ & $C(16)-C(18)$ & $1.519(5)$ \\
\hline $\mathrm{C}(1)-\mathrm{H}(1)$ & 1.0000 & $\mathrm{C}(17)-\mathrm{H}(17)$ & 0.9500 \\
\hline $\mathrm{C}(2)-\mathrm{O}(3)$ & $1.238(4)$ & $\mathrm{C}(18)-\mathrm{H}(18 \mathrm{~A})$ & 0.9900 \\
\hline $\mathrm{C}(2)-\mathrm{N}(1)$ & $1.331(5)$ & $\mathrm{C}(18)-\mathrm{H}(18 \mathrm{~B})$ & 0.9900 \\
\hline $\mathrm{C}(2)-\mathrm{C}(3)$ & $1.529(5)$ & $\mathrm{C}(19)-\mathrm{O}(1)$ & $1.191(5)$ \\
\hline $\mathrm{C}(3)-\mathrm{N}(2)$ & $1.454(4)$ & $\mathrm{C}(19)-\mathrm{O}(2)$ & $1.314(5)$ \\
\hline$C(3)-C(21)$ & $1.533(5)$ & $\mathrm{C}(20)-\mathrm{O}(2)$ & $1.463(5)$ \\
\hline $\mathrm{C}(3)-\mathrm{H}(3)$ & 1.0000 & $\mathrm{C}(20)-\mathrm{H}(20 \mathrm{~A})$ & 0.9800 \\
\hline $\mathrm{C}(4)-\mathrm{O}(4)$ & $1.222(4)$ & $\mathrm{C}(20)-\mathrm{H}(20 \mathrm{~B})$ & 0.9800 \\
\hline $\mathrm{C}(4)-\mathrm{N}(2)$ & $1.346(4)$ & $\mathrm{C}(20)-\mathrm{H}(20 \mathrm{C})$ & 0.9800 \\
\hline$C(4)-C(5)$ & $1.533(5)$ & $\mathrm{C}(21)-\mathrm{H}(21 \mathrm{~A})$ & 0.9800 \\
\hline $\mathrm{C}(5)-\mathrm{N}(3)$ & $1.464(4)$ & $\mathrm{C}(21)-\mathrm{H}(21 \mathrm{~B})$ & 0.9800 \\
\hline$C(5)-C(6)$ & $1.521(4)$ & $\mathrm{C}(21)-\mathrm{H}(21 \mathrm{C})$ & 0.9800 \\
\hline $\mathrm{C}(5)-\mathrm{H}(5)$ & 1.0000 & $\mathrm{C}(22)-\mathrm{N}(3)$ & $1.470(5)$ \\
\hline$C(6)-C(11)$ & $1.389(5)$ & $\mathrm{C}(22)-\mathrm{H}(22 \mathrm{~A})$ & 0.9800 \\
\hline$C(6)-C(7)$ & $1.398(5)$ & $\mathrm{C}(22)-\mathrm{H}(22 \mathrm{~B})$ & 0.9800 \\
\hline $\mathrm{C}(7)-\mathrm{C}(8)$ & $1.378(5)$ & $\mathrm{C}(22)-\mathrm{H}(22 \mathrm{C})$ & 0.9800 \\
\hline $\mathrm{C}(7)-\mathrm{H}(7)$ & 0.9500 & $\mathrm{C}(23)-\mathrm{O}(5)$ & $1.224(4)$ \\
\hline $\mathrm{C}(8)-\mathrm{C}(9)$ & $1.404(5)$ & $\mathrm{C}(23)-\mathrm{N}(3)$ & $1.343(5)$ \\
\hline $\mathrm{C}(8)-\mathrm{H}(8)$ & 0.9500 & $\mathrm{C}(23)-\mathrm{O}(6)$ & $1.342(4)$ \\
\hline $\mathrm{C}(9)-\mathrm{O}(7)$ & $1.362(4)$ & $\mathrm{C}(24)-\mathrm{C}(25 \mathrm{~A})$ & $1.416(7)$ \\
\hline$C(9)-C(10)$ & $1.395(5)$ & $\mathrm{C}(24)-\mathrm{O}(6)$ & $1.456(5)$ \\
\hline $\mathrm{C}(10)-\mathrm{C}(11)$ & $1.391(5)$ & $C(24)-C(25)$ & $1.596(8)$ \\
\hline $\mathrm{C}(10)-\mathrm{C}(12)$ & $1.482(5)$ & $\mathrm{C}(24)-\mathrm{H}(24 \mathrm{~A})$ & 0.9900 \\
\hline $\mathrm{C}(11)-\mathrm{H}(11)$ & 0.9500 & $\mathrm{C}(24)-\mathrm{H}(24 \mathrm{~B})$ & 0.9900 \\
\hline C(12)-C(17) & $1.395(5)$ & $C(25)-C(26)$ & 1.3900 \\
\hline C(12)-C(13) & $1.405(5)$ & $C(25)-C(30)$ & 1.3900 \\
\hline $\mathrm{C}(13)-\mathrm{O}(10)$ & $1.373(4)$ & $C(26)-C(27)$ & 1.3900 \\
\hline C(13)-C(14) & $1.393(5)$ & $\mathrm{C}(26)-\mathrm{H}(26)$ & 0.9500 \\
\hline C(14)-C(15) & $1.386(6)$ & $\mathrm{C}(27)-\mathrm{C}(28)$ & 1.3900 \\
\hline C(14)-H(14) & 0.9500 & $\mathrm{C}(27)-\mathrm{H}(27)$ & 0.9500 \\
\hline$C(15)-C(16)$ & $1.383(5)$ & $\mathrm{C}(28)-\mathrm{C}(29)$ & 1.3900 \\
\hline
\end{tabular}




\begin{tabular}{|c|c|c|c|}
\hline $\mathrm{C}(28)-\mathrm{H}(28)$ & 0.9500 & $\mathrm{C}(36)-\mathrm{H}(36 \mathrm{C})$ & 0.9800 \\
\hline$C(29)-C(30)$ & 1.3900 & $\mathrm{C}(37)-\mathrm{H}(37 \mathrm{~A})$ & 0.9800 \\
\hline $\mathrm{C}(29)-\mathrm{H}(29)$ & 0.9500 & $\mathrm{C}(37)-\mathrm{H}(37 \mathrm{~B})$ & 0.9800 \\
\hline $\mathrm{C}(30)-\mathrm{H}(30)$ & 0.9500 & $\mathrm{C}(37)-\mathrm{H}(37 \mathrm{C})$ & 0.9800 \\
\hline$C(25 A)-C(26 A)$ & 1.3900 & $\mathrm{C}(38)-\mathrm{O}(10)$ & $1.425(5)$ \\
\hline$C(25 A)-C(30 A)$ & 1.3900 & $C(38)-C(39 A)$ & $1.429(7)$ \\
\hline$C(26 A)-C(27 A)$ & 1.3900 & $C(38)-C(39)$ & $1.650(9)$ \\
\hline $\mathrm{C}(26 \mathrm{~A})-\mathrm{H}(26 \mathrm{~A})$ & 0.9500 & $\mathrm{C}(38)-\mathrm{H}(38 \mathrm{~A})$ & 0.9900 \\
\hline $\mathrm{C}(27 \mathrm{~A})-\mathrm{C}(28 \mathrm{~A})$ & 1.3900 & $\mathrm{C}(38)-\mathrm{H}(38 \mathrm{~B})$ & 0.9900 \\
\hline $\mathrm{C}(27 \mathrm{~A})-\mathrm{H}(27 \mathrm{~A})$ & 0.9500 & $C(39)-C(40)$ & 1.3900 \\
\hline $\mathrm{C}(28 \mathrm{~A})-\mathrm{C}(29 \mathrm{~A})$ & 1.3900 & $C(39)-C(44)$ & 1.3900 \\
\hline $\mathrm{C}(28 \mathrm{~A})-\mathrm{H}(28 \mathrm{~A})$ & 0.9500 & $\mathrm{C}(40)-\mathrm{C}(41)$ & 1.3900 \\
\hline$C(29 A)-C(30 A)$ & 1.3900 & $\mathrm{C}(40)-\mathrm{H}(40)$ & 0.9500 \\
\hline $\mathrm{C}(29 \mathrm{~A})-\mathrm{H}(29 \mathrm{~A})$ & 0.9500 & $\mathrm{C}(41)-\mathrm{C}(42)$ & 1.3900 \\
\hline $\mathrm{C}(30 \mathrm{~A})-\mathrm{H}(30 \mathrm{~A})$ & 0.9500 & $\mathrm{C}(41)-\mathrm{H}(41)$ & 0.9500 \\
\hline $\mathrm{C}(31)-\mathrm{O}(7)$ & $1.426(4)$ & $\mathrm{C}(42)-\mathrm{C}(43)$ & 1.3900 \\
\hline$C(31)-C(32)$ & $1.506(5)$ & $\mathrm{C}(42)-\mathrm{H}(42)$ & 0.9500 \\
\hline $\mathrm{C}(31)-\mathrm{H}(31 \mathrm{~A})$ & 0.9900 & $\mathrm{C}(43)-\mathrm{C}(44)$ & 1.3900 \\
\hline $\mathrm{C}(31)-\mathrm{H}(31 \mathrm{~B})$ & 0.9900 & $\mathrm{C}(43)-\mathrm{H}(43)$ & 0.9500 \\
\hline $\mathrm{C}(32)-\mathrm{N}(4)$ & $1.448(5)$ & $\mathrm{C}(44)-\mathrm{H}(44)$ & 0.9500 \\
\hline $\mathrm{C}(32)-\mathrm{H}(32 \mathrm{~A})$ & 0.9900 & $C(39 A)-C(40 A)$ & 1.3900 \\
\hline $\mathrm{C}(32)-\mathrm{H}(32 \mathrm{~B})$ & 0.9900 & $\mathrm{C}(39 \mathrm{~A})-\mathrm{C}(44 \mathrm{~A})$ & 1.3900 \\
\hline $\mathrm{C}(33)-\mathrm{O}(8)$ & $1.215(4)$ & $C(40 A)-C(41 A)$ & 1.3900 \\
\hline $\mathrm{C}(33)-\mathrm{O}(9)$ & $1.345(4)$ & $\mathrm{C}(40 \mathrm{~A})-\mathrm{H}(40 \mathrm{~A})$ & 0.9500 \\
\hline $\mathrm{C}(33)-\mathrm{N}(4)$ & $1.345(4)$ & $C(41 A)-C(42 A)$ & 1.3900 \\
\hline $\mathrm{C}(34)-\mathrm{O}(9)$ & $1.476(4)$ & $\mathrm{C}(41 \mathrm{~A})-\mathrm{H}(41 \mathrm{~A})$ & 0.9500 \\
\hline $\mathrm{C}(34)-\mathrm{C}(36)$ & $1.502(6)$ & $\mathrm{C}(42 \mathrm{~A})-\mathrm{C}(43 \mathrm{~A})$ & 1.3900 \\
\hline $\mathrm{C}(34)-\mathrm{C}(37)$ & $1.516(5)$ & $\mathrm{C}(42 \mathrm{~A})-\mathrm{H}(42 \mathrm{~A})$ & 0.9500 \\
\hline $\mathrm{C}(34)-\mathrm{C}(35)$ & $1.521(6)$ & $C(43 A)-C(44 A)$ & 1.3900 \\
\hline $\mathrm{C}(35)-\mathrm{H}(35 \mathrm{~A})$ & 0.9800 & $\mathrm{C}(43 \mathrm{~A})-\mathrm{H}(43 \mathrm{~A})$ & 0.9500 \\
\hline $\mathrm{C}(35)-\mathrm{H}(35 \mathrm{~B})$ & 0.9800 & $\mathrm{C}(44 \mathrm{~A})-\mathrm{H}(44 \mathrm{~A})$ & 0.9500 \\
\hline $\mathrm{C}(35)-\mathrm{H}(35 \mathrm{C})$ & 0.9800 & $\mathrm{~N}(1)-\mathrm{H}(1 \mathrm{~A})$ & 0.8800 \\
\hline $\mathrm{C}(36)-\mathrm{H}(36 \mathrm{~A})$ & 0.9800 & $\mathrm{~N}(2)-\mathrm{H}(2)$ & 0.8800 \\
\hline $\mathrm{C}(36)-\mathrm{H}(36 \mathrm{~B})$ & 0.9800 & $\mathrm{~N}(4)-\mathrm{H}(4)$ & 0.8800 \\
\hline $\mathrm{N}(1)-\mathrm{C}(1)-\mathrm{C}(18)$ & $112.8(3)$ & $\mathrm{N}(1)-\mathrm{C}(1)-\mathrm{C}(19)$ & 108.3(3) \\
\hline
\end{tabular}




\begin{tabular}{|c|c|c|c|}
\hline $\mathrm{C}(18)-\mathrm{C}(1)-\mathrm{C}(19)$ & $107.2(3)$ & $\mathrm{C}(9)-\mathrm{C}(10)-\mathrm{C}(12)$ & $124.4(3)$ \\
\hline $\mathrm{N}(1)-\mathrm{C}(1)-\mathrm{H}(1)$ & 109.5 & $C(10)-C(11)-C(6)$ & $122.6(3)$ \\
\hline $\mathrm{C}(18)-\mathrm{C}(1)-\mathrm{H}(1)$ & 109.5 & $\mathrm{C}(10)-\mathrm{C}(11)-\mathrm{H}(11)$ & 118.7 \\
\hline $\mathrm{C}(19)-\mathrm{C}(1)-\mathrm{H}(1)$ & 109.5 & $\mathrm{C}(6)-\mathrm{C}(11)-\mathrm{H}(11)$ & 118.7 \\
\hline $\mathrm{O}(3)-\mathrm{C}(2)-\mathrm{N}(1)$ & $122.9(3)$ & $C(17)-C(12)-C(13)$ & $118.0(3)$ \\
\hline $\mathrm{O}(3)-\mathrm{C}(2)-\mathrm{C}(3)$ & $120.2(3)$ & $\mathrm{C}(17)-\mathrm{C}(12)-\mathrm{C}(10)$ & $116.8(3)$ \\
\hline $\mathrm{N}(1)-\mathrm{C}(2)-\mathrm{C}(3)$ & $116.9(3)$ & $C(13)-C(12)-C(10)$ & $124.6(3)$ \\
\hline $\mathrm{N}(2)-\mathrm{C}(3)-\mathrm{C}(2)$ & $108.2(3)$ & $\mathrm{O}(10)-\mathrm{C}(13)-\mathrm{C}(14)$ & $123.7(3)$ \\
\hline $\mathrm{N}(2)-\mathrm{C}(3)-\mathrm{C}(21)$ & $111.1(3)$ & $\mathrm{O}(10)-\mathrm{C}(13)-\mathrm{C}(12)$ & $116.7(3)$ \\
\hline$C(2)-C(3)-C(21)$ & $110.0(3)$ & $\mathrm{C}(14)-\mathrm{C}(13)-\mathrm{C}(12)$ & $119.5(3)$ \\
\hline $\mathrm{N}(2)-\mathrm{C}(3)-\mathrm{H}(3)$ & 109.2 & $C(15)-C(14)-C(13)$ & $120.7(3)$ \\
\hline $\mathrm{C}(2)-\mathrm{C}(3)-\mathrm{H}(3)$ & 109.2 & $\mathrm{C}(15)-\mathrm{C}(14)-\mathrm{H}(14)$ & 119.6 \\
\hline $\mathrm{C}(21)-\mathrm{C}(3)-\mathrm{H}(3)$ & 109.2 & $\mathrm{C}(13)-\mathrm{C}(14)-\mathrm{H}(14)$ & 119.6 \\
\hline $\mathrm{O}(4)-\mathrm{C}(4)-\mathrm{N}(2)$ & $123.9(3)$ & $C(16)-C(15)-C(14)$ & $121.3(3)$ \\
\hline $\mathrm{O}(4)-\mathrm{C}(4)-\mathrm{C}(5)$ & $122.3(3)$ & $\mathrm{C}(16)-\mathrm{C}(15)-\mathrm{H}(15)$ & 119.4 \\
\hline $\mathrm{N}(2)-\mathrm{C}(4)-\mathrm{C}(5)$ & $113.8(3)$ & $\mathrm{C}(14)-\mathrm{C}(15)-\mathrm{H}(15)$ & 119.4 \\
\hline $\mathrm{N}(3)-\mathrm{C}(5)-\mathrm{C}(6)$ & $111.5(3)$ & $C(15)-C(16)-C(17)$ & $117.4(3)$ \\
\hline $\mathrm{N}(3)-\mathrm{C}(5)-\mathrm{C}(4)$ & $110.9(3)$ & $C(15)-C(16)-C(18)$ & $120.4(3)$ \\
\hline$C(6)-C(5)-C(4)$ & $110.6(3)$ & $C(17)-C(16)-C(18)$ & $122.1(3)$ \\
\hline $\mathrm{N}(3)-\mathrm{C}(5)-\mathrm{H}(5)$ & 107.9 & $\mathrm{C}(12)-\mathrm{C}(17)-\mathrm{C}(16)$ & $122.8(3)$ \\
\hline $\mathrm{C}(6)-\mathrm{C}(5)-\mathrm{H}(5)$ & 107.9 & $\mathrm{C}(12)-\mathrm{C}(17)-\mathrm{H}(17)$ & 118.6 \\
\hline $\mathrm{C}(4)-\mathrm{C}(5)-\mathrm{H}(5)$ & 107.9 & $\mathrm{C}(16)-\mathrm{C}(17)-\mathrm{H}(17)$ & 118.6 \\
\hline$C(11)-C(6)-C(7)$ & $118.1(3)$ & $C(16)-C(18)-C(1)$ & $117.3(3)$ \\
\hline$C(11)-C(6)-C(5)$ & $122.0(3)$ & $\mathrm{C}(16)-\mathrm{C}(18)-\mathrm{H}(18 \mathrm{~A})$ & 108.0 \\
\hline$C(7)-C(6)-C(5)$ & $119.8(3)$ & $\mathrm{C}(1)-\mathrm{C}(18)-\mathrm{H}(18 \mathrm{~A})$ & 108.0 \\
\hline$C(8)-C(7)-C(6)$ & $120.8(3)$ & $\mathrm{C}(16)-\mathrm{C}(18)-\mathrm{H}(18 \mathrm{~B})$ & 108.0 \\
\hline $\mathrm{C}(8)-\mathrm{C}(7)-\mathrm{H}(7)$ & 119.6 & $\mathrm{C}(1)-\mathrm{C}(18)-\mathrm{H}(18 \mathrm{~B})$ & 108.0 \\
\hline $\mathrm{C}(6)-\mathrm{C}(7)-\mathrm{H}(7)$ & 119.6 & $\mathrm{H}(18 \mathrm{~A})-\mathrm{C}(18)-\mathrm{H}(18 \mathrm{~B})$ & 107.2 \\
\hline $\mathrm{C}(7)-\mathrm{C}(8)-\mathrm{C}(9)$ & $120.0(3)$ & $\mathrm{O}(1)-\mathrm{C}(19)-\mathrm{O}(2)$ & $124.5(4)$ \\
\hline $\mathrm{C}(7)-\mathrm{C}(8)-\mathrm{H}(8)$ & 120.0 & $\mathrm{O}(1)-\mathrm{C}(19)-\mathrm{C}(1)$ & $123.3(3)$ \\
\hline $\mathrm{C}(9)-\mathrm{C}(8)-\mathrm{H}(8)$ & 120.0 & $\mathrm{O}(2)-\mathrm{C}(19)-\mathrm{C}(1)$ & $112.2(3)$ \\
\hline $\mathrm{O}(7)-\mathrm{C}(9)-\mathrm{C}(10)$ & $116.4(3)$ & $\mathrm{O}(2)-\mathrm{C}(20)-\mathrm{H}(20 \mathrm{~A})$ & 109.5 \\
\hline $\mathrm{O}(7)-\mathrm{C}(9)-\mathrm{C}(8)$ & $123.3(3)$ & $\mathrm{O}(2)-\mathrm{C}(20)-\mathrm{H}(20 \mathrm{~B})$ & 109.5 \\
\hline$C(10)-C(9)-C(8)$ & $120.3(3)$ & $\mathrm{H}(20 \mathrm{~A})-\mathrm{C}(20)-\mathrm{H}(20 \mathrm{~B})$ & 109.5 \\
\hline $\mathrm{C}(11)-\mathrm{C}(10)-\mathrm{C}(9)$ & $118.1(3)$ & $\mathrm{O}(2)-\mathrm{C}(20)-\mathrm{H}(20 \mathrm{C})$ & 109.5 \\
\hline$C(11)-C(10)-C(12)$ & 117.3(3) & $\mathrm{H}(20 \mathrm{~A})-\mathrm{C}(20)-\mathrm{H}(20 \mathrm{C})$ & 109.5 \\
\hline
\end{tabular}




\begin{tabular}{|c|c|c|c|}
\hline $\mathrm{H}(20 \mathrm{~B})-\mathrm{C}(20)-\mathrm{H}(20 \mathrm{C})$ & 109.5 & $\mathrm{C}(30)-\mathrm{C}(29)-\mathrm{H}(29)$ & 120.0 \\
\hline $\mathrm{C}(3)-\mathrm{C}(21)-\mathrm{H}(21 \mathrm{~A})$ & 109.5 & $\mathrm{C}(28)-\mathrm{C}(29)-\mathrm{H}(29)$ & 120.0 \\
\hline $\mathrm{C}(3)-\mathrm{C}(21)-\mathrm{H}(21 \mathrm{~B})$ & 109.5 & $C(29)-C(30)-C(25)$ & 120.0 \\
\hline $\mathrm{H}(21 \mathrm{~A})-\mathrm{C}(21)-\mathrm{H}(21 \mathrm{~B})$ & 109.5 & $\mathrm{C}(29)-\mathrm{C}(30)-\mathrm{H}(30)$ & 120.0 \\
\hline $\mathrm{C}(3)-\mathrm{C}(21)-\mathrm{H}(21 \mathrm{C})$ & 109.5 & $\mathrm{C}(25)-\mathrm{C}(30)-\mathrm{H}(30)$ & 120.0 \\
\hline $\mathrm{H}(21 \mathrm{~A})-\mathrm{C}(21)-\mathrm{H}(21 \mathrm{C})$ & 109.5 & $C(26 A)-C(25 A)-C(30 A)$ & 120.0 \\
\hline $\mathrm{H}(21 \mathrm{~B})-\mathrm{C}(21)-\mathrm{H}(21 \mathrm{C})$ & 109.5 & $C(26 \mathrm{~A})-\mathrm{C}(25 \mathrm{~A})-\mathrm{C}(24)$ & $118.3(5)$ \\
\hline $\mathrm{N}(3)-\mathrm{C}(22)-\mathrm{H}(22 \mathrm{~A})$ & 109.5 & $C(30 A)-C(25 A)-C(24)$ & $121.6(5)$ \\
\hline $\mathrm{N}(3)-\mathrm{C}(22)-\mathrm{H}(22 \mathrm{~B})$ & 109.5 & $C(27 A)-C(26 A)-C(25 A)$ & 120.0 \\
\hline $\mathrm{H}(22 \mathrm{~A})-\mathrm{C}(22)-\mathrm{H}(22 \mathrm{~B})$ & 109.5 & $C(27 A)-C(26 A)-H(26 A)$ & 120.0 \\
\hline $\mathrm{N}(3)-\mathrm{C}(22)-\mathrm{H}(22 \mathrm{C})$ & 109.5 & $C(25 A)-C(26 A)-H(26 A)$ & 120.0 \\
\hline $\mathrm{H}(22 \mathrm{~A})-\mathrm{C}(22)-\mathrm{H}(22 \mathrm{C})$ & 109.5 & $C(28 \mathrm{~A})-\mathrm{C}(27 \mathrm{~A})-\mathrm{C}(26 \mathrm{~A})$ & 120.0 \\
\hline $\mathrm{H}(22 \mathrm{~B})-\mathrm{C}(22)-\mathrm{H}(22 \mathrm{C})$ & 109.5 & $\mathrm{C}(28 \mathrm{~A})-\mathrm{C}(27 \mathrm{~A})-\mathrm{H}(27 \mathrm{~A})$ & 120.0 \\
\hline $\mathrm{O}(5)-\mathrm{C}(23)-\mathrm{N}(3)$ & $124.9(3)$ & $\mathrm{C}(26 \mathrm{~A})-\mathrm{C}(27 \mathrm{~A})-\mathrm{H}(27 \mathrm{~A})$ & 120.0 \\
\hline $\mathrm{O}(5)-\mathrm{C}(23)-\mathrm{O}(6)$ & $122.1(3)$ & $\mathrm{C}(29 \mathrm{~A})-\mathrm{C}(28 \mathrm{~A})-\mathrm{C}(27 \mathrm{~A})$ & 120.0 \\
\hline $\mathrm{N}(3)-\mathrm{C}(23)-\mathrm{O}(6)$ & $113.0(3)$ & $\mathrm{C}(29 \mathrm{~A})-\mathrm{C}(28 \mathrm{~A})-\mathrm{H}(28 \mathrm{~A})$ & 120.0 \\
\hline$C(25 A)-C(24)-O(6)$ & $111.3(4)$ & $\mathrm{C}(27 \mathrm{~A})-\mathrm{C}(28 \mathrm{~A})-\mathrm{H}(28 \mathrm{~A})$ & 120.0 \\
\hline $\mathrm{O}(6)-\mathrm{C}(24)-\mathrm{C}(25)$ & $102.9(4)$ & $C(28 \mathrm{~A})-\mathrm{C}(29 \mathrm{~A})-\mathrm{C}(30 \mathrm{~A})$ & 120.0 \\
\hline $\mathrm{O}(6)-\mathrm{C}(24)-\mathrm{H}(24 \mathrm{~A})$ & 111.2 & $\mathrm{C}(28 \mathrm{~A})-\mathrm{C}(29 \mathrm{~A})-\mathrm{H}(29 \mathrm{~A})$ & 120.0 \\
\hline $\mathrm{C}(25)-\mathrm{C}(24)-\mathrm{H}(24 \mathrm{~A})$ & 111.2 & $C(30 A)-C(29 A)-H(29 A)$ & 120.0 \\
\hline $\mathrm{O}(6)-\mathrm{C}(24)-\mathrm{H}(24 \mathrm{~B})$ & 111.2 & $C(29 A)-C(30 A)-C(25 A)$ & 120.0 \\
\hline $\mathrm{C}(25)-\mathrm{C}(24)-\mathrm{H}(24 \mathrm{~B})$ & 111.2 & $C(29 A)-C(30 A)-H(30 A)$ & 120.0 \\
\hline $\mathrm{H}(24 \mathrm{~A})-\mathrm{C}(24)-\mathrm{H}(24 \mathrm{~B})$ & 109.1 & $\mathrm{C}(25 \mathrm{~A})-\mathrm{C}(30 \mathrm{~A})-\mathrm{H}(30 \mathrm{~A})$ & 120.0 \\
\hline$C(26)-C(25)-C(30)$ & 120.0 & $\mathrm{O}(7)-\mathrm{C}(31)-\mathrm{C}(32)$ & $104.6(3)$ \\
\hline$C(26)-C(25)-C(24)$ & $127.5(5)$ & $\mathrm{O}(7)-\mathrm{C}(31)-\mathrm{H}(31 \mathrm{~A})$ & 110.8 \\
\hline$C(30)-C(25)-C(24)$ & $112.5(5)$ & $\mathrm{C}(32)-\mathrm{C}(31)-\mathrm{H}(31 \mathrm{~A})$ & 110.8 \\
\hline$C(27)-C(26)-C(25)$ & 120.0 & $\mathrm{O}(7)-\mathrm{C}(31)-\mathrm{H}(31 \mathrm{~B})$ & 110.8 \\
\hline $\mathrm{C}(27)-\mathrm{C}(26)-\mathrm{H}(26)$ & 120.0 & $\mathrm{C}(32)-\mathrm{C}(31)-\mathrm{H}(31 \mathrm{~B})$ & 110.8 \\
\hline $\mathrm{C}(25)-\mathrm{C}(26)-\mathrm{H}(26)$ & 120.0 & $\mathrm{H}(31 \mathrm{~A})-\mathrm{C}(31)-\mathrm{H}(31 \mathrm{~B})$ & 108.9 \\
\hline$C(28)-C(27)-C(26)$ & 120.0 & $\mathrm{~N}(4)-\mathrm{C}(32)-\mathrm{C}(31)$ & $110.0(3)$ \\
\hline $\mathrm{C}(28)-\mathrm{C}(27)-\mathrm{H}(27)$ & 120.0 & $\mathrm{~N}(4)-\mathrm{C}(32)-\mathrm{H}(32 \mathrm{~A})$ & 109.7 \\
\hline $\mathrm{C}(26)-\mathrm{C}(27)-\mathrm{H}(27)$ & 120.0 & $\mathrm{C}(31)-\mathrm{C}(32)-\mathrm{H}(32 \mathrm{~A})$ & 109.7 \\
\hline $\mathrm{C}(27)-\mathrm{C}(28)-\mathrm{C}(29)$ & 120.0 & N(4)-C(32)-H(32B) & 109.7 \\
\hline $\mathrm{C}(27)-\mathrm{C}(28)-\mathrm{H}(28)$ & 120.0 & $\mathrm{C}(31)-\mathrm{C}(32)-\mathrm{H}(32 \mathrm{~B})$ & 109.7 \\
\hline $\mathrm{C}(29)-\mathrm{C}(28)-\mathrm{H}(28)$ & 120.0 & $\mathrm{H}(32 \mathrm{~A})-\mathrm{C}(32)-\mathrm{H}(32 \mathrm{~B})$ & 108.2 \\
\hline$C(30)-C(29)-C(28)$ & 120.0 & $\mathrm{O}(8)-\mathrm{C}(33)-\mathrm{O}(9)$ & $126.2(3)$ \\
\hline
\end{tabular}




\begin{tabular}{|c|c|c|c|}
\hline $\mathrm{O}(8)-\mathrm{C}(33)-\mathrm{N}(4)$ & $123.9(3)$ & $\mathrm{C}(41)-\mathrm{C}(40)-\mathrm{C}(39)$ & 120.0 \\
\hline $\mathrm{O}(9)-\mathrm{C}(33)-\mathrm{N}(4)$ & $109.8(3)$ & $\mathrm{C}(41)-\mathrm{C}(40)-\mathrm{H}(40)$ & 120.0 \\
\hline $\mathrm{O}(9)-\mathrm{C}(34)-\mathrm{C}(36)$ & $111.4(3)$ & $\mathrm{C}(39)-\mathrm{C}(40)-\mathrm{H}(40)$ & 120.0 \\
\hline $\mathrm{O}(9)-\mathrm{C}(34)-\mathrm{C}(37)$ & $102.9(3)$ & $C(42)-C(41)-C(40)$ & 120.0 \\
\hline$C(36)-C(34)-C(37)$ & $110.7(4)$ & $\mathrm{C}(42)-\mathrm{C}(41)-\mathrm{H}(41)$ & 120.0 \\
\hline $\mathrm{O}(9)-\mathrm{C}(34)-\mathrm{C}(35)$ & $108.3(3)$ & $\mathrm{C}(40)-\mathrm{C}(41)-\mathrm{H}(41)$ & 120.0 \\
\hline$C(36)-C(34)-C(35)$ & $112.8(4)$ & $\mathrm{C}(41)-\mathrm{C}(42)-\mathrm{C}(43)$ & 120.0 \\
\hline $\mathrm{C}(37)-\mathrm{C}(34)-\mathrm{C}(35)$ & $110.3(3)$ & $\mathrm{C}(41)-\mathrm{C}(42)-\mathrm{H}(42)$ & 120.0 \\
\hline $\mathrm{C}(34)-\mathrm{C}(35)-\mathrm{H}(35 \mathrm{~A})$ & 109.5 & $\mathrm{C}(43)-\mathrm{C}(42)-\mathrm{H}(42)$ & 120.0 \\
\hline $\mathrm{C}(34)-\mathrm{C}(35)-\mathrm{H}(35 \mathrm{~B})$ & 109.5 & $\mathrm{C}(44)-\mathrm{C}(43)-\mathrm{C}(42)$ & 120.0 \\
\hline $\mathrm{H}(35 \mathrm{~A})-\mathrm{C}(35)-\mathrm{H}(35 \mathrm{~B})$ & 109.5 & $\mathrm{C}(44)-\mathrm{C}(43)-\mathrm{H}(43)$ & 120.0 \\
\hline $\mathrm{C}(34)-\mathrm{C}(35)-\mathrm{H}(35 \mathrm{C})$ & 109.5 & $\mathrm{C}(42)-\mathrm{C}(43)-\mathrm{H}(43)$ & 120.0 \\
\hline $\mathrm{H}(35 \mathrm{~A})-\mathrm{C}(35)-\mathrm{H}(35 \mathrm{C})$ & 109.5 & $\mathrm{C}(43)-\mathrm{C}(44)-\mathrm{C}(39)$ & 120.0 \\
\hline $\mathrm{H}(35 \mathrm{~B})-\mathrm{C}(35)-\mathrm{H}(35 \mathrm{C})$ & 109.5 & $\mathrm{C}(43)-\mathrm{C}(44)-\mathrm{H}(44)$ & 120.0 \\
\hline $\mathrm{C}(34)-\mathrm{C}(36)-\mathrm{H}(36 \mathrm{~A})$ & 109.5 & $\mathrm{C}(39)-\mathrm{C}(44)-\mathrm{H}(44)$ & 120.0 \\
\hline $\mathrm{C}(34)-\mathrm{C}(36)-\mathrm{H}(36 \mathrm{~B})$ & 109.5 & $C(40 A)-C(39 A)-C(44 A)$ & 120.0 \\
\hline $\mathrm{H}(36 \mathrm{~A})-\mathrm{C}(36)-\mathrm{H}(36 \mathrm{~B})$ & 109.5 & $\mathrm{C}(40 \mathrm{~A})-\mathrm{C}(39 \mathrm{~A})-\mathrm{C}(38)$ & $118.3(4)$ \\
\hline $\mathrm{C}(34)-\mathrm{C}(36)-\mathrm{H}(36 \mathrm{C})$ & 109.5 & $\mathrm{C}(44 \mathrm{~A})-\mathrm{C}(39 \mathrm{~A})-\mathrm{C}(38)$ & $121.7(4)$ \\
\hline $\mathrm{H}(36 \mathrm{~A})-\mathrm{C}(36)-\mathrm{H}(36 \mathrm{C})$ & 109.5 & $C(39 A)-C(40 A)-C(41 A)$ & 120.0 \\
\hline $\mathrm{H}(36 \mathrm{~B})-\mathrm{C}(36)-\mathrm{H}(36 \mathrm{C})$ & 109.5 & $\mathrm{C}(39 \mathrm{~A})-\mathrm{C}(40 \mathrm{~A})-\mathrm{H}(40 \mathrm{~A})$ & 120.0 \\
\hline $\mathrm{C}(34)-\mathrm{C}(37)-\mathrm{H}(37 \mathrm{~A})$ & 109.5 & $\mathrm{C}(41 \mathrm{~A})-\mathrm{C}(40 \mathrm{~A})-\mathrm{H}(40 \mathrm{~A})$ & 120.0 \\
\hline $\mathrm{C}(34)-\mathrm{C}(37)-\mathrm{H}(37 \mathrm{~B})$ & 109.5 & $\mathrm{C}(40 \mathrm{~A})-\mathrm{C}(41 \mathrm{~A})-\mathrm{C}(42 \mathrm{~A})$ & 120.0 \\
\hline $\mathrm{H}(37 \mathrm{~A})-\mathrm{C}(37)-\mathrm{H}(37 \mathrm{~B})$ & 109.5 & $\mathrm{C}(40 \mathrm{~A})-\mathrm{C}(41 \mathrm{~A})-\mathrm{H}(41 \mathrm{~A})$ & 120.0 \\
\hline $\mathrm{C}(34)-\mathrm{C}(37)-\mathrm{H}(37 \mathrm{C})$ & 109.5 & $\mathrm{C}(42 \mathrm{~A})-\mathrm{C}(41 \mathrm{~A})-\mathrm{H}(41 \mathrm{~A})$ & 120.0 \\
\hline $\mathrm{H}(37 \mathrm{~A})-\mathrm{C}(37)-\mathrm{H}(37 \mathrm{C})$ & 109.5 & $C(41 \mathrm{~A})-\mathrm{C}(42 \mathrm{~A})-\mathrm{C}(43 \mathrm{~A})$ & 120.0 \\
\hline H(37B)-C(37)-H(37C) & 109.5 & $\mathrm{C}(41 \mathrm{~A})-\mathrm{C}(42 \mathrm{~A})-\mathrm{H}(42 \mathrm{~A})$ & 120.0 \\
\hline $\mathrm{O}(10)-\mathrm{C}(38)-\mathrm{C}(39 \mathrm{~A})$ & $114.2(5)$ & $\mathrm{C}(43 \mathrm{~A})-\mathrm{C}(42 \mathrm{~A})-\mathrm{H}(42 \mathrm{~A})$ & 120.0 \\
\hline $\mathrm{O}(10)-\mathrm{C}(38)-\mathrm{C}(39)$ & $101.0(5)$ & $C(44 A)-C(43 A)-C(42 A)$ & 120.0 \\
\hline $\mathrm{O}(10)-\mathrm{C}(38)-\mathrm{H}(38 \mathrm{~A})$ & 111.6 & $\mathrm{C}(44 \mathrm{~A})-\mathrm{C}(43 \mathrm{~A})-\mathrm{H}(43 \mathrm{~A})$ & 120.0 \\
\hline C(39)-C(38)-H(38A) & 111.6 & $\mathrm{C}(42 \mathrm{~A})-\mathrm{C}(43 \mathrm{~A})-\mathrm{H}(43 \mathrm{~A})$ & 120.0 \\
\hline $\mathrm{O}(10)-\mathrm{C}(38)-\mathrm{H}(38 \mathrm{~B})$ & 111.6 & $\mathrm{C}(43 \mathrm{~A})-\mathrm{C}(44 \mathrm{~A})-\mathrm{C}(39 \mathrm{~A})$ & 120.0 \\
\hline $\mathrm{C}(39)-\mathrm{C}(38)-\mathrm{H}(38 \mathrm{~B})$ & 111.6 & $\mathrm{C}(43 \mathrm{~A})-\mathrm{C}(44 \mathrm{~A})-\mathrm{H}(44 \mathrm{~A})$ & 120.0 \\
\hline $\mathrm{H}(38 \mathrm{~A})-\mathrm{C}(38)-\mathrm{H}(38 \mathrm{~B})$ & 109.4 & $\mathrm{C}(39 \mathrm{~A})-\mathrm{C}(44 \mathrm{~A})-\mathrm{H}(44 \mathrm{~A})$ & 120.0 \\
\hline$C(40)-C(39)-C(44)$ & 120.0 & $\mathrm{C}(2)-\mathrm{N}(1)-\mathrm{C}(1)$ & $120.7(3)$ \\
\hline $\mathrm{C}(40)-\mathrm{C}(39)-\mathrm{C}(38)$ & $125.6(5)$ & $\mathrm{C}(2)-\mathrm{N}(1)-\mathrm{H}(1 \mathrm{~A})$ & 119.7 \\
\hline $\mathrm{C}(44)-\mathrm{C}(39)-\mathrm{C}(38)$ & $114.4(5)$ & $\mathrm{C}(1)-\mathrm{N}(1)-\mathrm{H}(1 \mathrm{~A})$ & 119.7 \\
\hline
\end{tabular}




$\begin{array}{ll}\mathrm{C}(4)-\mathrm{N}(2)-\mathrm{C}(3) & 122.0(3) \\ \mathrm{C}(4)-\mathrm{N}(2)-\mathrm{H}(2) & 119.0 \\ \mathrm{C}(3)-\mathrm{N}(2)-\mathrm{H}(2) & 119.0 \\ \mathrm{C}(23)-\mathrm{N}(3)-\mathrm{C}(5) & 121.8(3) \\ \mathrm{C}(23)-\mathrm{N}(3)-\mathrm{C}(22) & 117.9(3) \\ \mathrm{C}(5)-\mathrm{N}(3)-\mathrm{C}(22) & 120.1(3) \\ \mathrm{C}(33)-\mathrm{N}(4)-\mathrm{C}(32) & 122.3(3) \\ \mathrm{C}(33)-\mathrm{N}(4)-\mathrm{H}(4) & 118.8 \\ \mathrm{C}(32)-\mathrm{N}(4)-\mathrm{H}(4) & 118.8 \\ \mathrm{C}(19)-\mathrm{O}(2)-\mathrm{C}(20) & 114.7(3) \\ \mathrm{C}(23)-\mathrm{O}(6)-\mathrm{C}(24) & 114.8(3) \\ \mathrm{C}(9)-\mathrm{O}(7)-\mathrm{C}(31) & 117.7(3) \\ \mathrm{C}(33)-\mathrm{O}(9)-\mathrm{C}(34) & 119.5(3) \\ \mathrm{C}(13)-\mathrm{O}(10)-\mathrm{C}(38) & 119.0(3)\end{array}$


Symmetry transformations used to generate equivalent atoms: 


\section{Supporting Information}

Table 4. Anisotropic displacement parameters $\left(\AA^{2} \times 10^{3}\right)$ for gene852. The anisotropic displacement factor exponent takes the form: $-2 \pi^{2}\left[h^{2} a^{* 2} U^{11}+\ldots+2 h k a^{*} b^{*} U^{12}\right]$

\begin{tabular}{|c|c|c|c|c|c|c|}
\hline & $\mathrm{U}^{11}$ & $\mathrm{U}^{22}$ & $\mathrm{U}^{33}$ & $\mathrm{U}^{23}$ & $\mathrm{U}^{13}$ & $\mathrm{U}^{12}$ \\
\hline $\mathrm{C}(1)$ & $26(2)$ & $41(2)$ & $35(2)$ & $-9(2)$ & $0(1)$ & $-3(1)$ \\
\hline $\mathrm{C}(2)$ & $28(2)$ & $35(2)$ & $34(2)$ & $-8(1)$ & $0(1)$ & $0(1)$ \\
\hline$C(3)$ & $27(2)$ & $33(2)$ & $38(2)$ & $-6(1)$ & $0(1)$ & $-1(1)$ \\
\hline$C(4)$ & $23(2)$ & $22(1)$ & $40(2)$ & $4(1)$ & $3(1)$ & $-2(1)$ \\
\hline$C(5)$ & $20(1)$ & $29(2)$ & $36(2)$ & $4(1)$ & $2(1)$ & $1(1)$ \\
\hline$C(6)$ & $23(1)$ & $28(2)$ & $35(2)$ & $1(1)$ & $2(1)$ & $3(1)$ \\
\hline$C(7)$ & $30(2)$ & $33(2)$ & $31(2)$ & $1(1)$ & $5(1)$ & $4(1)$ \\
\hline $\mathrm{C}(8)$ & $33(2)$ & $29(2)$ & $33(2)$ & $-4(1)$ & $5(1)$ & $2(1)$ \\
\hline $\mathrm{C}(9)$ & $29(2)$ & $24(2)$ & $36(2)$ & $-1(1)$ & $3(1)$ & $3(1)$ \\
\hline$C(10)$ & $29(2)$ & $24(1)$ & $34(2)$ & $1(1)$ & $0(1)$ & $6(1)$ \\
\hline $\mathrm{C}(11)$ & $26(2)$ & $26(2)$ & $32(2)$ & $-1(1)$ & $2(1)$ & $2(1)$ \\
\hline $\mathrm{C}(12)$ & $30(2)$ & $24(1)$ & $32(2)$ & $0(1)$ & $-4(1)$ & $-3(1)$ \\
\hline $\mathrm{C}(13)$ & $27(2)$ & $27(2)$ & $42(2)$ & $1(1)$ & $-2(1)$ & $0(1)$ \\
\hline $\mathrm{C}(14)$ & $36(2)$ & $29(2)$ & $42(2)$ & $9(1)$ & $-9(2)$ & $-5(1)$ \\
\hline$C(15)$ & $33(2)$ & $34(2)$ & $36(2)$ & $3(1)$ & $-7(1)$ & $-9(1)$ \\
\hline$C(16)$ & $27(2)$ & $33(2)$ & $33(2)$ & $0(1)$ & $-4(1)$ & $-7(1)$ \\
\hline $\mathrm{C}(17)$ & $27(2)$ & $28(2)$ & $33(2)$ & $2(1)$ & $-2(1)$ & $-1(1)$ \\
\hline $\mathrm{C}(18)$ & $36(2)$ & $38(2)$ & $32(2)$ & $-3(2)$ & $4(1)$ & $-6(2)$ \\
\hline $\mathrm{C}(19)$ & $41(2)$ & $41(2)$ & $40(2)$ & $-6(2)$ & $6(2)$ & $1(2)$ \\
\hline$C(20)$ & $52(2)$ & $44(2)$ & $55(2)$ & $-6(2)$ & $17(2)$ & $9(2)$ \\
\hline$C(21)$ & $47(2)$ & $33(2)$ & $67(3)$ & $-10(2)$ & $8(2)$ & $-1(2)$ \\
\hline $\mathrm{C}(22)$ & $26(2)$ & $44(2)$ & $56(2)$ & $6(2)$ & $9(2)$ & $6(2)$ \\
\hline $\mathrm{C}(23)$ & $32(2)$ & $36(2)$ & $35(2)$ & $1(1)$ & $1(1)$ & $-5(1)$ \\
\hline $\mathrm{C}(24)$ & $49(2)$ & $47(2)$ & $62(3)$ & $24(2)$ & $-14(2)$ & $-16(2)$ \\
\hline $\mathrm{C}(31)$ & $36(2)$ & $29(2)$ & $35(2)$ & $-4(1)$ & $-2(1)$ & $0(1)$ \\
\hline $\mathrm{C}(32)$ & $34(2)$ & $28(2)$ & $40(2)$ & $-2(1)$ & $-7(1)$ & $2(1)$ \\
\hline $\mathrm{C}(33)$ & $34(2)$ & $30(2)$ & $30(2)$ & $0(1)$ & $-2(1)$ & $3(1)$ \\
\hline $\mathrm{C}(34)$ & $45(2)$ & $34(2)$ & $35(2)$ & $-4(2)$ & $-7(2)$ & $15(2)$ \\
\hline$C(35)$ & $49(2)$ & $63(3)$ & $40(2)$ & $-2(2)$ & $-4(2)$ & $23(2)$ \\
\hline $\mathrm{C}(36)$ & $66(3)$ & $38(2)$ & $57(3)$ & $10(2)$ & $-11(2)$ & $8(2)$ \\
\hline $\mathrm{C}(37)$ & $57(2)$ & $49(2)$ & $38(2)$ & $-3(2)$ & $-11(2)$ & $21(2)$ \\
\hline
\end{tabular}


Supporting Information

\begin{tabular}{lllllll}
$\mathrm{C}(38)$ & $41(2)$ & $49(2)$ & $72(3)$ & $-7(2)$ & $-11(2)$ & $16(2)$ \\
$\mathrm{N}(1)$ & $26(1)$ & $31(1)$ & $35(1)$ & $-5(1)$ & $-2(1)$ & $-1(1)$ \\
$\mathrm{N}(2)$ & $24(1)$ & $30(1)$ & $36(1)$ & $1(1)$ & $-2(1)$ & $1(1)$ \\
$\mathrm{N}(3)$ & $24(1)$ & $34(2)$ & $46(2)$ & $5(1)$ & $5(1)$ & $2(1)$ \\
$\mathrm{N}(4)$ & $43(2)$ & $27(1)$ & $39(2)$ & $-9(1)$ & $-11(1)$ & $3(1)$ \\
$\mathrm{O}(1)$ & $51(2)$ & $94(3)$ & $67(2)$ & $-46(2)$ & $12(2)$ & $-15(2)$ \\
$\mathrm{O}(2)$ & $39(1)$ & $40(1)$ & $46(1)$ & $-7(1)$ & $10(1)$ & $0(1)$ \\
$\mathrm{O}(3)$ & $27(1)$ & $58(2)$ & $44(1)$ & $6(1)$ & $0(1)$ & $-1(1)$ \\
$\mathrm{O}(4)$ & $24(1)$ & $36(1)$ & $48(1)$ & $-4(1)$ & $-3(1)$ & $-2(1)$ \\
$\mathrm{O}(5)$ & $34(1)$ & $48(2)$ & $51(2)$ & $4(1)$ & $13(1)$ & $-7(1)$ \\
$\mathrm{O}(6)$ & $32(1)$ & $34(1)$ & $47(1)$ & $9(1)$ & $-1(1)$ & $-6(1)$ \\
$\mathrm{O}(7)$ & $45(1)$ & $25(1)$ & $32(1)$ & $-5(1)$ & $2(1)$ & $-3(1)$ \\
$\mathrm{O}(8)$ & $49(2)$ & $26(1)$ & $35(1)$ & $-4(1)$ & $-9(1)$ & $3(1)$ \\
$\mathrm{O}(9)$ & $48(2)$ & $34(1)$ & $37(1)$ & $-9(1)$ & $-12(1)$ & $13(1)$ \\
$\mathrm{O}(10)$ & $47(2)$ & $33(1)$ & $47(1)$ & $3(1)$ & $-1(1)$ & $14(1)$ \\
& & & & & & \\
\hline
\end{tabular}




\section{Supporting Information}

Table 5. Hydrogen coordinates ( $\left.\mathrm{x} 10^{4}\right)$ and isotropic displacement parameters $\left(\AA^{2} \times 10^{3}\right)$ for gene852.

\begin{tabular}{|c|c|c|c|c|}
\hline & $\mathrm{x}$ & $\mathrm{y}$ & z & $\mathrm{U}(\mathrm{eq})$ \\
\hline $\mathrm{H}(1)$ & 4719 & 7109 & 4538 & 41 \\
\hline $\mathrm{H}(3)$ & 6516 & 7902 & 3842 & 39 \\
\hline $\mathrm{H}(5)$ & 6398 & 7591 & 1015 & 34 \\
\hline $\mathrm{H}(7)$ & 6518 & 6818 & 138 & 37 \\
\hline $\mathrm{H}(8)$ & 6095 & 6100 & 258 & 38 \\
\hline $\mathrm{H}(11)$ & 6565 & 6920 & 2811 & 34 \\
\hline $\mathrm{H}(14)$ & 6387 & 5421 & 4824 & 43 \\
\hline $\mathrm{H}(15)$ & 5841 & 5935 & 5729 & 41 \\
\hline $\mathrm{H}(17)$ & 5511 & 6721 & 3609 & 35 \\
\hline $\mathrm{H}(18 \mathrm{~A})$ & 5693 & 6817 & 5842 & 43 \\
\hline $\mathrm{H}(18 \mathrm{~B})$ & 4953 & 6606 & 5708 & 43 \\
\hline $\mathrm{H}(20 \mathrm{~A})$ & 4083 & 7592 & 7113 & 76 \\
\hline $\mathrm{H}(20 \mathrm{~B})$ & 3376 & 7635 & 6586 & 76 \\
\hline $\mathrm{H}(20 \mathrm{C})$ & 3959 & 8002 & 6457 & 76 \\
\hline $\mathrm{H}(21 \mathrm{~A})$ & 6342 & 8620 & 3203 & 73 \\
\hline $\mathrm{H}(21 \mathrm{~B})$ & 5914 & 8572 & 4104 & 73 \\
\hline $\mathrm{H}(21 \mathrm{C})$ & 5537 & 8529 & 3164 & 73 \\
\hline $\mathrm{H}(22 \mathrm{~A})$ & 8014 & 6958 & 610 & 63 \\
\hline $\mathrm{H}(22 \mathrm{~B})$ & 7891 & 7024 & 1653 & 63 \\
\hline $\mathrm{H}(22 \mathrm{C})$ & 8404 & 7346 & 1132 & 63 \\
\hline $\mathrm{H}(24 \mathrm{~A})$ & 7079 & 8396 & -932 & 63 \\
\hline $\mathrm{H}(24 \mathrm{~B})$ & 7569 & 8620 & -194 & 63 \\
\hline $\mathrm{H}(26)$ & 6134 & 8549 & 1114 & 72 \\
\hline $\mathrm{H}(27)$ & 5266 & 9074 & 1317 & 85 \\
\hline $\mathrm{H}(28)$ & 5130 & 9654 & 296 & 124 \\
\hline $\mathrm{H}(29)$ & 5863 & 9708 & -929 & 140 \\
\hline $\mathrm{H}(30)$ & 6731 & 9183 & -1132 & 98 \\
\hline $\mathrm{H}(26 \mathrm{~A})$ & 6167 & 8593 & 865 & 72 \\
\hline $\mathrm{H}(27 \mathrm{~A})$ & 5216 & 9064 & 831 & 85 \\
\hline $\mathrm{H}(28 \mathrm{~A})$ & 5006 & 9503 & -422 & 124 \\
\hline
\end{tabular}


Supporting Information

\begin{tabular}{|c|c|c|c|c|}
\hline $\mathrm{H}(29 \mathrm{~A})$ & 5747 & 9472 & -1641 & 140 \\
\hline $\mathrm{H}(30 \mathrm{~A})$ & 6698 & 9001 & -1607 & 98 \\
\hline $\mathrm{H}(31 \mathrm{~A})$ & 5997 & 5368 & 605 & 40 \\
\hline $\mathrm{H}(31 \mathrm{~B})$ & 5248 & 5591 & 595 & 40 \\
\hline $\mathrm{H}(32 \mathrm{~A})$ & 4865 & 5073 & 1669 & 41 \\
\hline $\mathrm{H}(32 \mathrm{~B})$ & 5149 & 4810 & 819 & 41 \\
\hline $\mathrm{H}(35 \mathrm{~A})$ & 7502 & 4043 & 1487 & 76 \\
\hline $\mathrm{H}(35 \mathrm{~B})$ & 6880 & 3836 & 933 & 76 \\
\hline $\mathrm{H}(35 \mathrm{C})$ & 7424 & 3515 & 1399 & 76 \\
\hline $\mathrm{H}(36 \mathrm{~A})$ & 5883 & 3471 & 2750 & 80 \\
\hline $\mathrm{H}(36 \mathrm{~B})$ & 6469 & 3135 & 2435 & 80 \\
\hline $\mathrm{H}(36 \mathrm{C})$ & 6015 & 3390 & 1713 & 80 \\
\hline $\mathrm{H}(37 \mathrm{~A})$ & 7502 & 4027 & 3106 & 72 \\
\hline $\mathrm{H}(37 \mathrm{~B})$ & 7457 & 3496 & 3104 & 72 \\
\hline $\mathrm{H}(37 \mathrm{C})$ & 6905 & 3781 & 3642 & 72 \\
\hline $\mathrm{H}(38 \mathrm{~A})$ & 6943 & 4913 & 3649 & 65 \\
\hline $\mathrm{H}(38 \mathrm{~B})$ & 7394 & 5326 & 4006 & 65 \\
\hline $\mathrm{H}(40)$ & 7258 & 5538 & 1702 & 85 \\
\hline $\mathrm{H}(41)$ & 8055 & 5388 & 581 & 120 \\
\hline $\mathrm{H}(42)$ & 8959 & 4898 & 850 & 95 \\
\hline $\mathrm{H}(43)$ & 9068 & 4557 & 2240 & 78 \\
\hline $\mathrm{H}(44)$ & 8272 & 4707 & 3361 & 66 \\
\hline $\mathrm{H}(40 \mathrm{~A})$ & 7280 & 5400 & 1823 & 85 \\
\hline $\mathrm{H}(41 \mathrm{~A})$ & 8116 & 5188 & 795 & 120 \\
\hline $\mathrm{H}(42 \mathrm{~A})$ & 9004 & 4715 & 1229 & 95 \\
\hline $\mathrm{H}(43 \mathrm{~A})$ & 9056 & 4453 & 2691 & 78 \\
\hline $\mathrm{H}(44 \mathrm{~A})$ & 8220 & 4665 & 3719 & 66 \\
\hline $\mathrm{H}(1 \mathrm{~A})$ & 6065 & 7357 & 4649 & 37 \\
\hline $\mathrm{H}(2)$ & 5826 & 7788 & 2236 & 36 \\
\hline $\mathrm{H}(4)$ & 5977 & 4929 & 2305 & 44 \\
\hline
\end{tabular}


Supporting Information
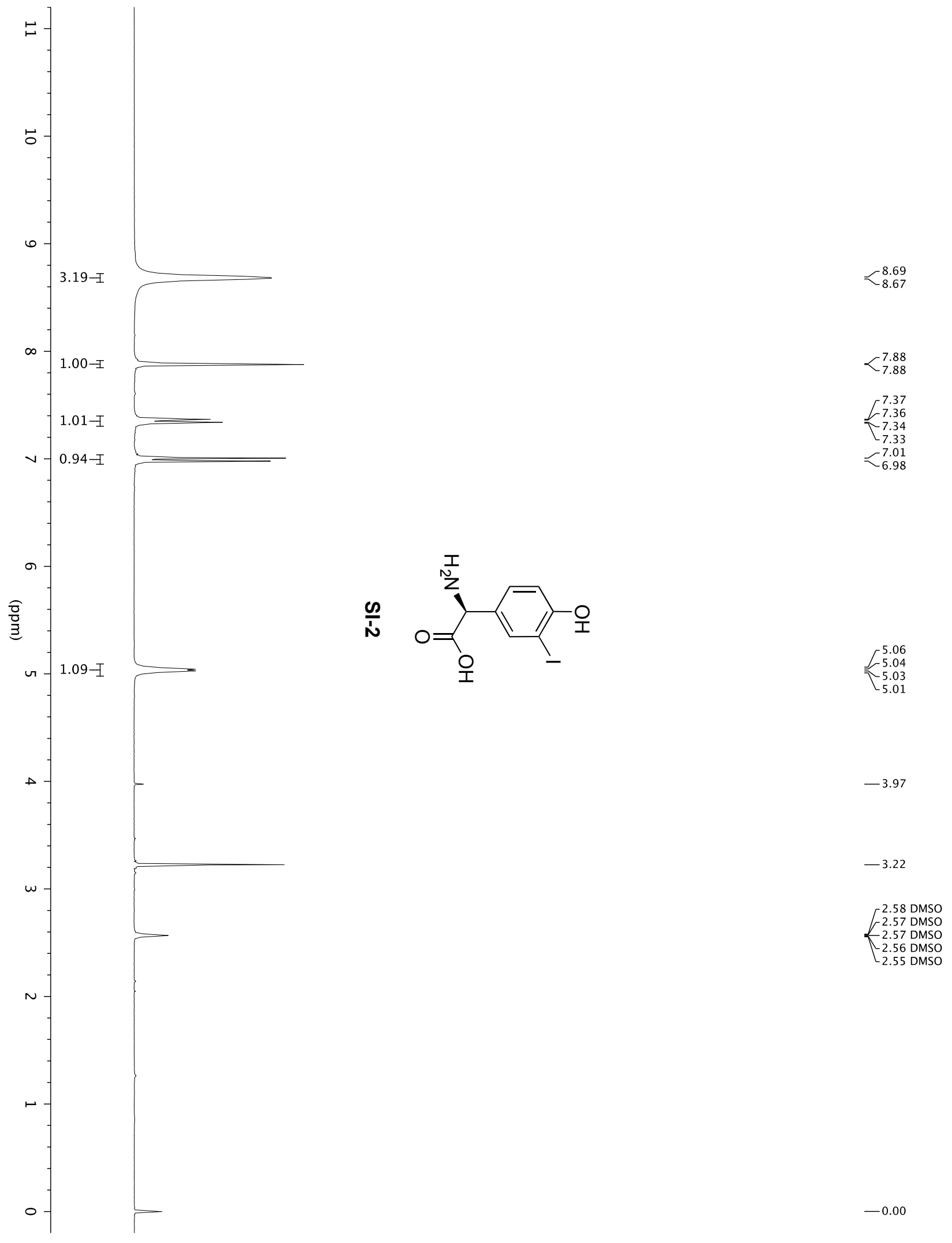

$-0.00$ 
Supporting Information
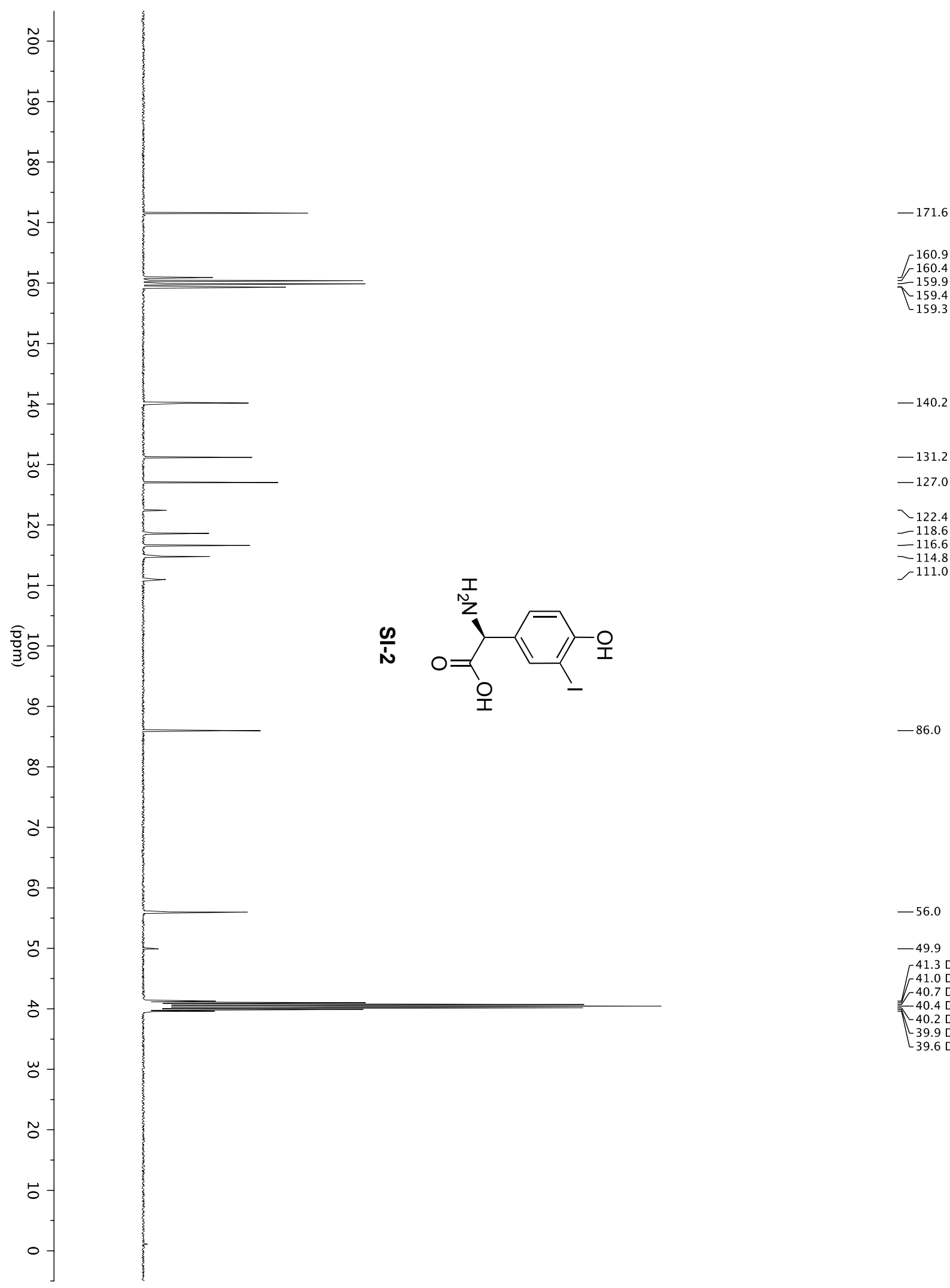

$-140.2$

$-131.2$

$-127.0$

\urcorner 122.4

$-118.6$

$-114.8$

$-114.8$

$-86.0$

$-56.0$

$-49.9$

41.3 DMSO

41.0 DMSO

40.7 DMSO

40.4 DMSO

40.2 DMSO

39.9 DMSO

[39.6 DMSO 
Supporting Information
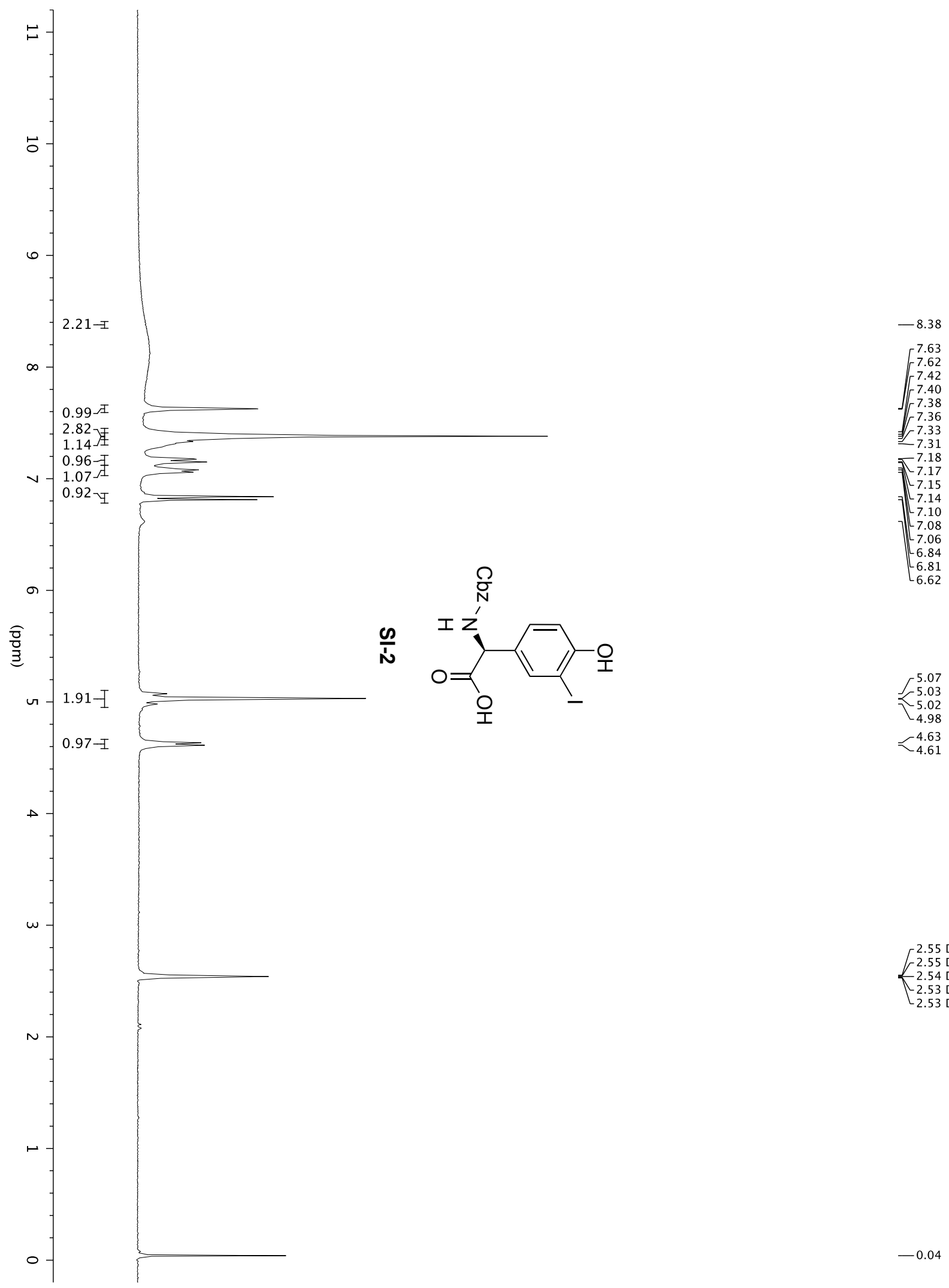

2.55 DMSO 2.55
$2.5 M S O$

2.53 DMSO

2.53 DMSO

$-0.04$ 


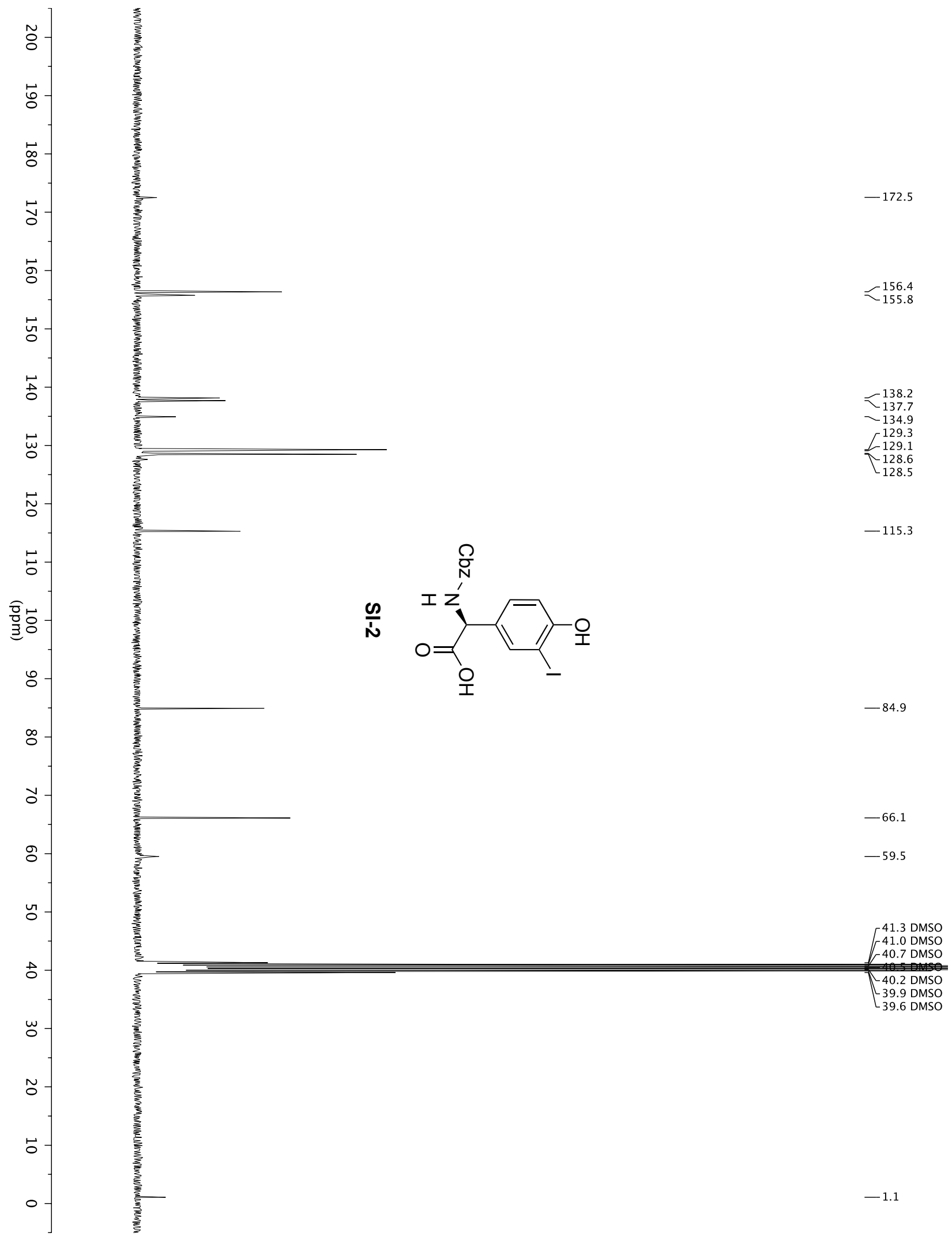


Supporting Information

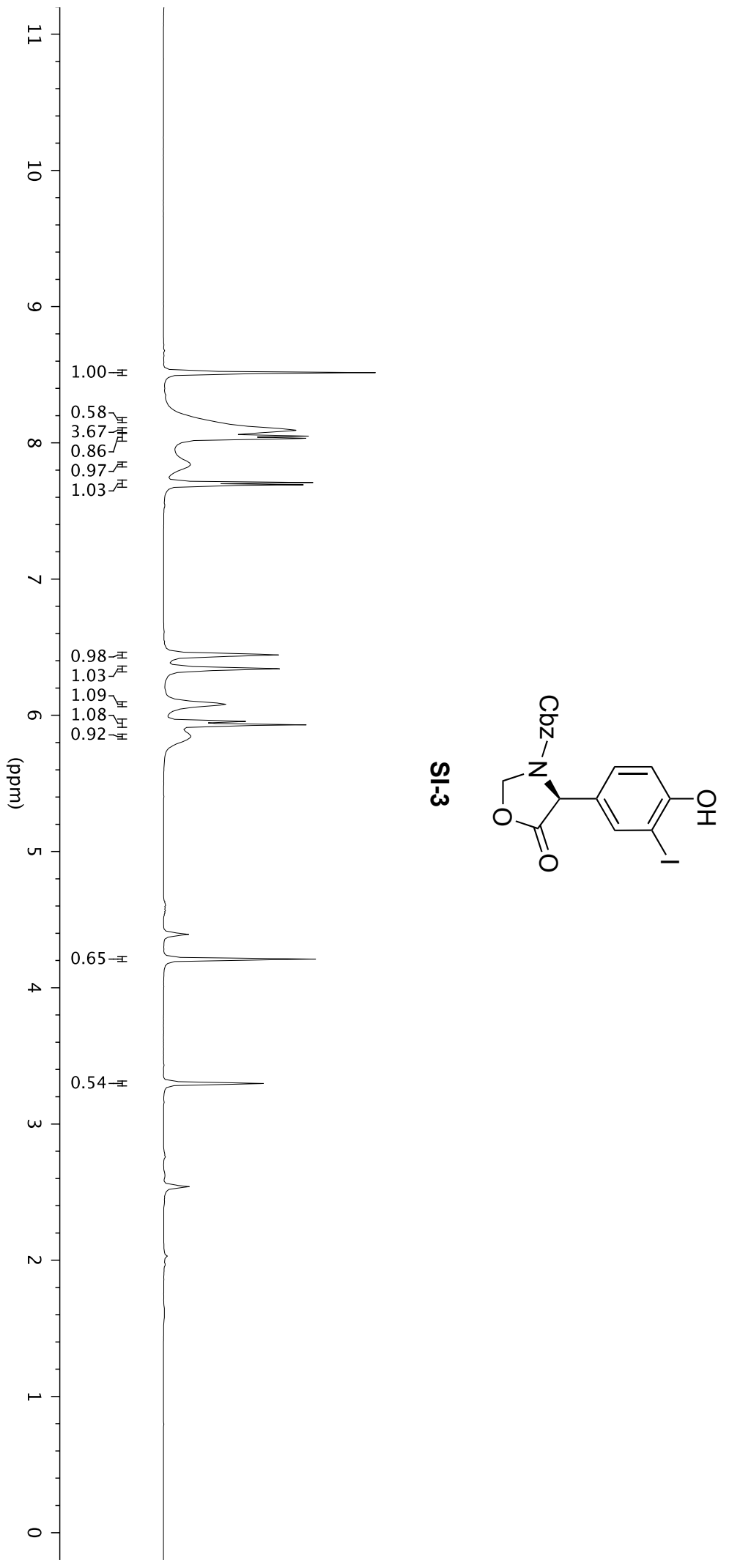

6.45
-6.44

-6.44
-6.34 $<6.34$ $-6.08$ 5.96
-5.93 -5.93
$\sim 5.84$ $-5.84$

$-2.00$ 
Supporting Information

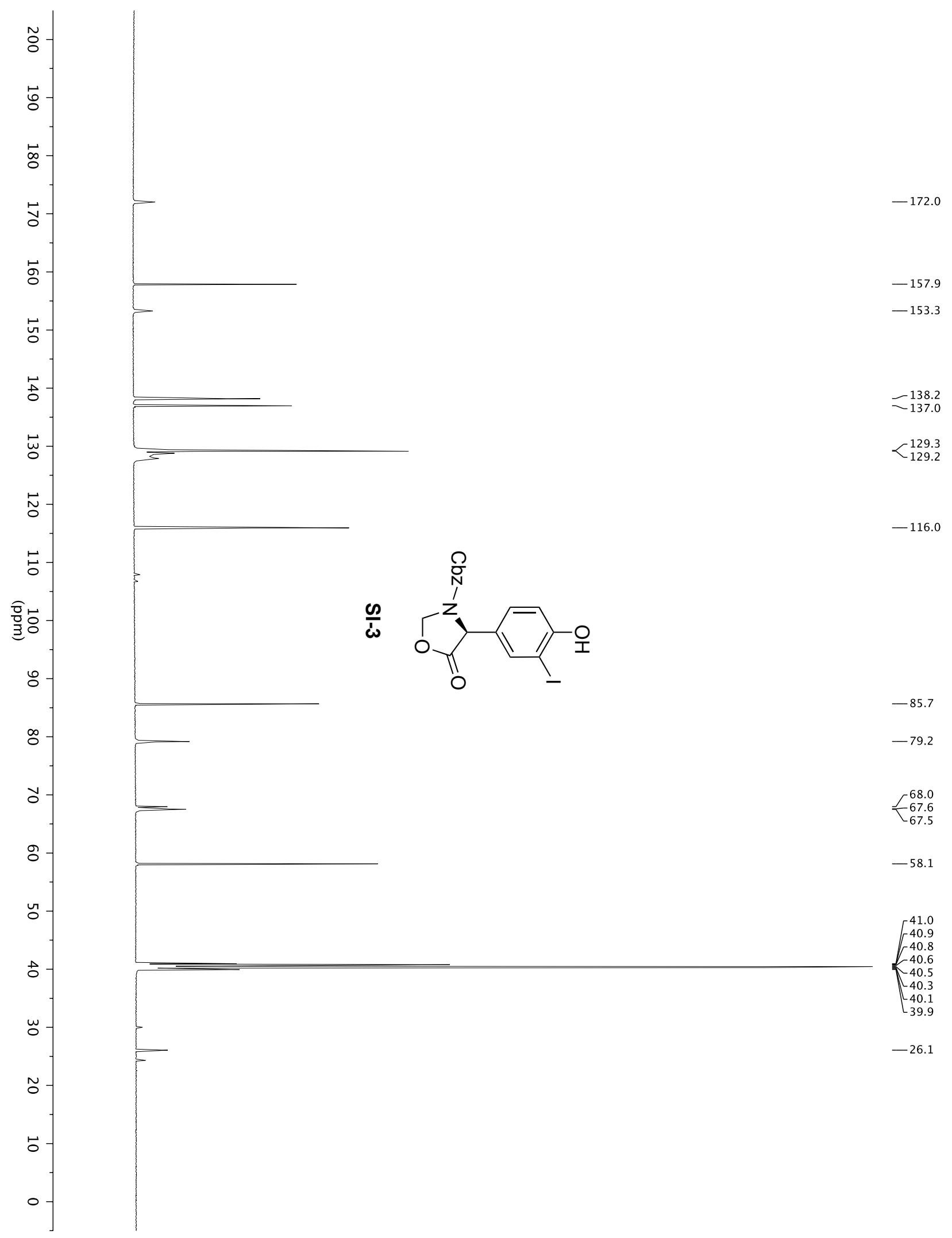


Supporting Information

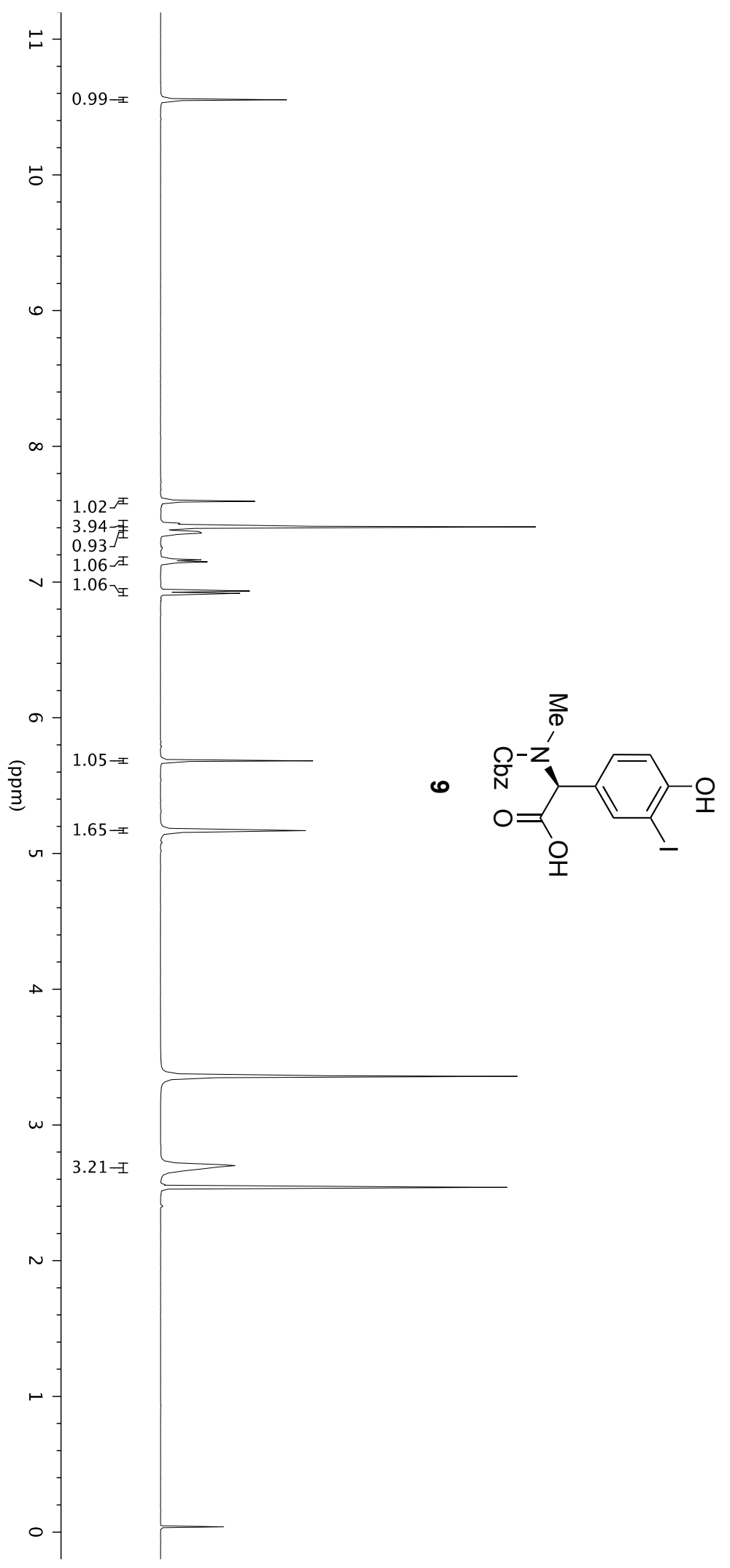

$-3.36 \mathrm{HDO}$ 
Supporting Information

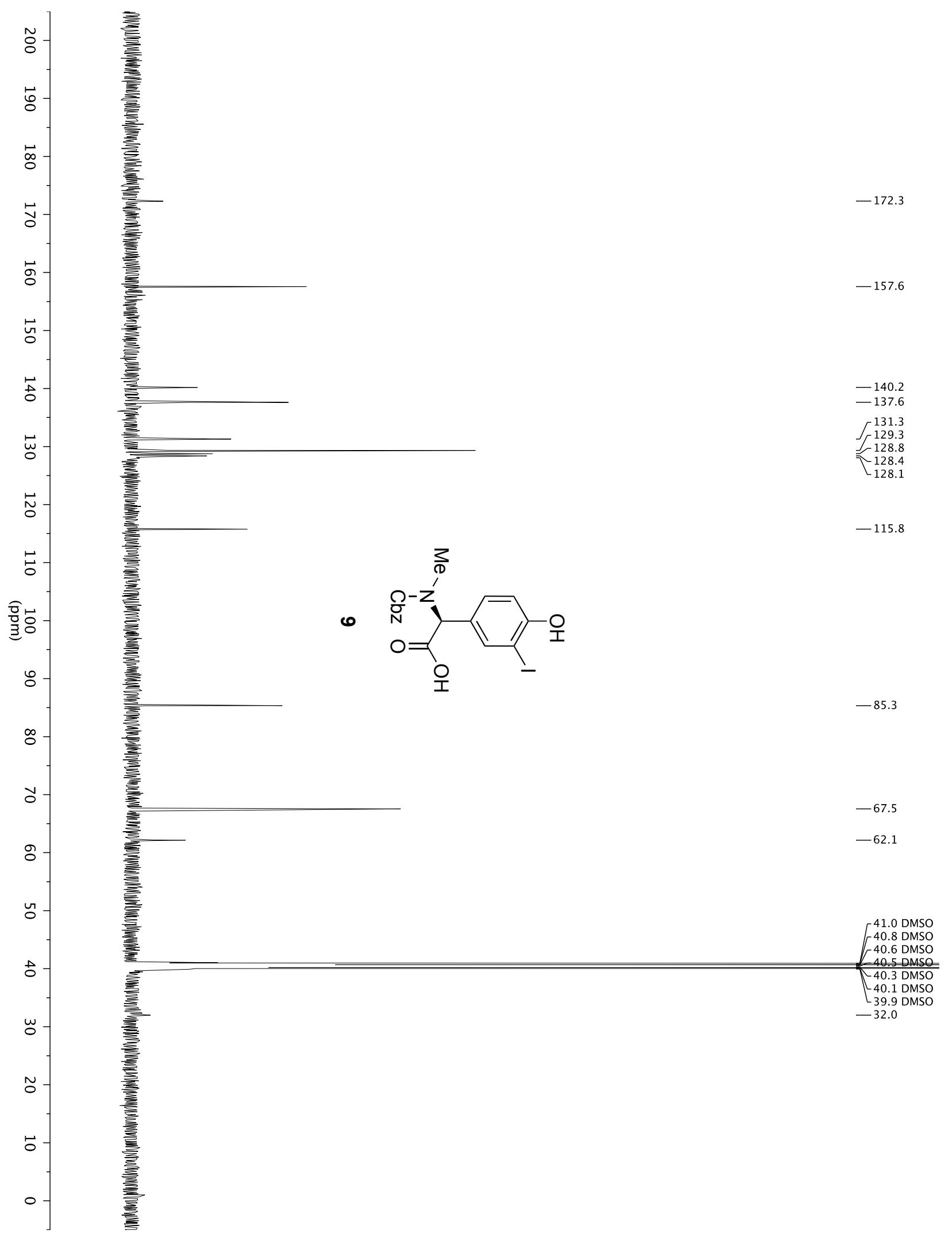


Supporting Information
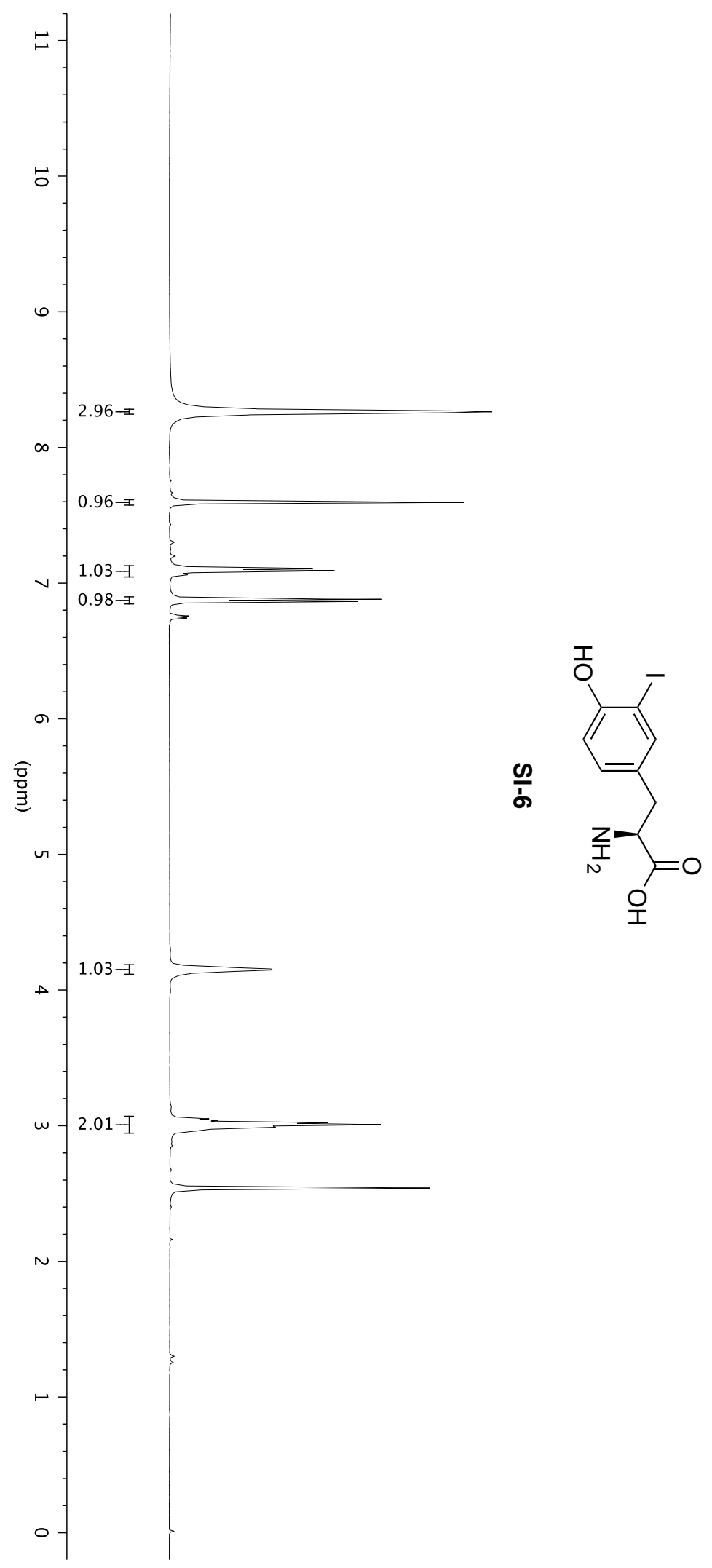

$-8.26$

$<\begin{array}{r}7.60 \\ <.59\end{array}$ 7.11
-7.11 7.11 $C_{7.09}^{7.09}$ 7.08 - 7.06

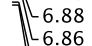
$\left[\begin{array}{r}6.86 \\ 6.76 \\ 6.74\end{array}\right.$

4.17
4.16 4.16
-4.15
-4.13 4.13
4.15

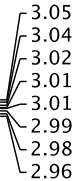
-2.54 DMSO 
Supporting Information

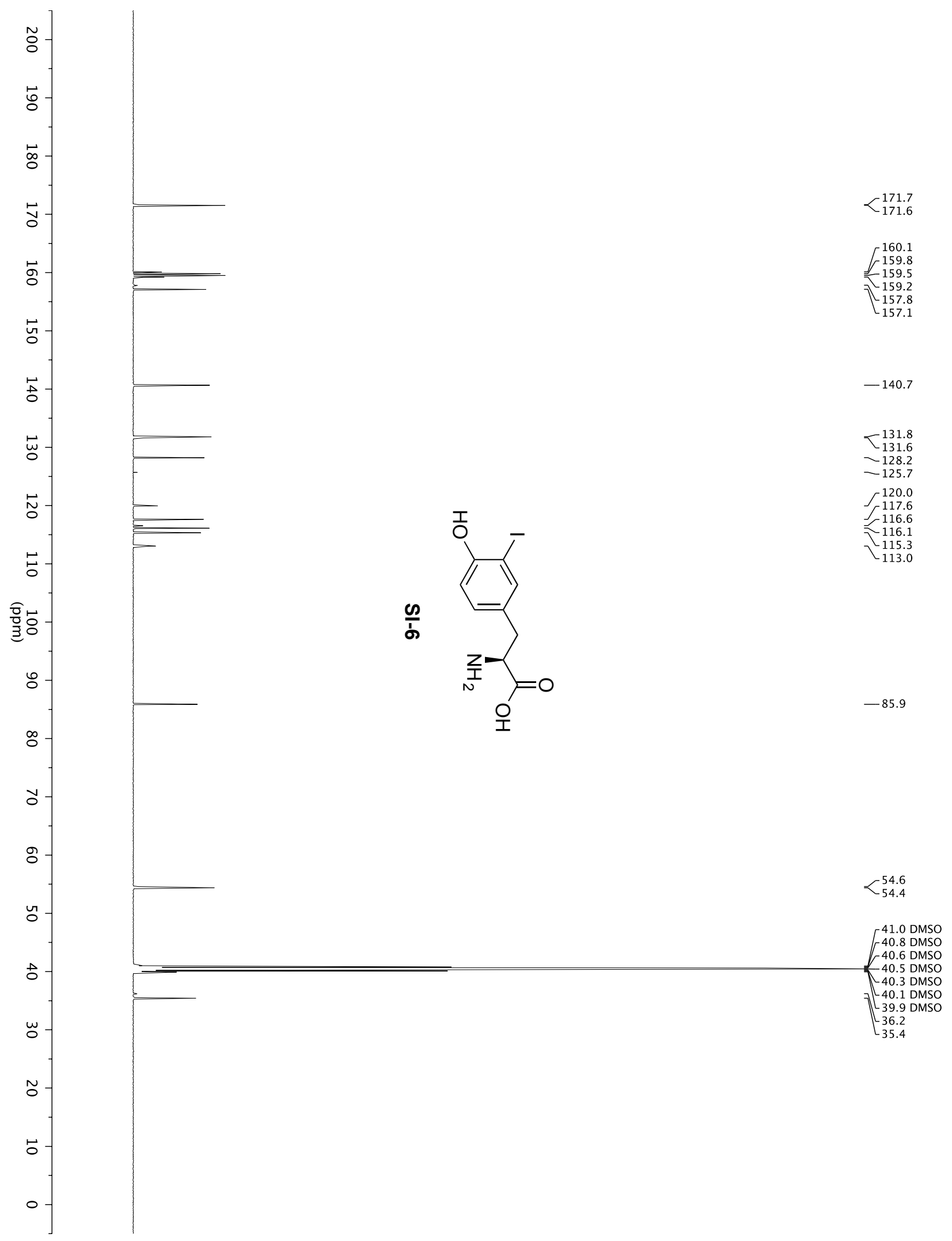


Supporting Information

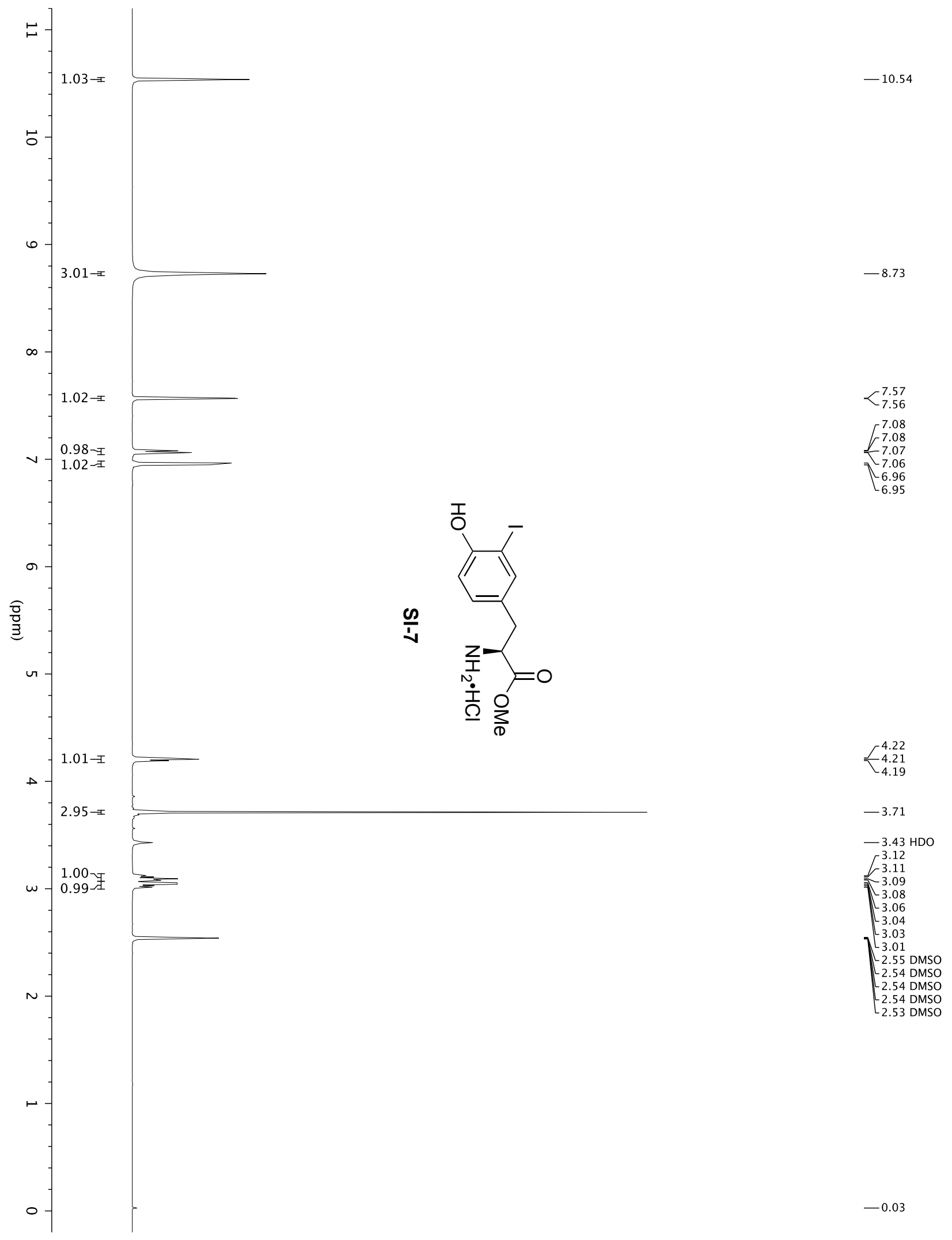


Supporting Information

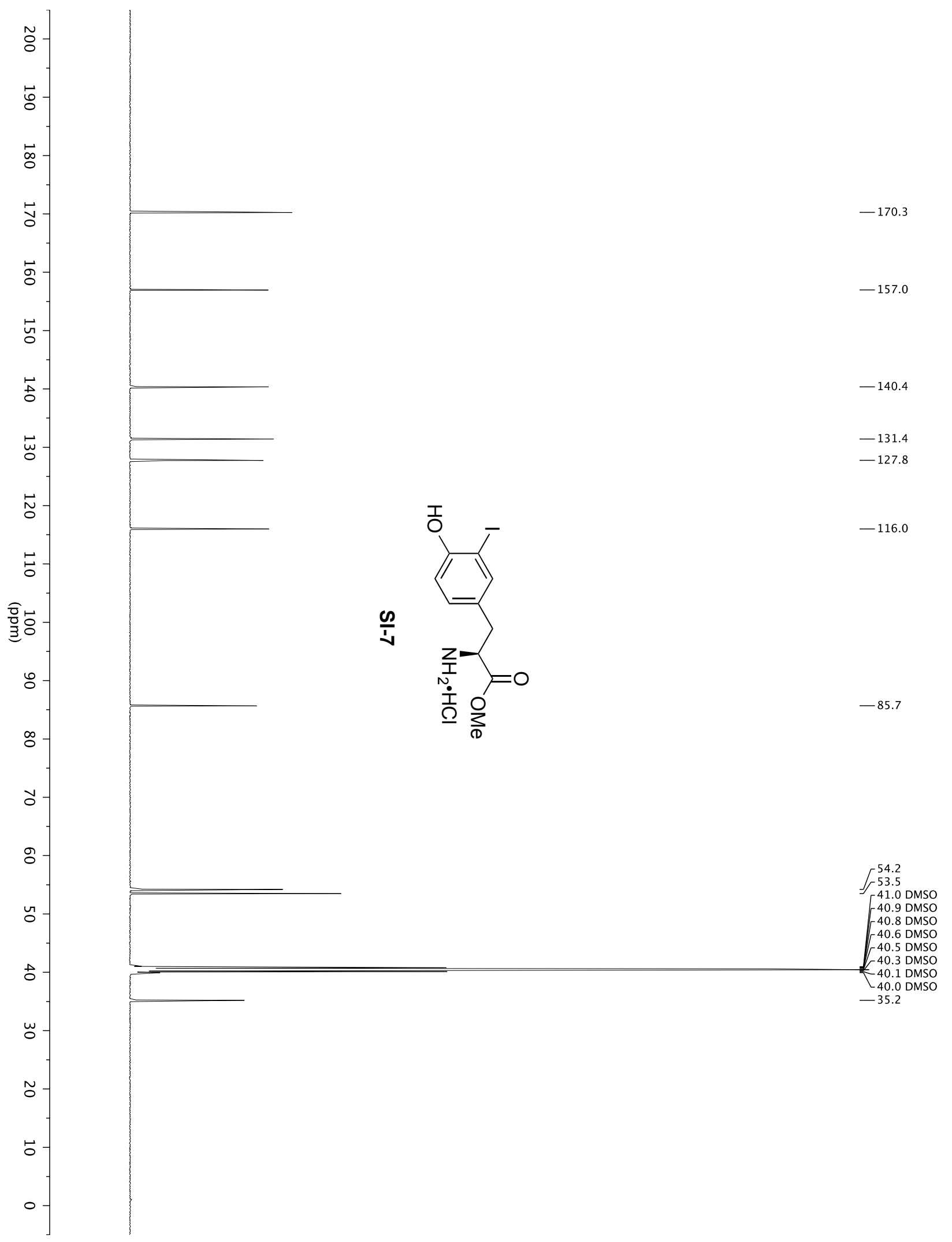


Supporting Information
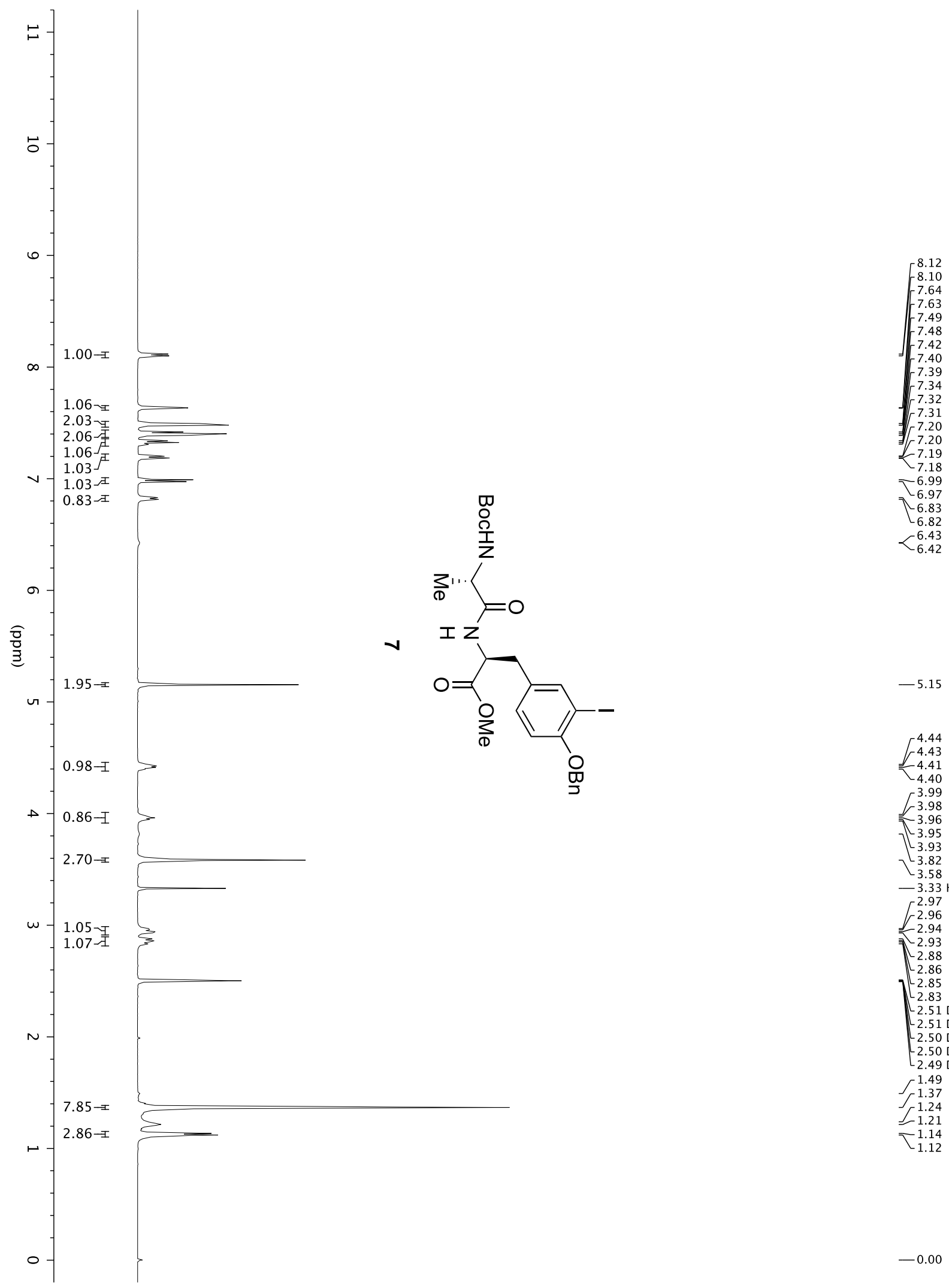

4.44
-4.43 4.43
-4.41 4.40
3.99 3.99
-3.98 3.98
-3.96 -3.96
-3.95

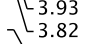
3.58 $-3.33 \mathrm{HDO}$ 2.97 2.96
-2.94 -2.93
2.88 2.88
2.86 2.85

2.83

2.51 DMSO 2.51 DMSO

2.50 DMSO

2.49 DMSO

1.49
1.37 $\tau^{1.37}$ $\Gamma^{1.24}$ -1.14 1.12

$-0.00$ 
Supporting Information

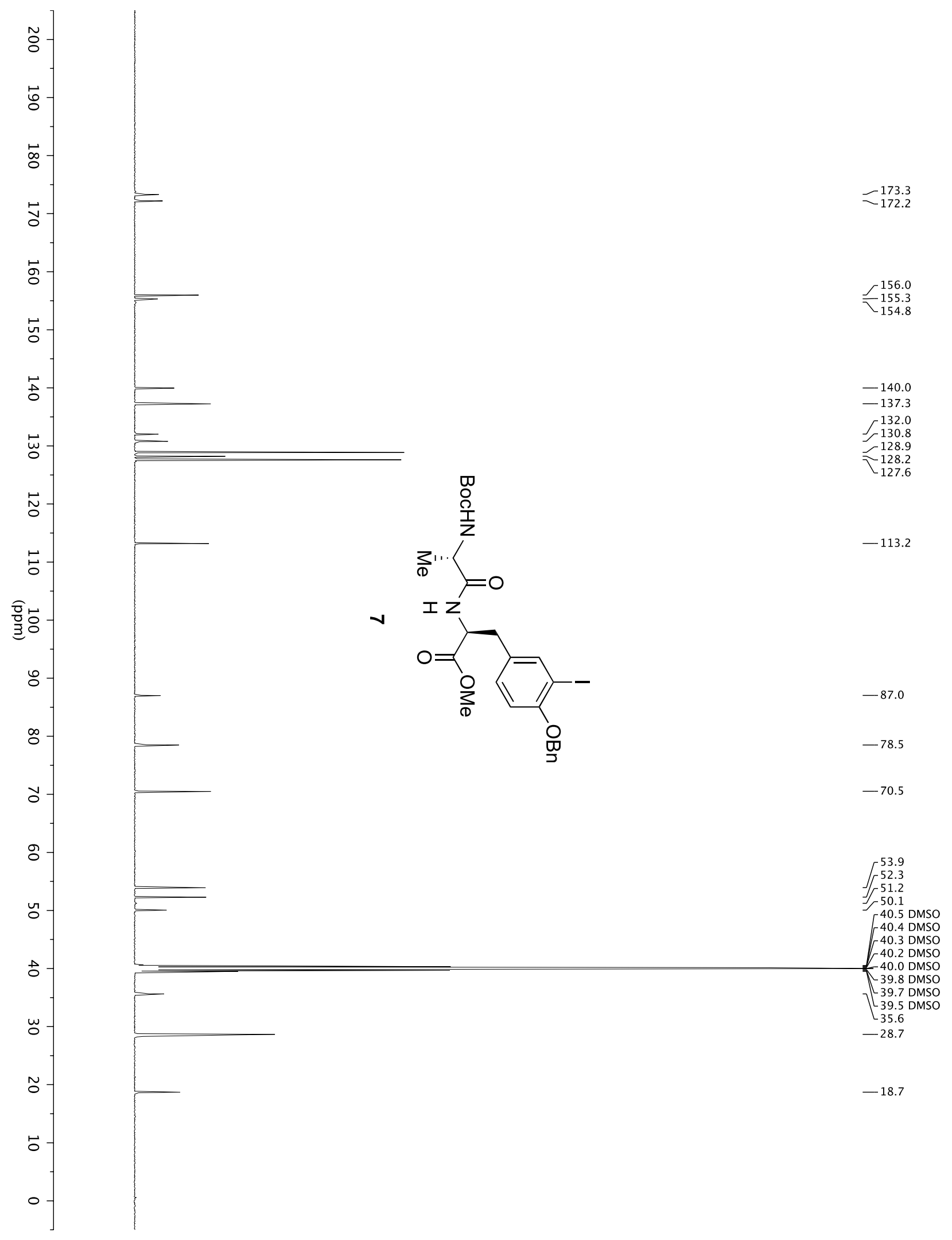


Supporting Information
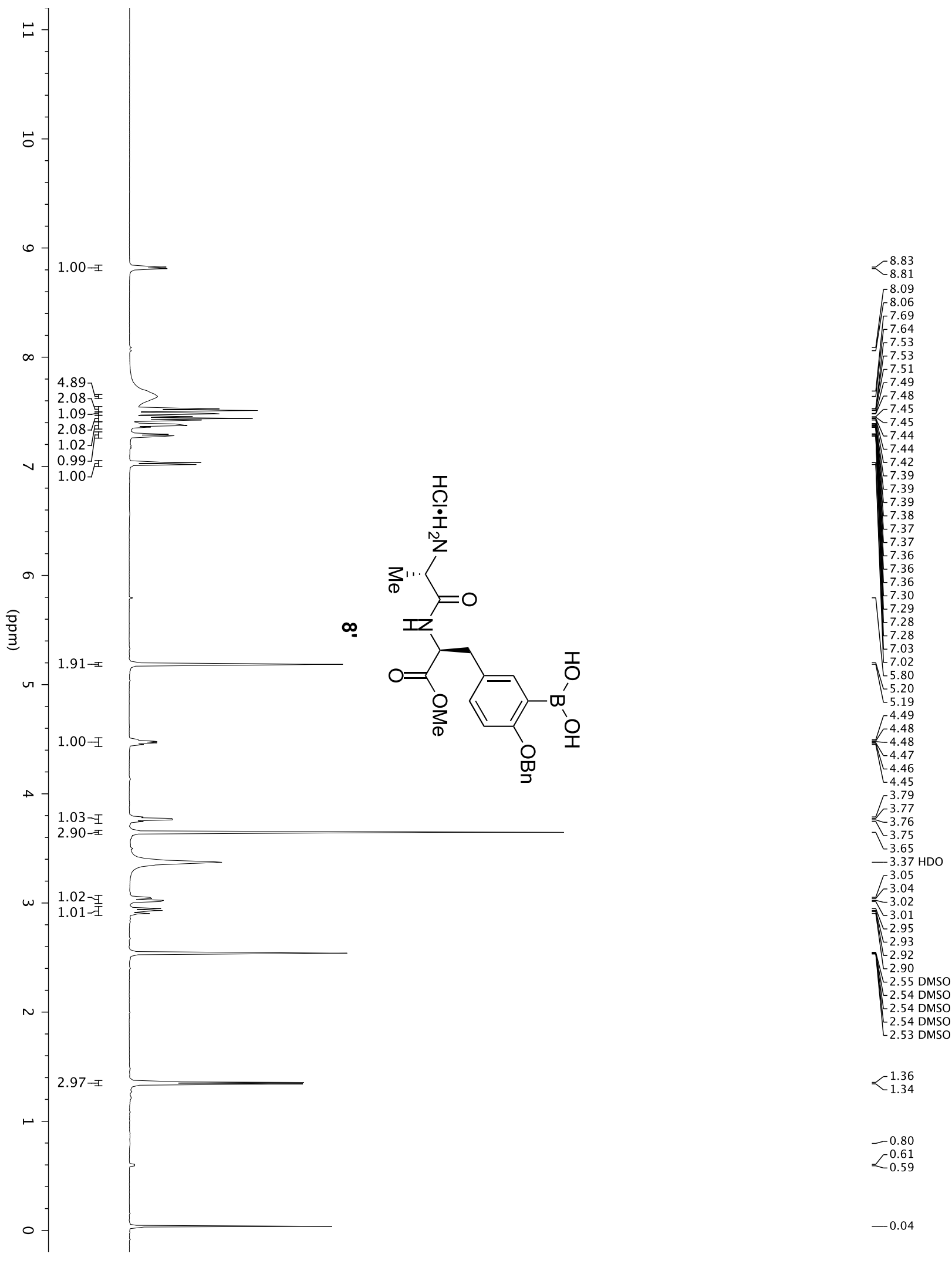
Supporting Information

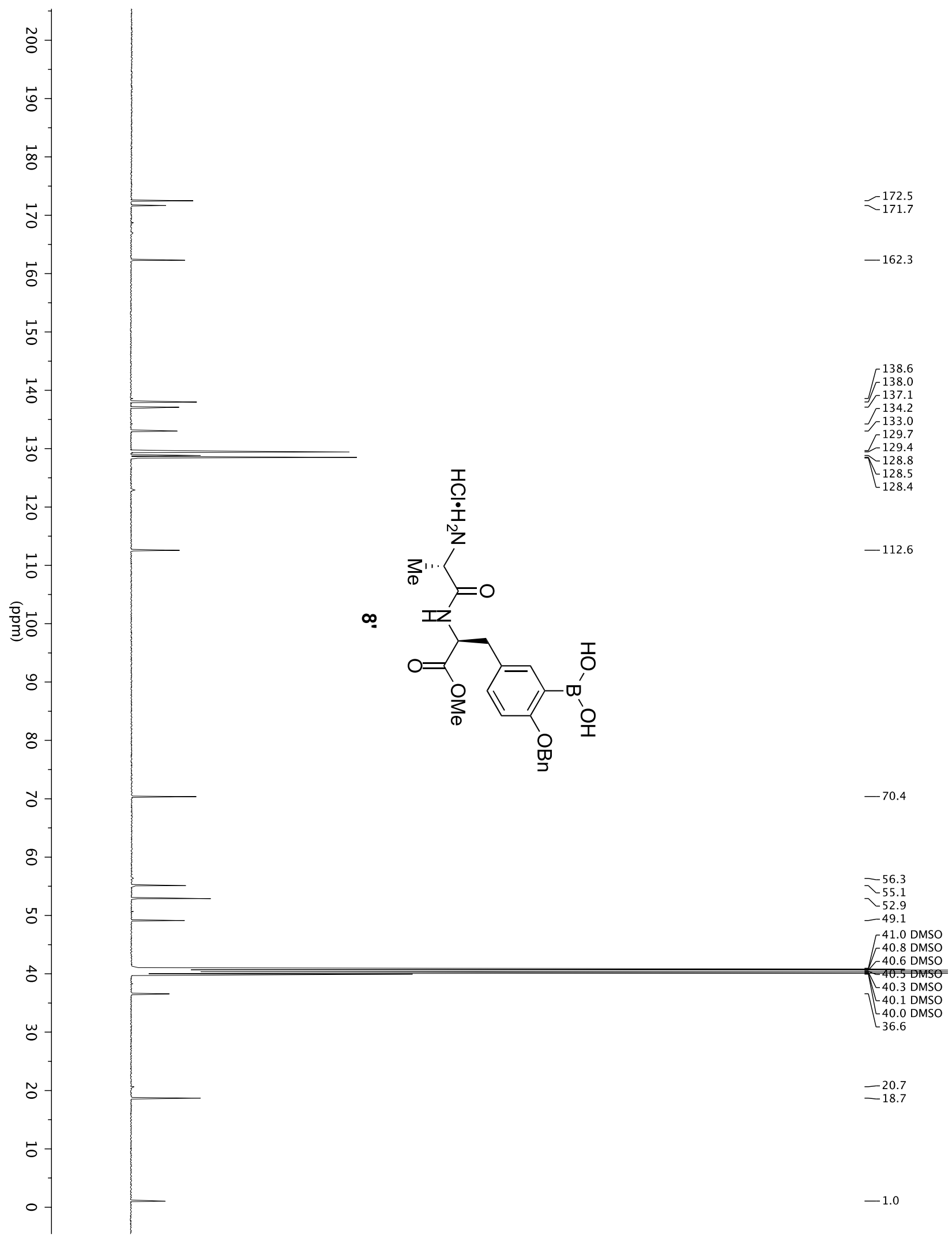




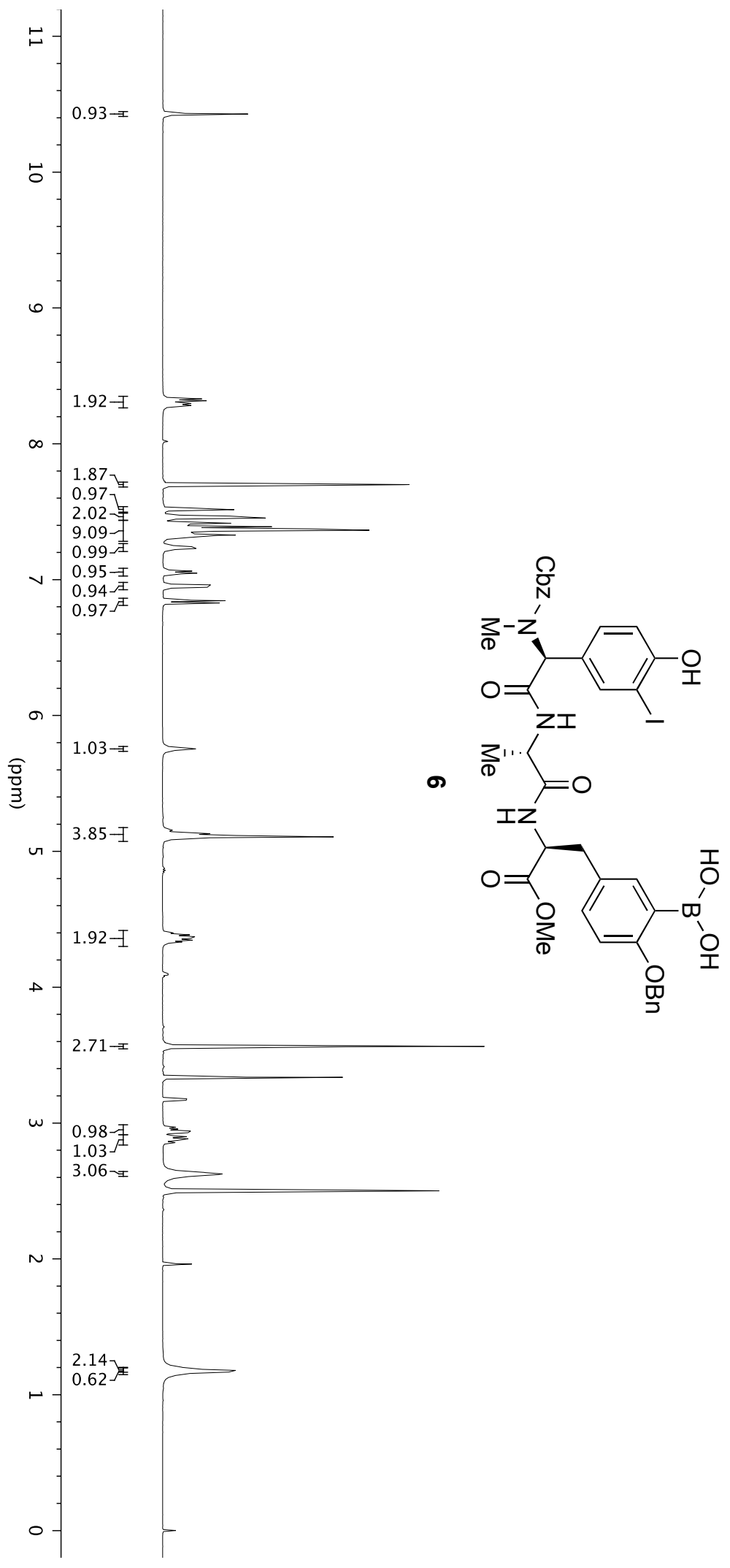




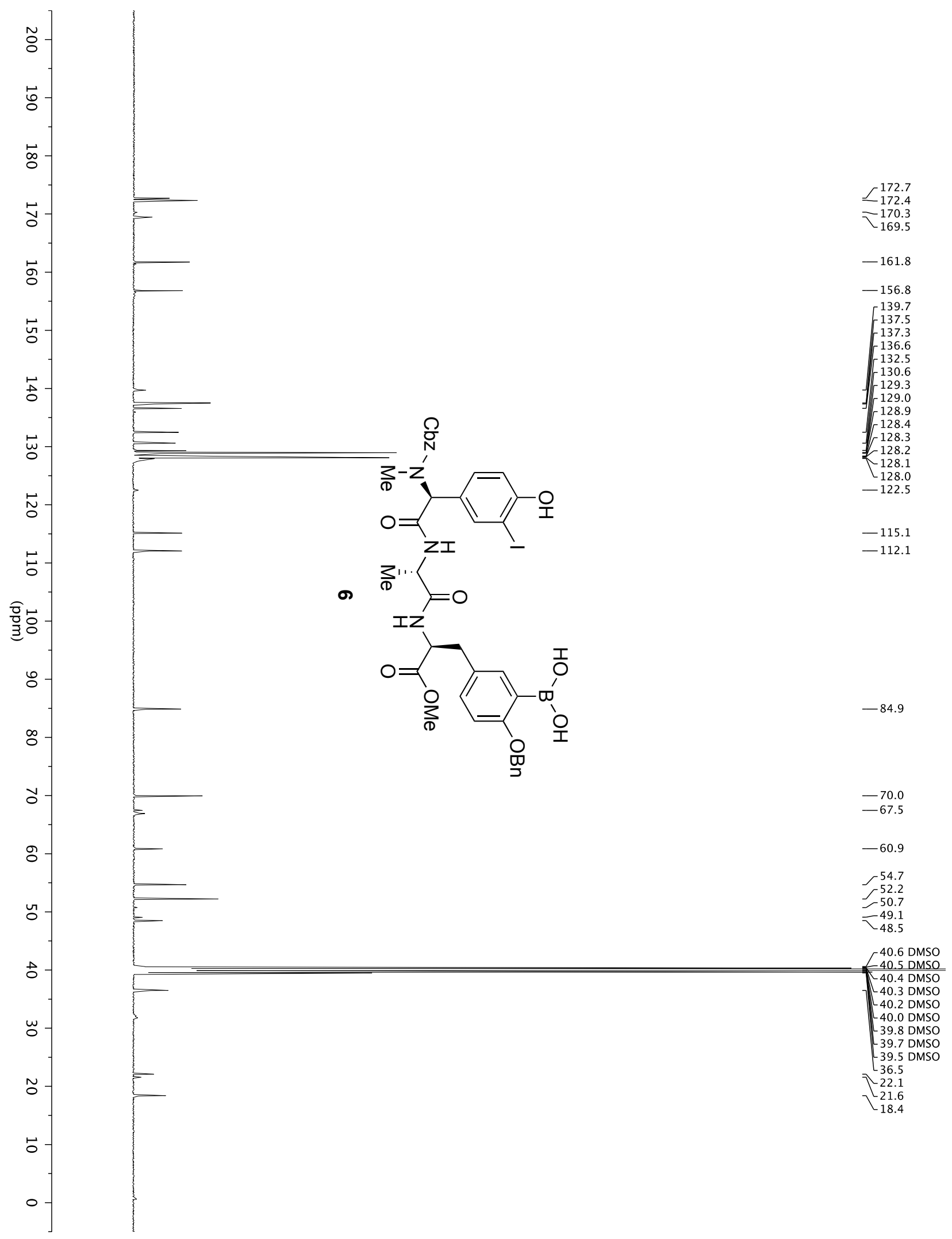


Supporting Information

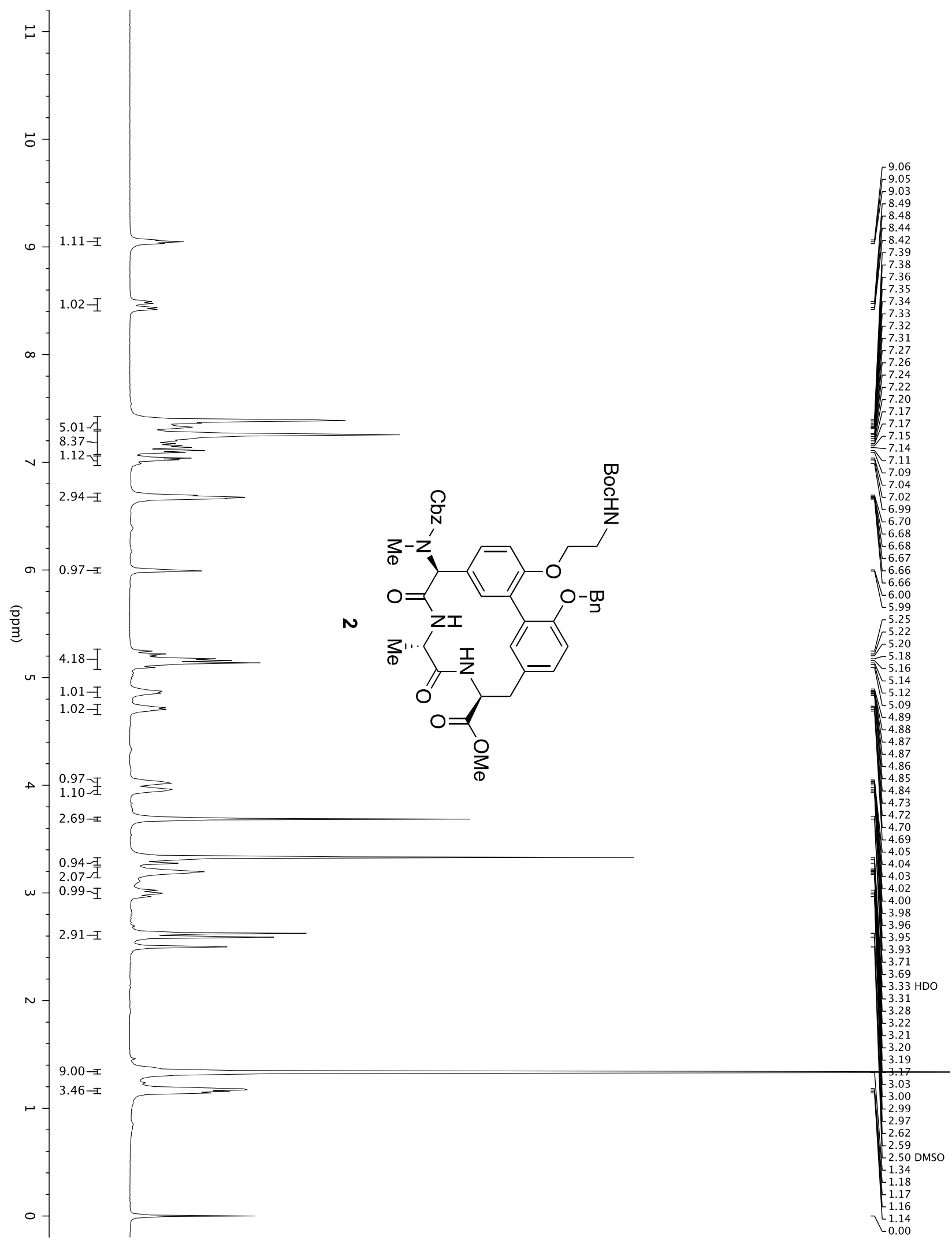


Supporting Information

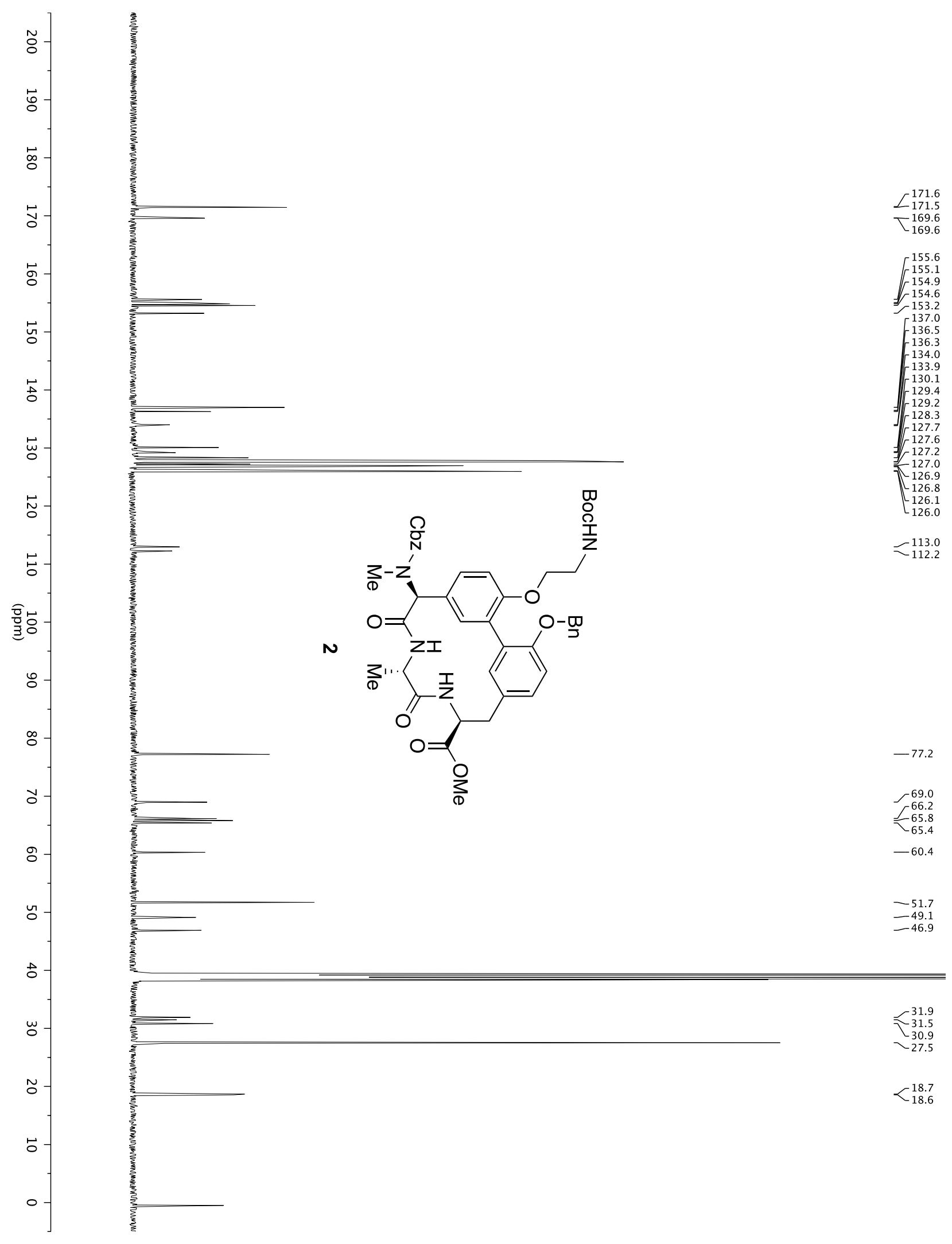


Supporting Information

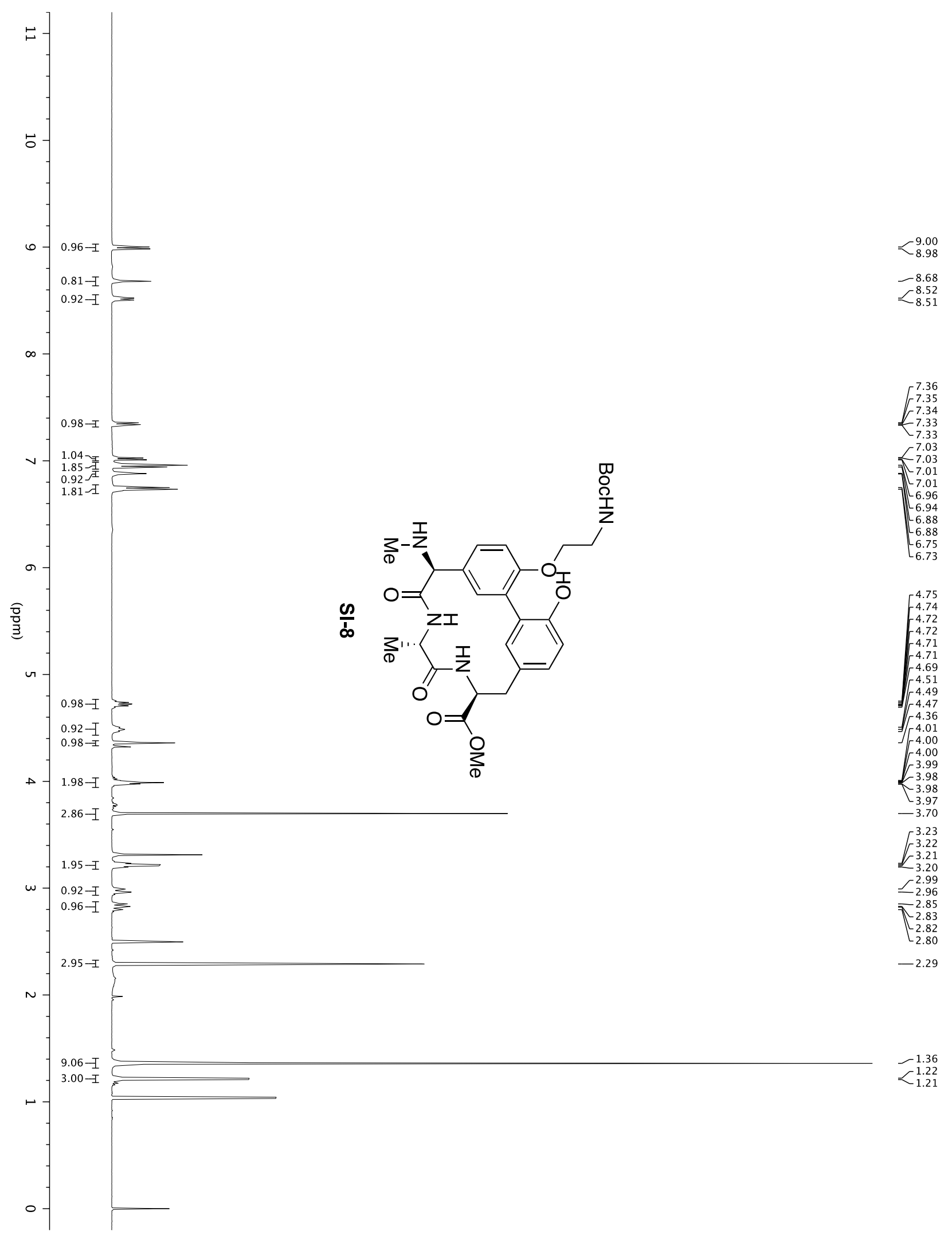




\section{Supporting Information}

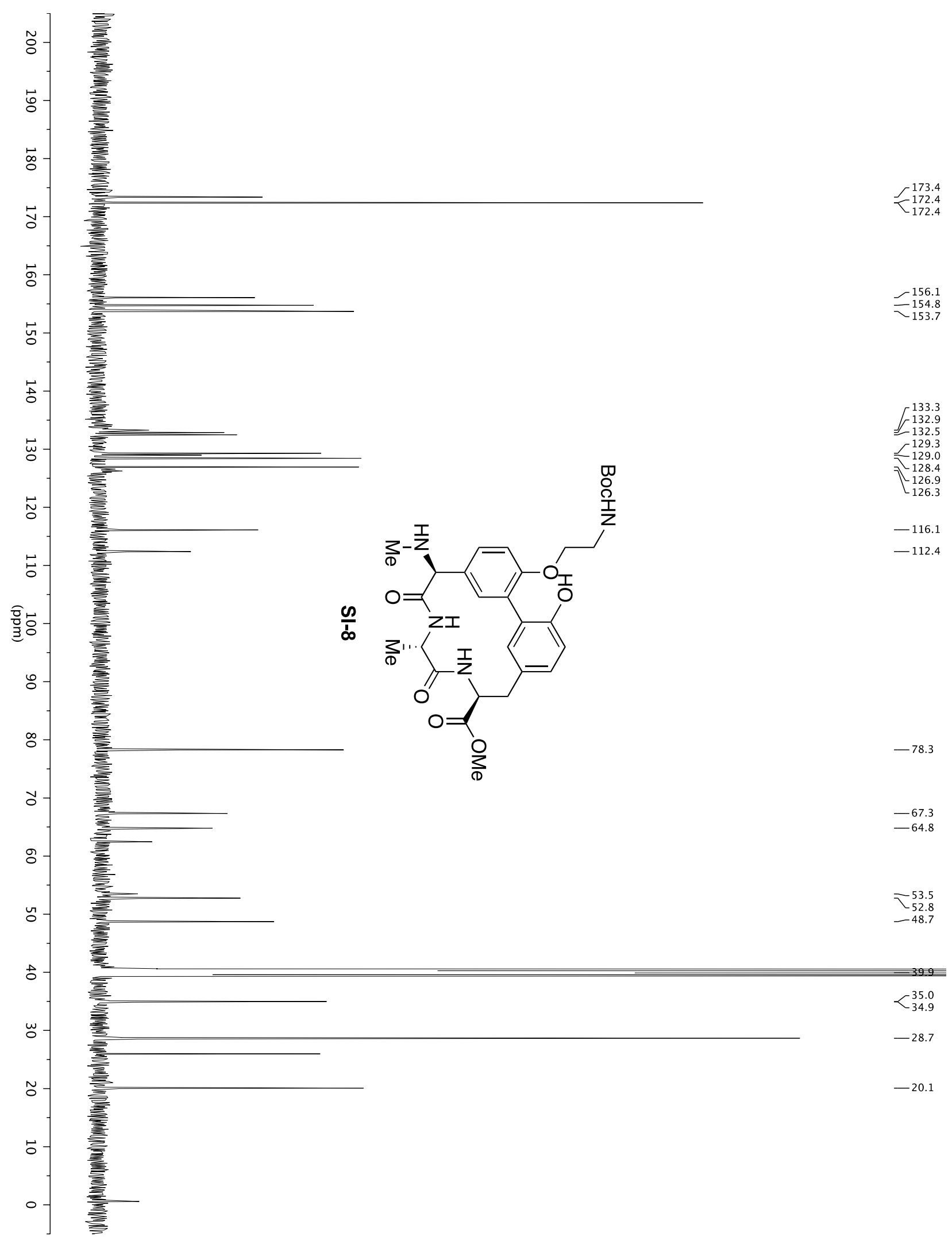




\section{Supporting Information}

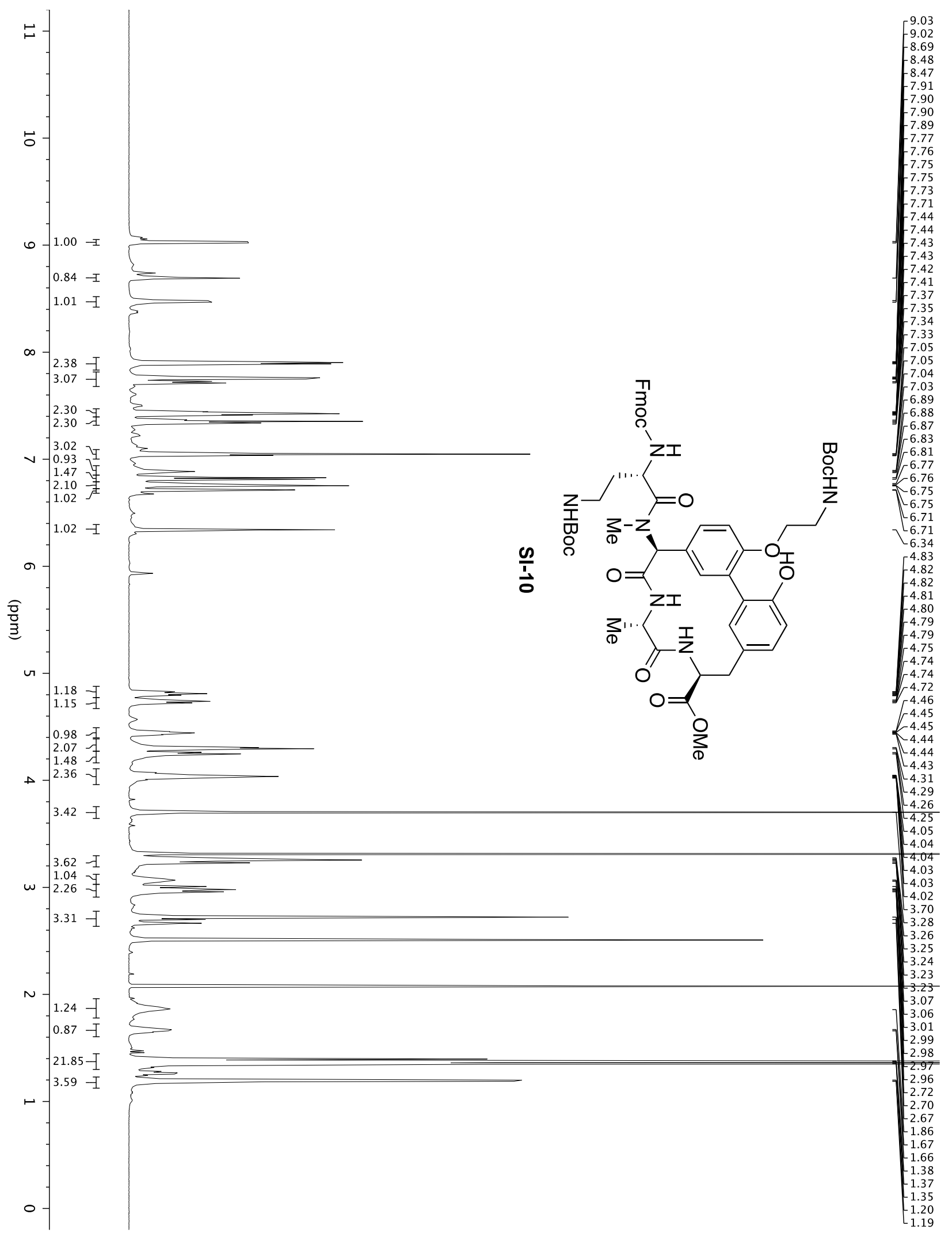


Supporting Information

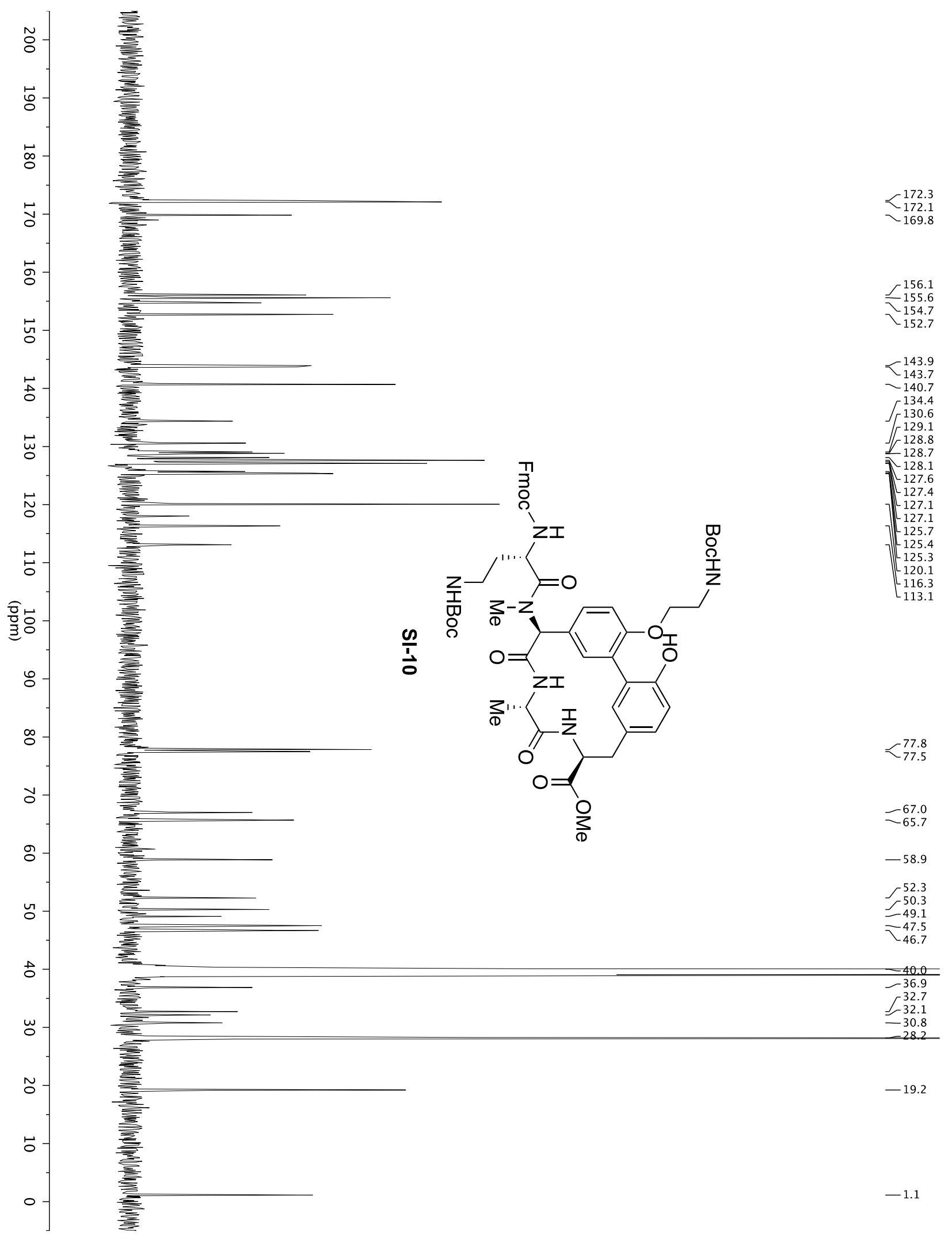


Supporting Information

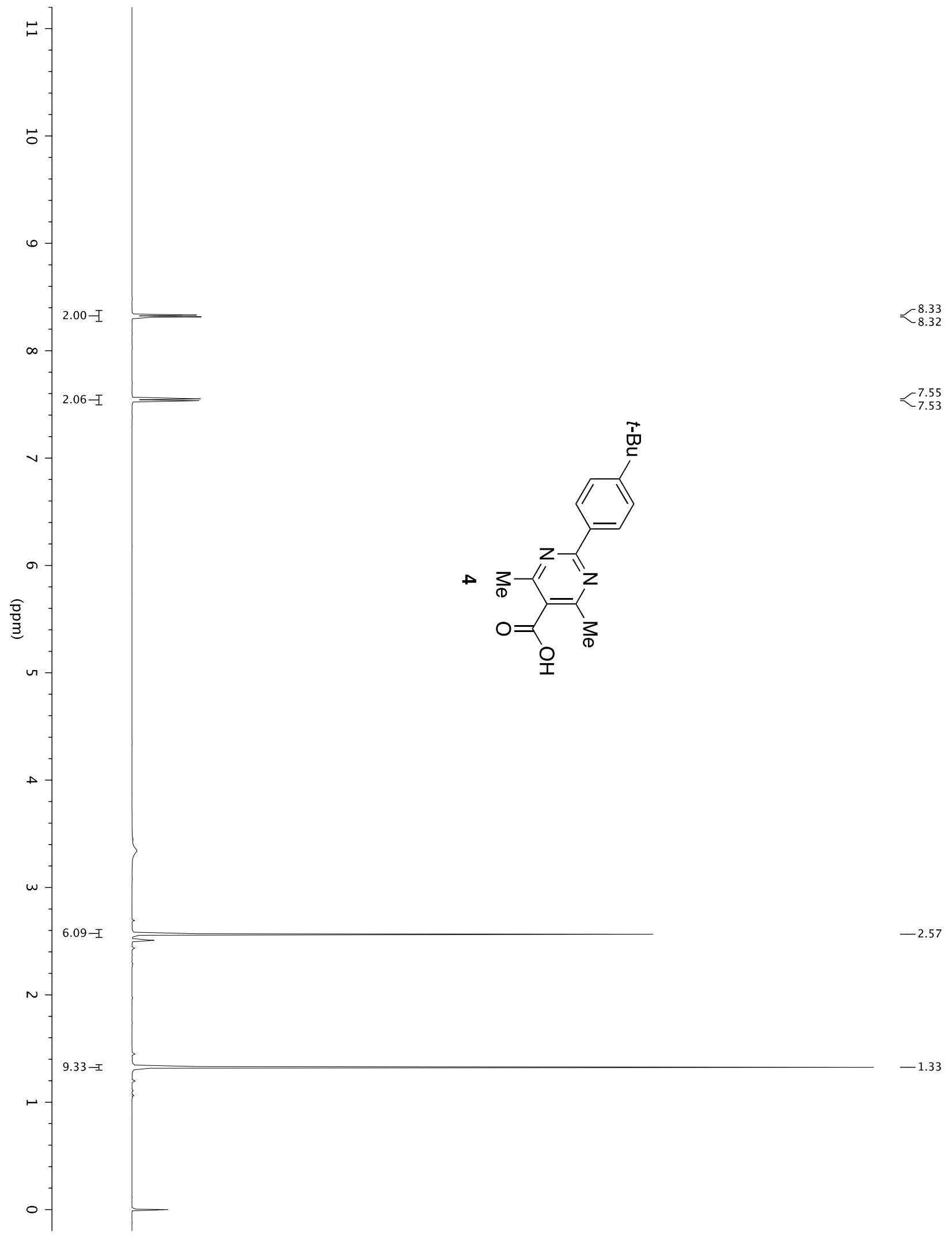


Supporting Information

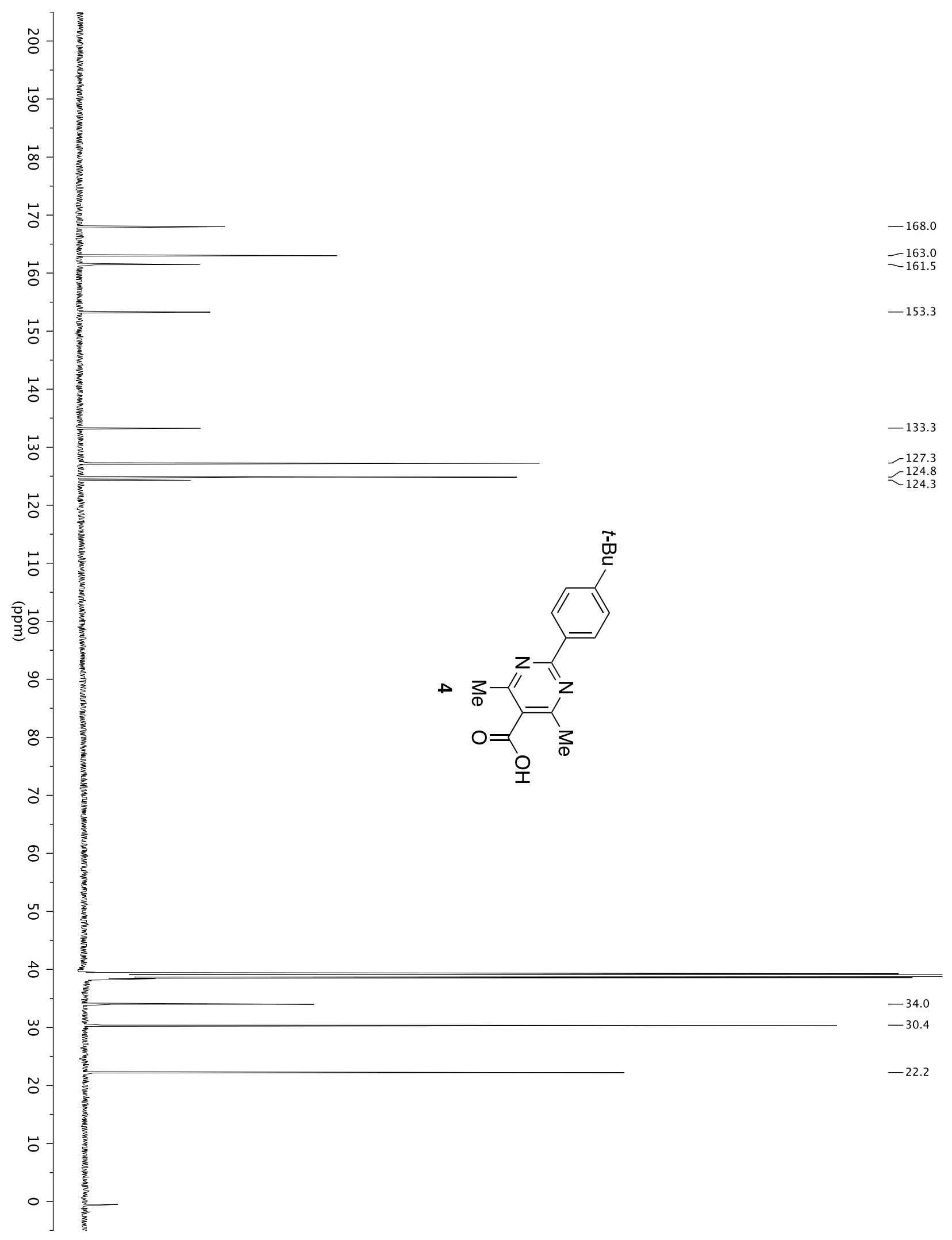


Supporting Information

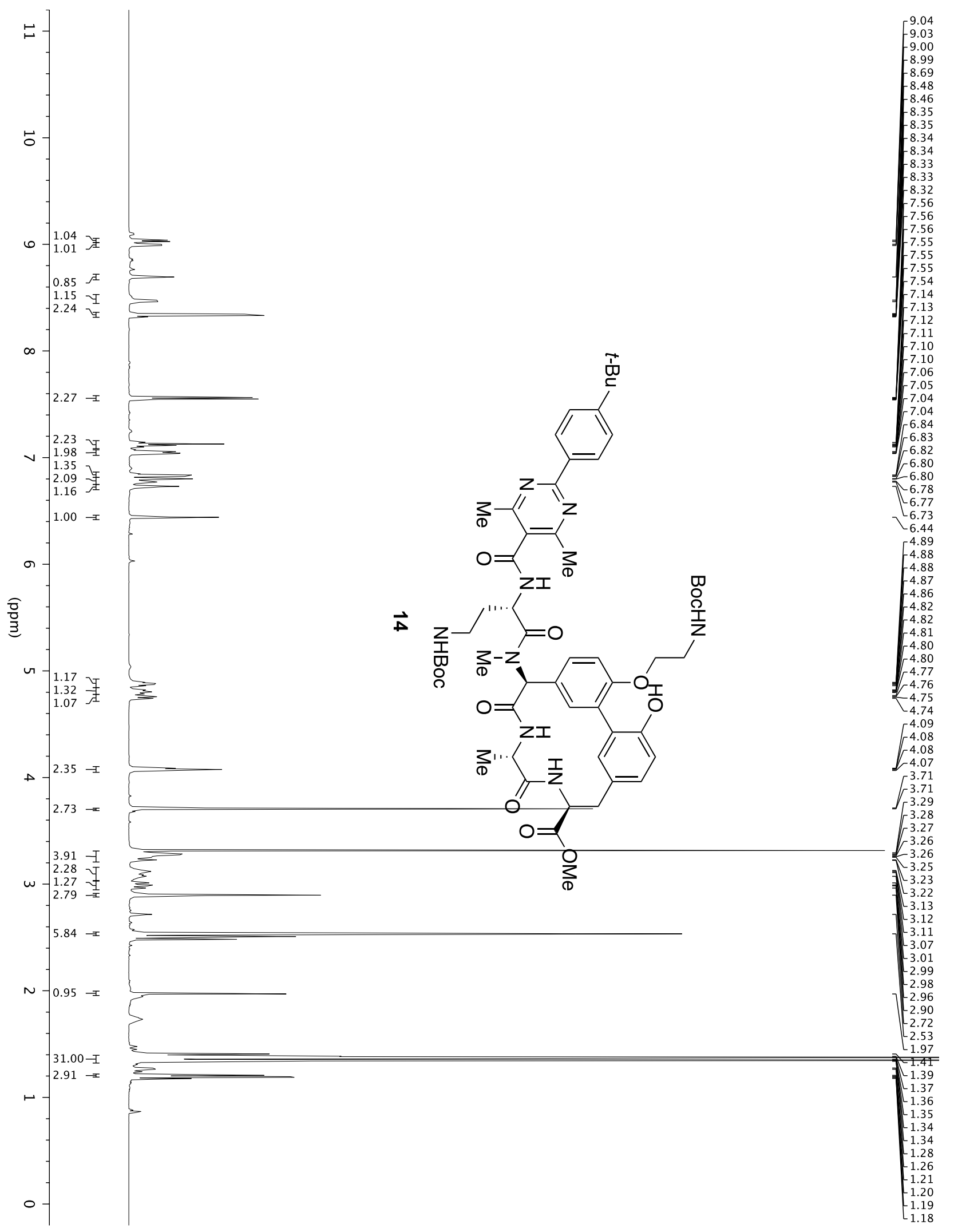


Supporting Information

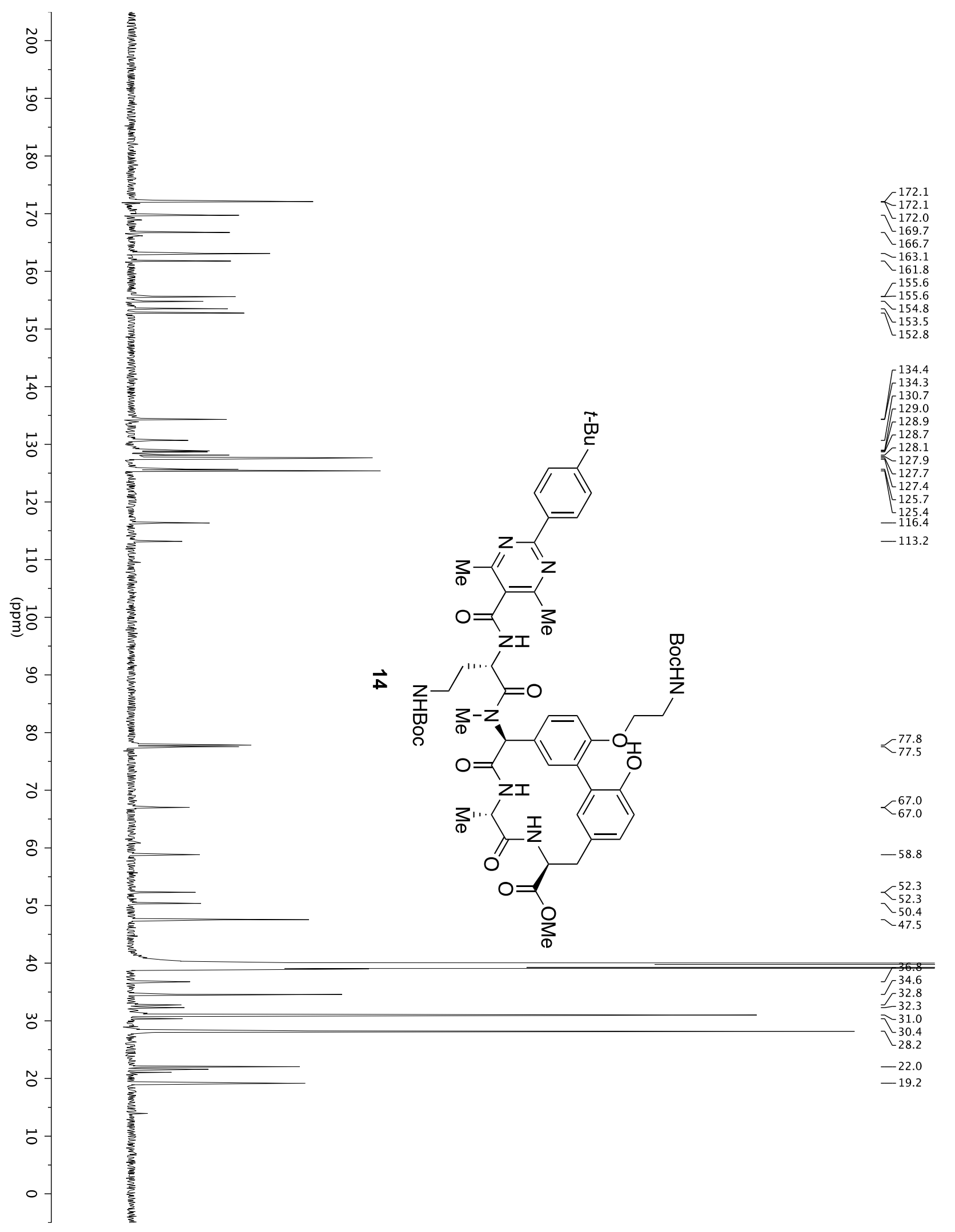


Supporting Information

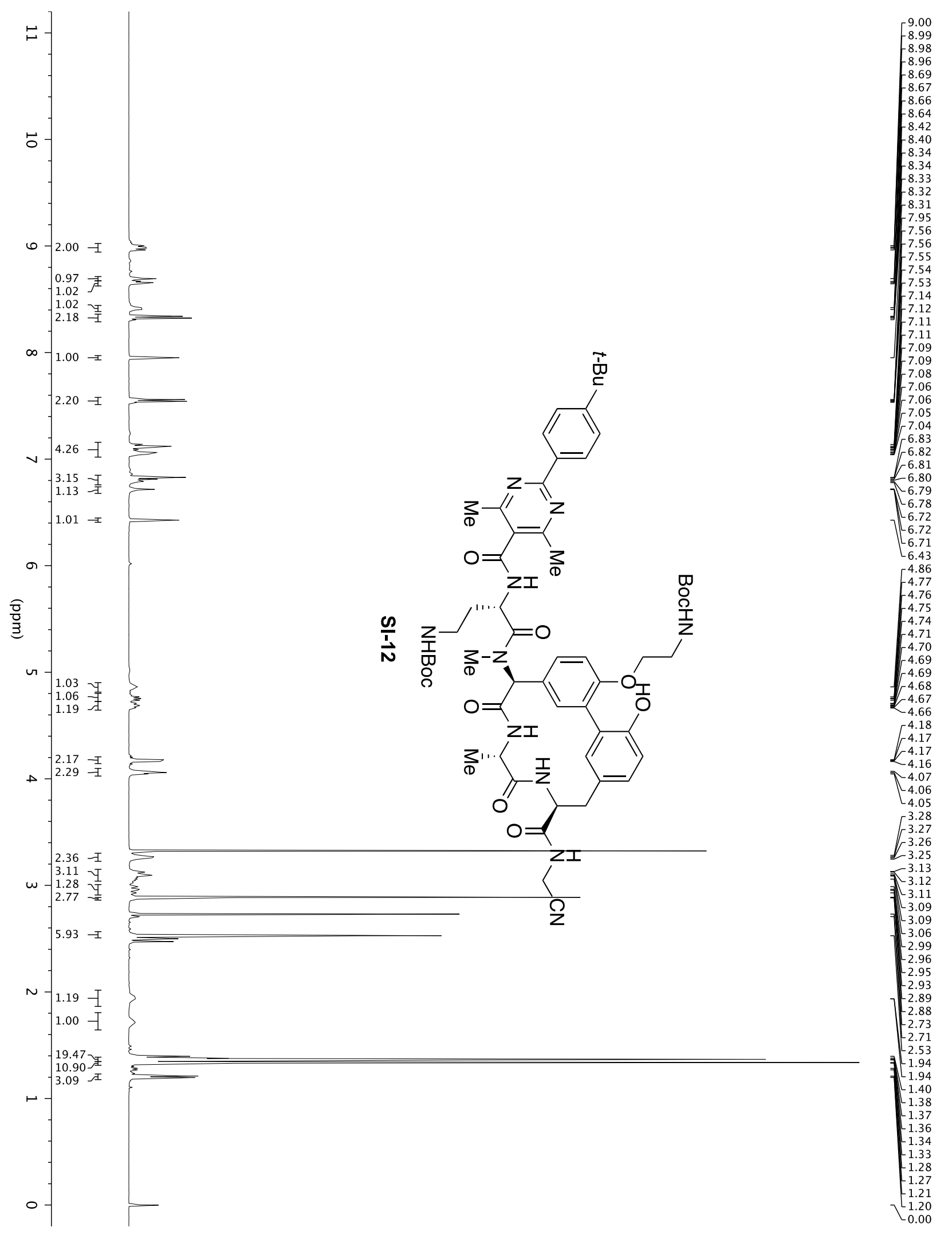


Supporting Information

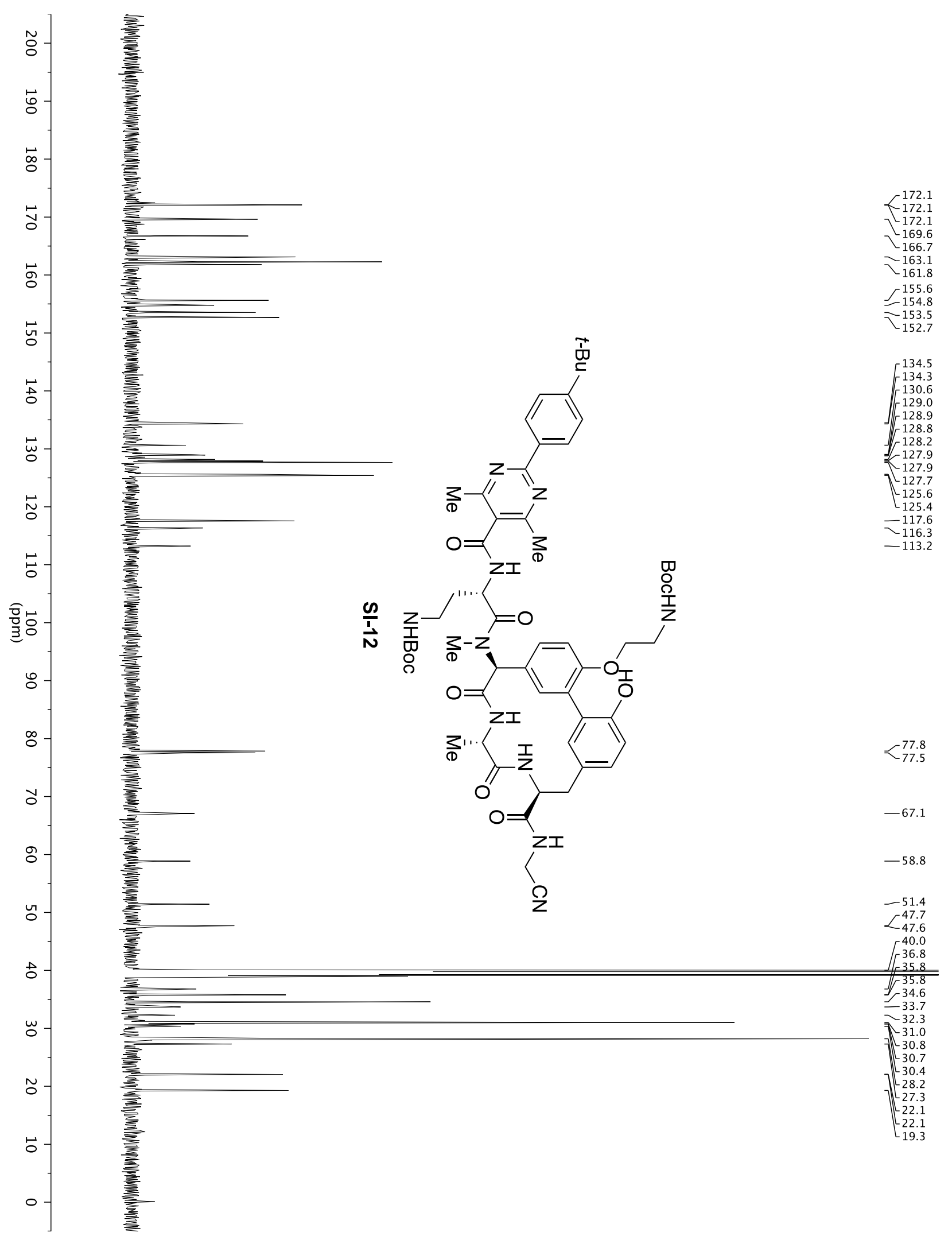


Supporting Information

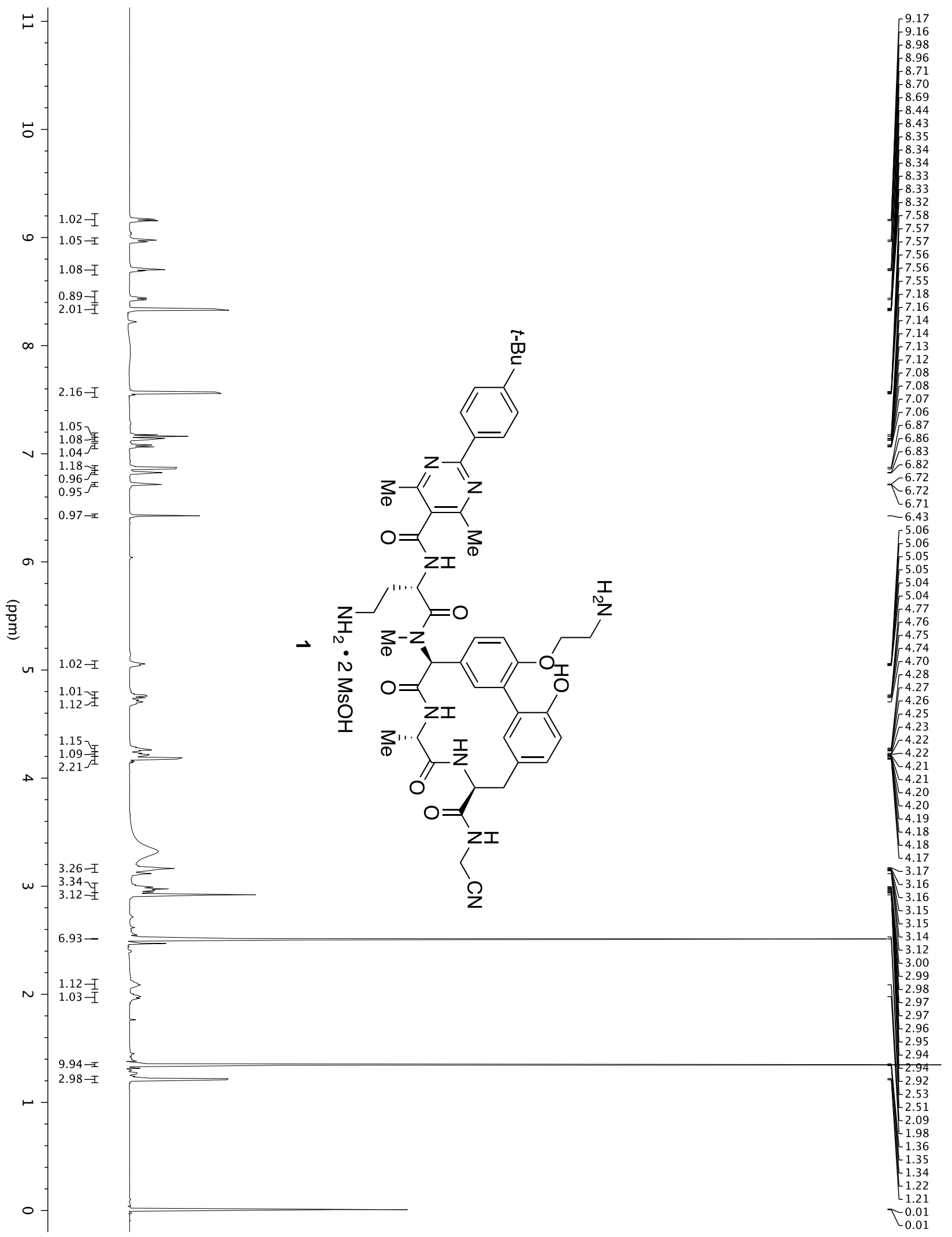




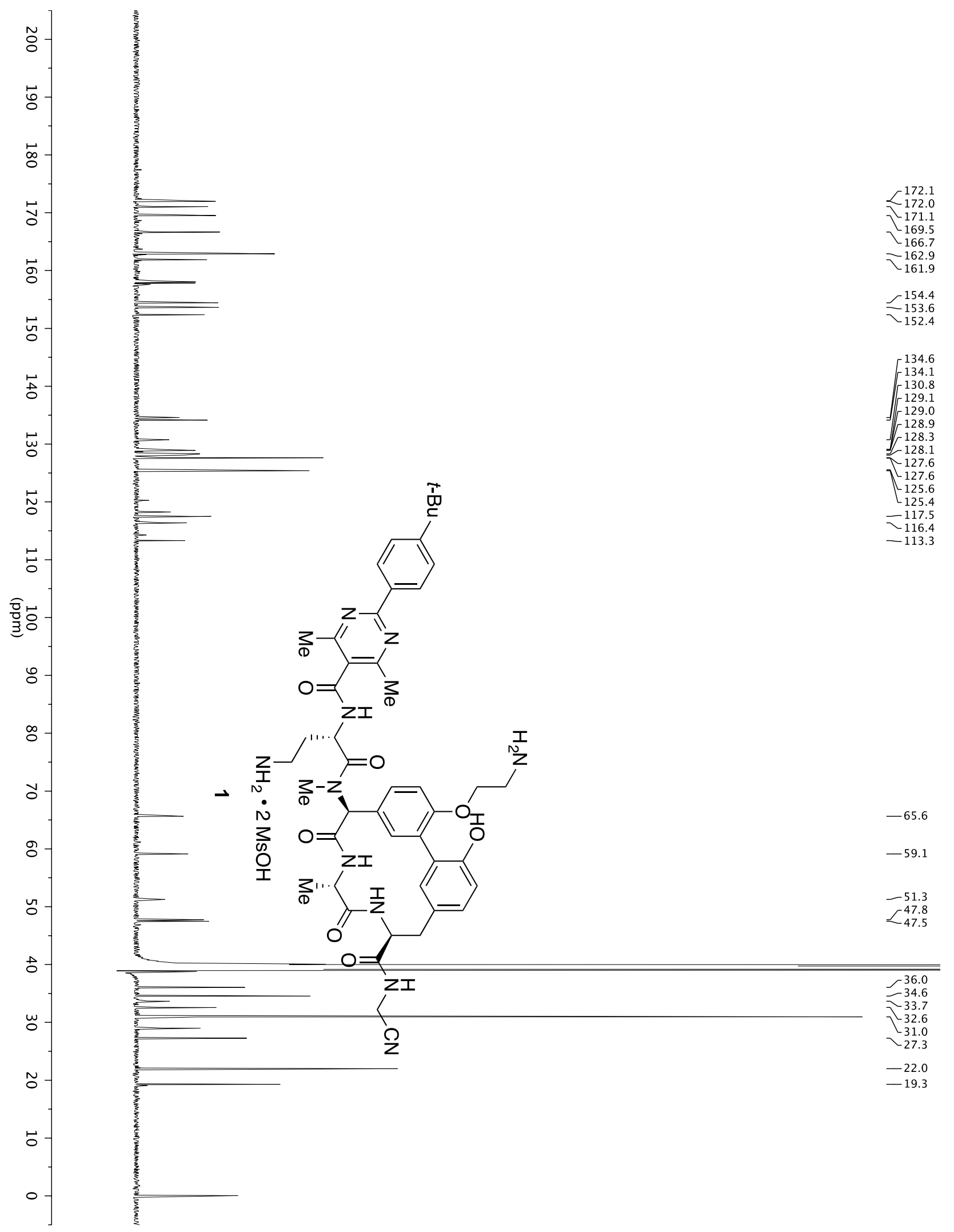

